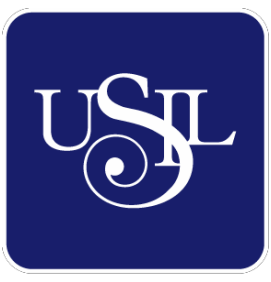

UNIVERSIDAD

SAN IGNACIO

DE LOYOLA

FACULTAD DE CIENCIAS EMPRESARIALES

Carrera de International Business

\title{
ANÁLISIS DE FACTORES DE PROMOCIÓN QUE INCIDIERON EN LA EVOLUCIÓN DE LAS EXPORTACIONES DE PISCO HACIA ESTADOS UNIDOS 2015-2019
}

Tesis para optar el Título Profesional de Licenciado en International Business

KELLY GISSEL CUYA CELIS (0000-0002-4238-4669)

ARIANA ALEXANDRA RODRIGUEZ PAZ (0000-0001-92603797)

Asesor:

JIMMY ELIAS SÁNCHEZ GÓMEZ (0000-0002-0425-6404)

Lima - Perú

2020 


\section{DEDICATORIA}

“Este trabajo va dedicado a mis abuelos, a mi mamá, hermanos y tios quienes siempre han sido mi soporte durante todo mi desarrollo profesional. Y a Dios por brindarme la tenacidad y persistencia que necesitaba para desarrollar esta investigación. "

Kelly Cuya Celis.

"Dedico el presente trabajo a mi madre, por ser mi apoyo, motor y guía en cada paso que doy en mi vida personal y profesional. A mi padre, por ser mi ejemplo de superación y a mi hermano, por alentarme a conseguir mis objetivos. Finalmente, agradecer a Dios por darme la fortaleza para perseguir mis sueños."

Ariana Rodriguez Paz. 


\section{AGRADECIMIENTOS}

“Agradecer a Dios por permitirme alcanzar esta nueva meta y a mi abuelo, Elviro Celis, por ser mi ejemplo de responsabilidad, superación y por incentivarme a no tener límites en mis sueños. A mi abuela y a mi madre, por ser símbolo de amor y comprensión.

Agradecer a Ariana por la paciencia y la persistencia para realizar juntas este trabajo. Así como, a nuestro asesor Jimmy Sánchez por sus aportes durante el avance de nuestra tesis.

A la Universidad San Ignacio de Loyola, por formarme en la carrera que tanto amo.”

Kelly Cuya Celis.

“Agradezco a Dios por cada día vivido y las fuerza que me dio para no rendirme. A mi madre, padre y hermano por todo el amor, confianza y apoyo incondicional en cada etapa de mi vida. A mi abuela, tía y primos por siempre confiar en mi potencial.

Agradecer a Kelly por la perseverancia y empeño para trabajar juntas en esta investigación tan importante para nuestra vida profesional. Adicionalmente, un agradecimiento especial a nuestro asesor Jimmy Sánchez quien fue nuestro guía para lograr esta meta.

Finalmente, agradecer a la Universidad San Ignacio de Loyola, por brindarme las enseñanzas y formarme para emprender mis sueños y conseguir mis metas"

Ariana Rodríguez Paz. 


\section{Resumen}

El pisco peruano, es hoy en día unos de los principales productos bandera del país, el mismo que presenta factores de promoción que generan incidencia en los volúmenes de exportaciones hacia el principal mercado de destino de este sector que resulta ser los Estados Unidos en los últimos años.

En este sentido, podemos señalar que la tesis en mención se focaliza en analizar aquellos factores promocionales referidos a los reconocimientos, eventos y acciones de posicionamiento que explican el comportamiento de las exportaciones del pisco peruano en los años 2015 al 2019 hacia el mercado norteamericano. Para ello, se ha realizado un análisis de las variables involucradas en base a sus antecedentes y bases teóricas. Asimismo, en lo referente a la validación de las hipótesis planteadas en el estudio, ésta se hizo bajo un enfoque mixto, vale decir bajo la combinación de los enfoques cualitativo y cuantitativo, siendo el caso que para el primer enfoque se utilizó una relación de causalidad al interrelacionar las variables dependiente e independiente y para el segundo enfoque se buscó el develamiento de las causas en términos de casuísticas, para ello se elaboraron instrumentos de entrevistas y encuestas que nos permitieron demostrar y alcanzar las hipótesis y los objetivos planteados respectivamente en la presente investigación.

Palabras clave: Promoción; Exportaciones; posicionamiento; pisco; reconocimientos, eventos 


\begin{abstract}
Peruvian pisco is today one of the main flagship products of the country, the same one that presents promotional factors that generate incidence in the volumes of exports to the main destination market of this sector, which turns out to be the United States in recent years.

In this sense, we can point out that the thesis in question focuses on analyzing those promotional factors referred to the recognitions, events and positioning actions that explain the behavior of Peruvian pisco exports in the years 2015 to 2019 to the North American market. For this, an analysis of the variables involved has been carried out based on their antecedents and theoretical bases. Also, regarding the validation of the hypotheses raised in the study, this was done under a mixed approach, that is, under the combination of qualitative and quantitative approaches, being the case that for the first approach a causal relationship was used by interrelating the dependent and independent variables and for the second approach, the unveiling of the causes was sought in terms of casuistry, for this, interview and survey instruments were developed that allowed us to demostrate and achieve the hypotheses and the objectives set out respectively in this research.
\end{abstract}

Keywords: Promotion; Exports; positioning; pisco; recognitions, events 
Capítulo 1 .........................................................................

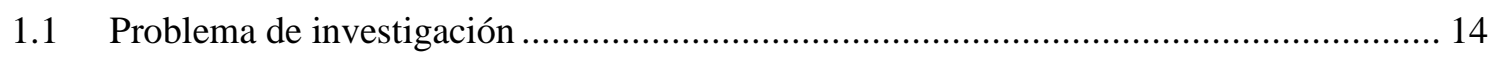

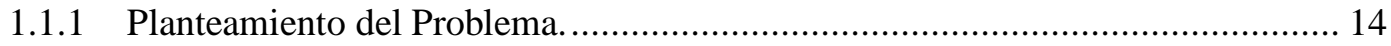

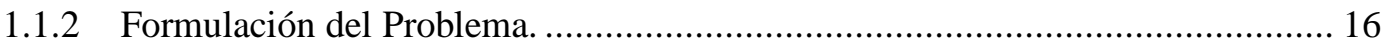

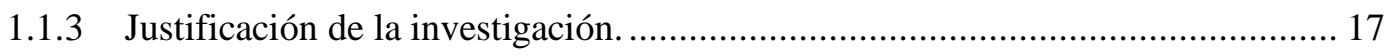

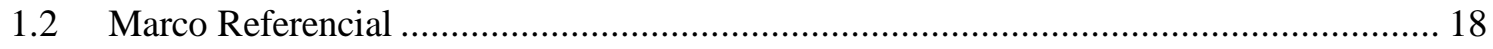

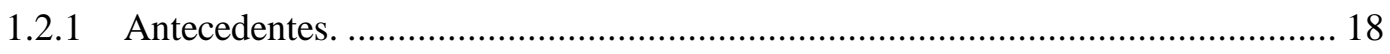

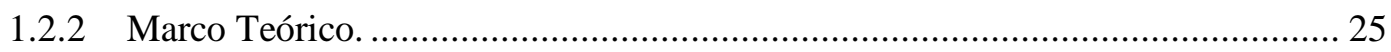

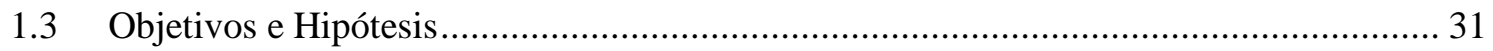

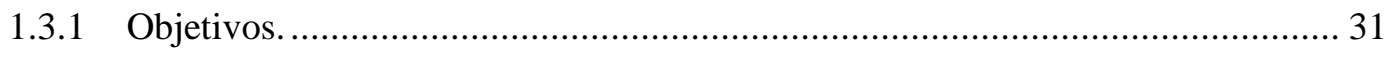

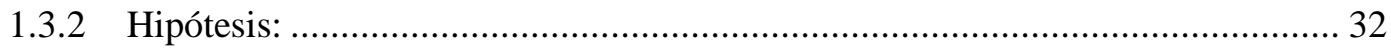

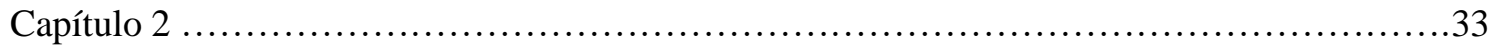

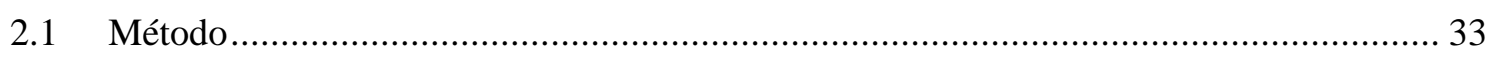

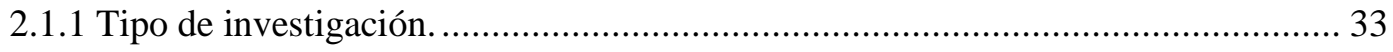

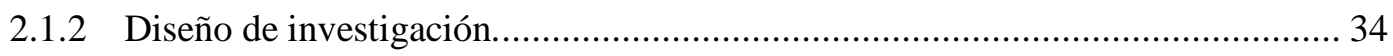

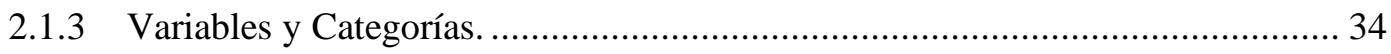

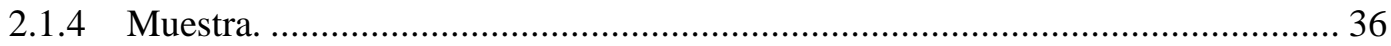

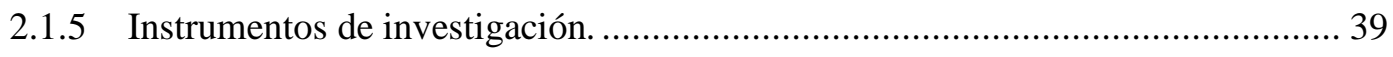

2.1.6 Procedimientos de recolección de datos. ....................................................... 42

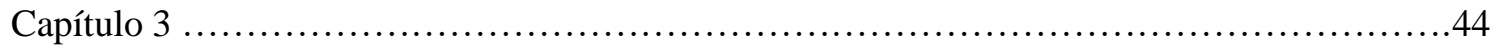

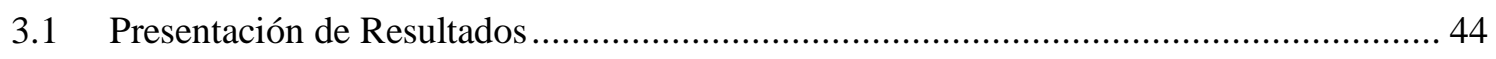

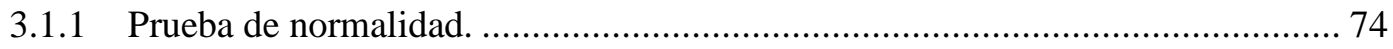

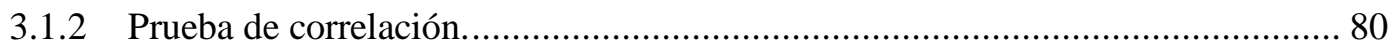

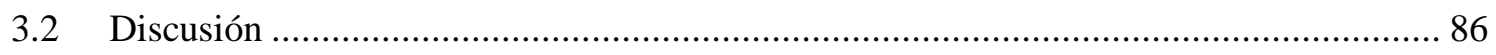

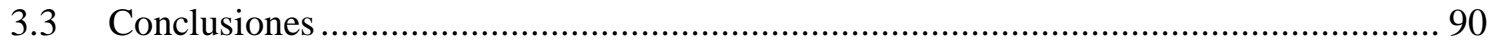

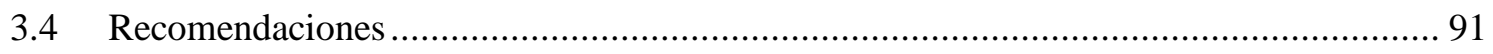

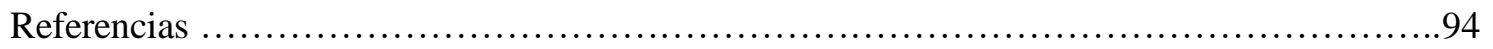




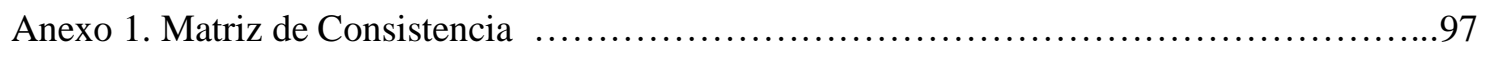

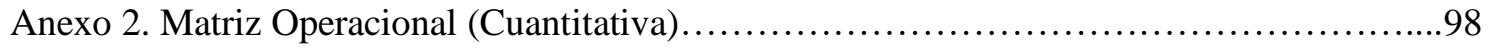

Anexo 3. Matriz Operacional (Cualitativa) ....................................... 100

Anexo 4. Exportación de Pisco en US\$ ................................................... 101

Anexo 5. Exportación de pisco por destino .......................................... 101

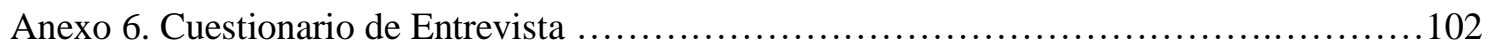

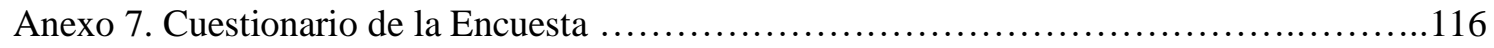

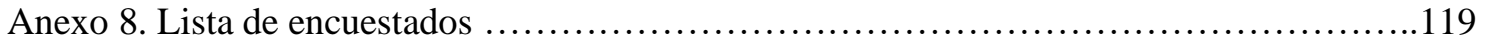

Anexo 9. Validación del cuestionario ............................................. 121

Anexo 10. Mercado objetivo en Estados Unidos ..................................... 132 


\section{Lista de Cuadros}

Tabla 1. Comercio exterior peruano (valor en USD) .................................................. 14

Tabla 2. Presupuesto para promoción de marca Perú (Millones de soles) ...............................15

Tabla 3. Gastos Publicitarios de las empresas productoras de Pisco (En USD) .......................15

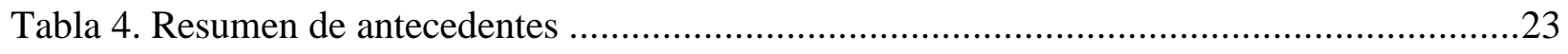

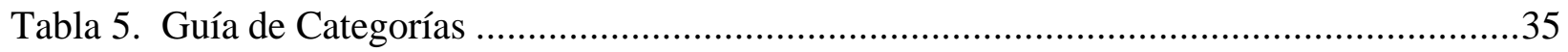

Tabla 6. Exportación de Pisco a EEUU - participación de las marcas (\%) ...............................37

Tabla 7. Principales empresas exportadoras de Pisco en los últimos años a EEUU ..................38

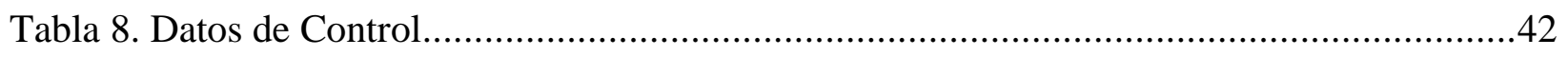

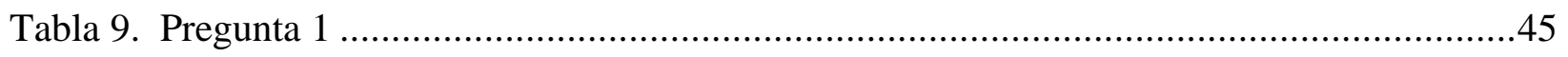

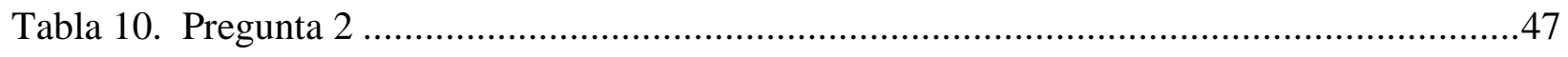

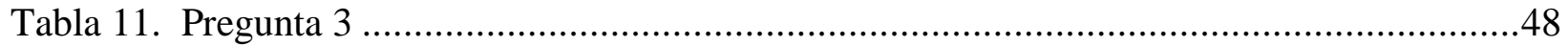

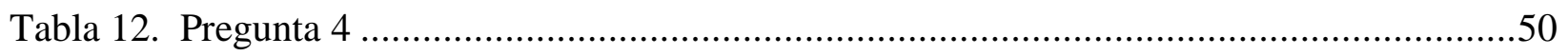

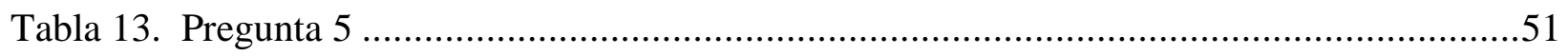

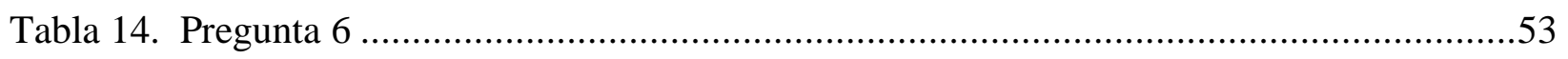

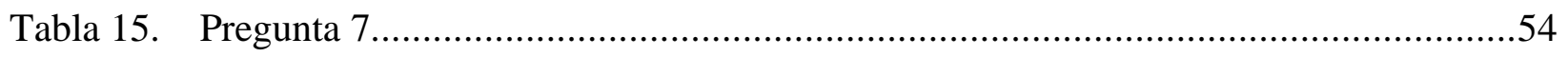

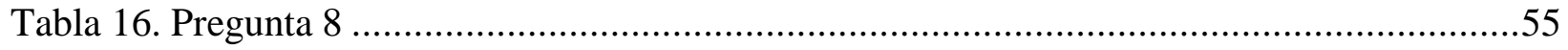

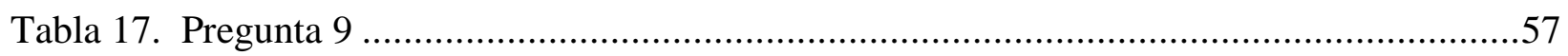

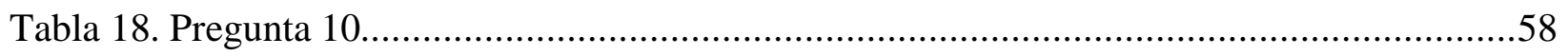

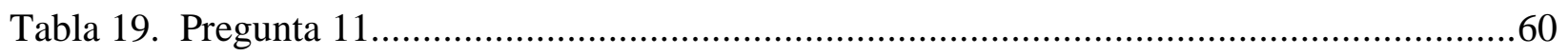

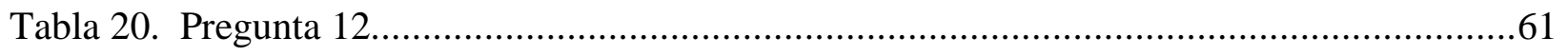

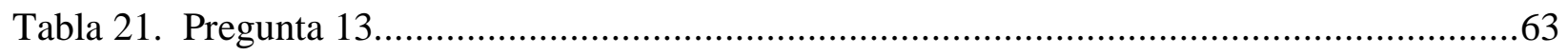

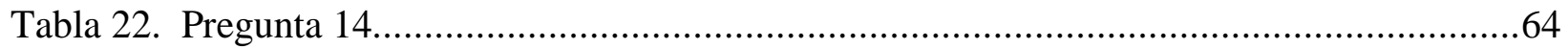

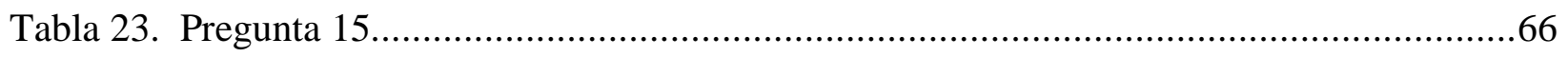

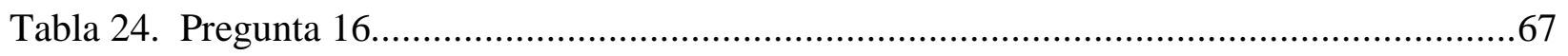

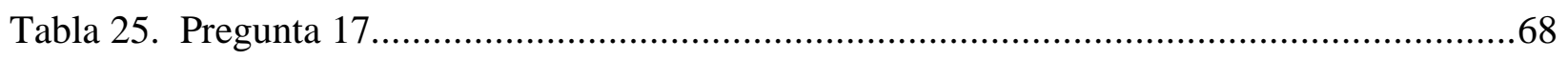

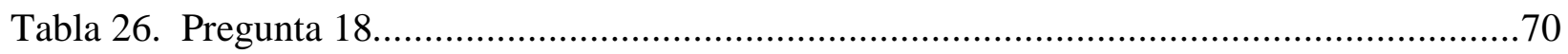




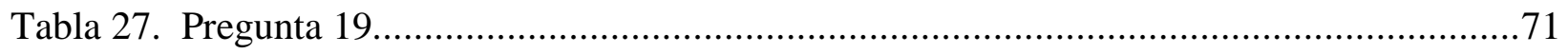

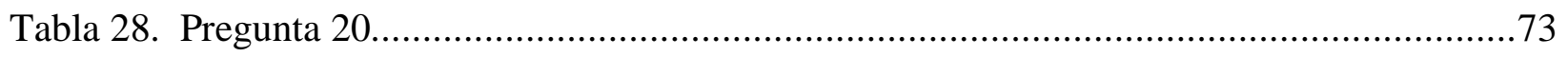

Tabla 29. Prueba d normalidad - variable factores de promoción ..............................................75

Tabla 30. Prueba de normalidad - exportación del pisco ………………………………..............76

Tabla 31. Prueba de normalidad - denominación de origen .....................................................77

Tabla 32. Pruebas de normalidad - eventos de feria ………....................................................

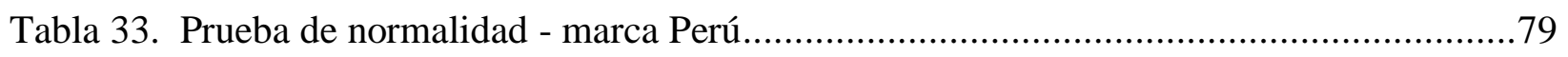

Tabla 34. Prueba de normalidad - términos de intercambio..................................................... 80

Tabla 35. Prueba de correlación - Hipótesis especifica 1.............................................................81

Tabla 36. Prueba de correlación - hipótesis especifica 2 ……………………………................ 82

Tabla 37. Prueba de correlación - hipótesis especifica 3 ……………………………............... 83

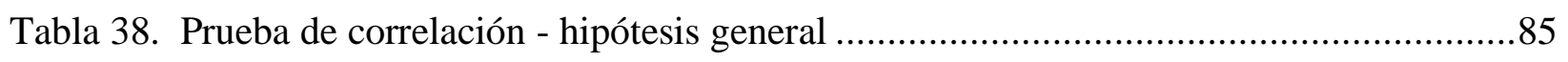

Tabla 39. Tabla de contingencia con los resultados de la investigación.......................................86 


\section{Lista de Figuras}

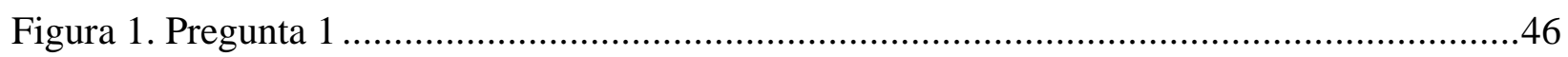

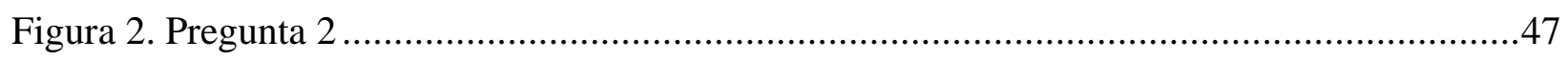

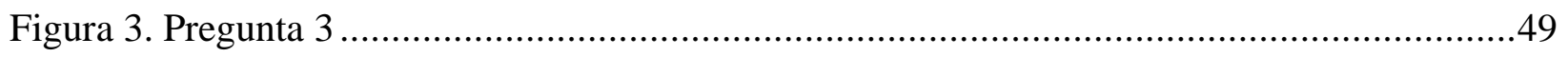

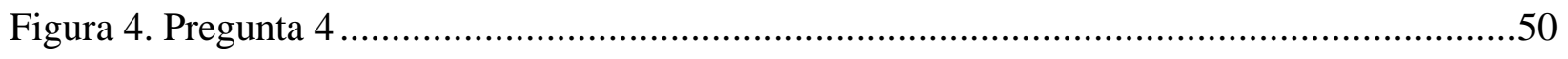

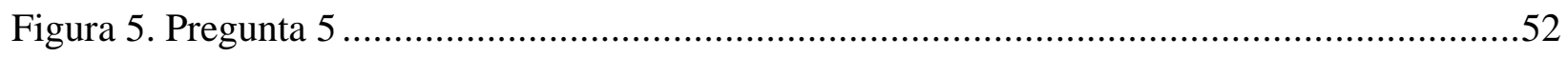

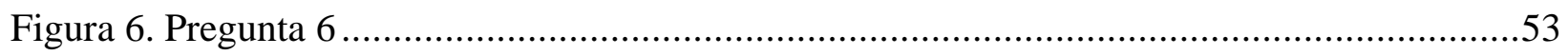

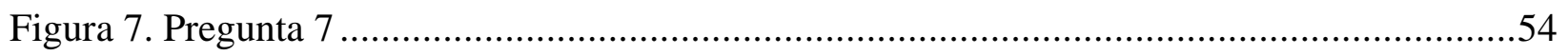

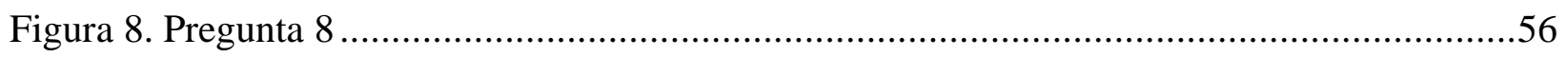

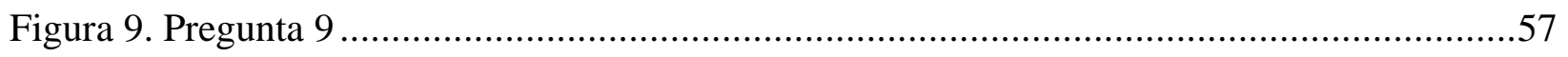

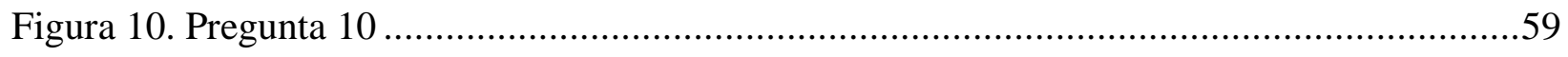

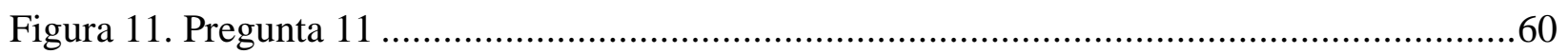

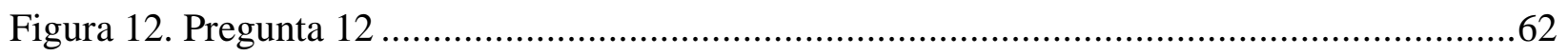

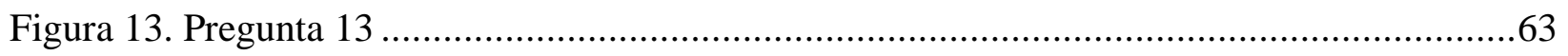

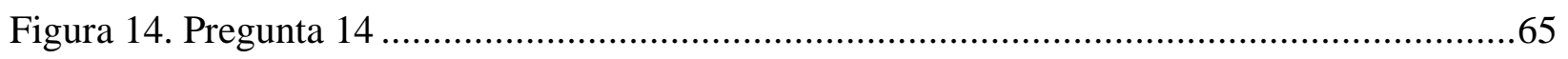

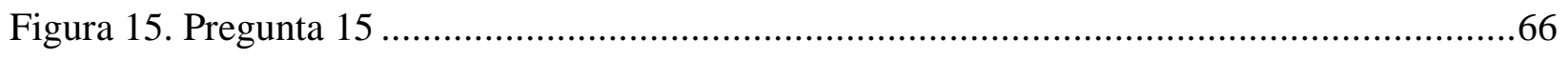

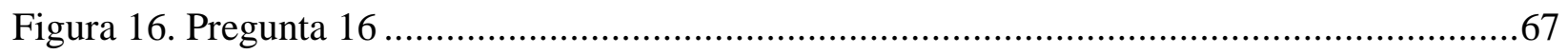

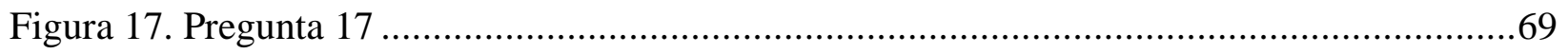

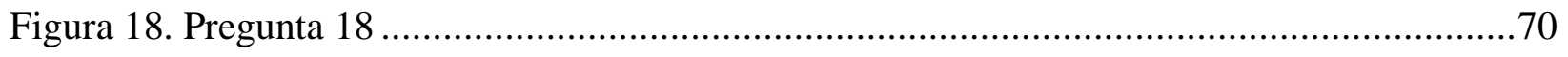

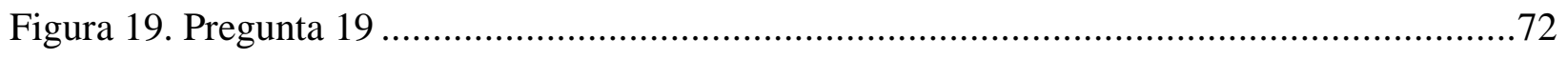

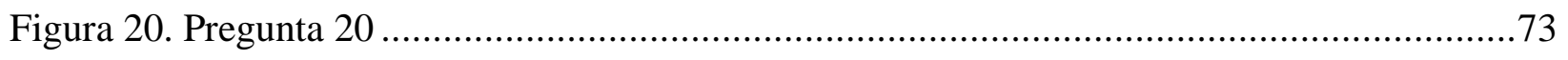

Figura 21. Resultados de los factores de promoción ................................................................ 87 


\section{Introducción}

La presente tesis, busca y orienta sus esfuerzos investigativos en analizar aquellos factores de promoción que han incidido en el comportamiento a lo largo de los últimos cinco años de las exportaciones de pisco hacia los Estados Unidos, es así que lo que se busca es hacer una investigación que demuestre, de un lado, la situación real de los esfuerzos promocionales del pisco y, de otro lado, las perspectivas que existen en el sector de la manufactura de este licor en relación a la venta de este mismo producto en el exterior.

Es en esta perspectiva, que nuestro estudio se esfuerza en relacionar los aspectos de promoción privada y/o estatal que redunden en el fomento del mercado del pisco peruano en el exterior, para nuestro caso en particular, con el mercado norteamericano, a la vez de determinar la interacción entre las variables presentadas en nuestro estudio, más aún si en el mercado exterior muchas veces el nombre de nuestro producto bandera en mención enfrenta la confusión respecto a la denominación de origen, lo que hace crecer la necesidad de seguir promocionando a nivel internacional para un cada vez mayor posicionamiento del pisco peruano en el exterior. En cuanto a los tópicos de metodología implementadas en nuestra tesis, podemos afirmar que generamos estándares mínimos exigidos en todo lo concerniente en el procesamiento de la información, recolección de data mediante la conocida información primaria, que consiste en la elaboración de encuestas y entrevistas (para erigir información propia) y la llamada información secundaria (para usar la información existente), todo ello con la finalidad de obtener altos grados de veracidad requeridos.

En base a lo anterior, nuestros esfuerzos investigativos se basarán en ejecutar metodológicamente instrumentos de recolección de datos en base a las técnicas planteadas como 
el diseño y puesta en marcha de encuestas, entrevistas en profundidad y lo referente al análisis de contenido, todo ello con la finalidad de contar con data suficiente que nos permita demostrar la incidencia de los factores de promoción del pisco con la evolución de este licor en las exportaciones hacia los Estados Unidos, asimismo, importante señalar que esta misma data nos genera análisis deductivo e inductivo a fin de facilitar las conclusiones y recomendaciones que buscamos aportar. De otro lado, indicamos que los aportes de nuestro estudio apuntan a generar más conocimiento del mercado del pisco peruano en base a su comportamiento en el mercado nacional como en el mercado americano, siendo ello muy útil en materia cognitiva a favor de la comunidad universitaria, investigadora, promotora empresarial y estatal, entre otros similares, dado que todo lo mencionado lo sustentamos en los siguientes conceptos:

- Conocimientos actuales respecto a los esfuerzos publicitarios del pisco peruano que favorecen a las exportaciones de este producto bandera.

- Generar un enfoque presente y futuro de lo que puede significar un mayor desarrollo de la promoción del pisco peruano en términos internacionales.

- Contribuir con sustentos investigativos a otros estudios relacionados en donde nuestros aportes sean tomados en cuenta en el conocimiento del mercado del pisco peruano.

- Contribuir con aportes de conocimiento de los factores de promoción del pisco con impacto real en mercados internacionales.

De otro lado, es importante indicar que el presente estudio cuenta con la siguiente estructura, en el capítulo I se presentan el problema de investigación; en el capítulo II se detalla el plan 
metodológico de la investigación; en el capítulo III se establecen los resultados obtenidos, así como las conclusiones y recomendaciones obtenidas como resultado del estudio.

En conclusión, la presente tesis es entregada a las autoridades de las respectivas áreas académicas de nuestra facultad con la finalidad que nuestros aportes científicos en el objeto de estudio escogido, sea evaluado respectos a los objetivos alcanzados, las hipótesis demostradas y demás propósitos que hemos buscado aportar con el uso metodológico exigido y siempre a favor de un producto bandera de nuestro país. 


\section{Capítulo 1}

\subsection{Problema de investigación}

\subsubsection{Planteamiento del Problema.}

El planteamiento del problema de la presente tesis se sustenta en encontrar las razones de mercado que explican los volúmenes de exportación hacia los Estados Unidos, siendo el caso que se asume que existen muchos y variopintos factores que tienen incidencia en lo declarado, no obstante, nuestros esfuerzos investigativos apuntan a centrarse en la relación que tienen los factores de promoción privados y estatales en la evolución exportadora del pisco peruano en el mercado americano.

En los últimos cinco años se puede visualizar que el comportamiento de los volúmenes de exportación de uno de los principales productos bandera como lo es el pisco peruano no ha mostrado un comportamiento ascendente y por el contrario podemos visualizar comportamientos disímiles entre unos años y otros, tal como podemos apreciar en la siguiente tabla:

Tabla 1.

Comercio exterior peruano (valor en USD)

\begin{tabular}{llll}
\hline Año & $\begin{array}{l}\text { Exportación Perú } \\
\text { al mundo }\end{array}$ & $\begin{array}{l}\text { Exportación Perú } \\
\text { EEUU }\end{array}$ & $\begin{array}{l}\text { Exportación Perú- } \\
\text { EEUU/Exportación Perú } \\
\text { mundo }\end{array}$ \\
\hline 2015 & 34414.35 & 5025 & $16 \%$ \\
2016 & 37019.78 & 6182 & $17 \%$ \\
2017 & 45421.59 & 6868 & $15 \%$ \\
2018 & 49066.48 & 7822 & $16 \%$ \\
2019 & 45985.00 & 7920 & $17 \%$ \\
\hline
\end{tabular}

Nota: En la tabla 1 se puede observar que la exportación de Perú al mundo va cada vez en aumento de igual manera las exportaciones de Perú a Estados Unidos, pero en el año 2017 se ve que la exportación mundial disminuye a 15\% a diferencia de los años pasados y siguientes, esto significa que la exportación hacia Estados Unidos en el 2015 se 
redujo significativamente. Autoría propia.

Fuente: INEI

En la siguiente tabla se observa el presupuesto para la promoción de la marca Perú

Tabla 2.

Presupuesto para promoción de marca Perú (Millones de soles)

\begin{tabular}{ccccc}
\hline 2015 & 2016 & 2017 & 2018 & 2019 \\
& & & & \\
\hline 48 & 52 & 51 & 50 & 57
\end{tabular}

Nota: En la tabla 2 se puede observar que el presupuesto para la promoción de marca Perú también va en aumento al igual que las exportaciones de Perú a Estados Unidos vistas en la tabla anterior, lo que también significa que para el Estado Peruano la marca Perú es uno de los factores de promoción más importantes en la actualidad. Autoría propia. Fuente: PROMPERU

Siguiendo con las causas, la siguiente tabla muestra otro factor sobre el origen de la problemática

Tabla 3.

Gastos Publicitarios de las empresas productoras de Pisco (En USD)

\begin{tabular}{ccccc}
\hline 2015 & 2016 & 2017 & 2018 & 2019 \\
& & & & \\
\hline $4,996,000$ & $5,500,000$ & $5,996,000$ & $4,200,000$ & $5,500,000$
\end{tabular}

Nota: En la tabla 3 se observa que los gastos publicitarios de las empresas productoras de Pisco han vuelto para el 2019 su tendencia ascendente lo que configura un escenario positivo como en las tablas anteriores en donde se puede inferir el mayor esfuerzo de las empresas productoras de pisco para conquistar el mercado de los Estados Unidos. Autoría propia.

Fuente: PROMPERU

De otro lado, teniendo en cuenta que Promperú (2019) realizó una recolección de datos entre los cuales destacan el hecho de cómo los precios de exportación del pisco peruano, en particular de aquellos que se exportan hacia los Estados Unidos, cuentan con factores de promoción en torno a la marca Perú para promover cada vez más y mejor los objetivos de recordación y de posicionamiento en el mercado norteamericano del pisco peruano, siendo así, es de entender que de seguir esta tendencia favorable los factores de promoción analizados en la presente tesis se convertirán en cada vez más fundamentales y estratégicos para el aumento de los términos de intercambio del producto bandera como lo representa el pisco peruano. 
De esta manera, la perspectiva de futuro arriba indicada nos hace pronosticar que son los esfuerzos de promoción, los mismos que se reflejan presupuestos, gastos, inversiones y otros similares que vienen siendo en aumento, lo cual refleja comportamientos ascendentes hacia el futuro.

Finalmente, podemos inferir que existe una problemática referida en determinar los factores de promoción tanto de esfuerzos privados como estatales en generar una cada vez mejor apoyo efectivo para el posicionamiento en el mercado americano de uno de los principales productos banderas de nuestro país que es el pisco peruano.

\subsubsection{Formulación del Problema.}

\section{Problema General.}

¿Cómo inciden los factores de promoción en la evolución de las exportaciones de pisco hacia Estados Unidos 2015 - 2019?

\section{Problemas Específicos.}

¿Cómo incide la promoción de la denominación de origen en la evolución de las exportaciones de pisco hacia los Estados Unidos 2015 - 2019?

¿Cómo incide la promoción de eventos de ferias en la evolución de las exportaciones de pisco hacia los Estados Unidos 2015 - 2019?

¿Cómo incide la promoción de la marca Perú en la evolución de las exportaciones de pisco hacia los Estados Unidos 2015 - 2019? 


\subsubsection{Justificación de la investigación.}

\section{Conveniencia.}

La presente tesis busca conocer de manera científica cómo los factores de promoción del pisco tanto de orden estatal como privada vienen siendo desarrollados, ello en la línea de generar puntos de vista y tendencias de opinión respecto a sí es o no conveniente hacer ajustes en las políticas de apoyo y soporte al comercio internacional que viene experimentando nuestro producto bandera que es objeto de estudio.

\section{Relevancia Social.}

Es importante resaltar que la presente tesis busca aportar en base a un enfoque social, lograr una cada vez mayor identificación con el pisco peruano, en tanto mediante el estudio se pueda visualizar también las oportunidades de negocios internacionales a favor de varios actores potenciales o no de este mercado, como son la comunidad estudiantil, gerencial, empresarial, inversores, productores de pisco y relacionados, de forma tal que este documento sirva a ellos también como una fuente de consulta académica referencial.

\section{Implicaciones Prácticas.}

El presente estudio tiene una arista práctica en el sentido que, a partir de los resultados obtenidos, puede servir como un documento base para la toma de decisiones en todos aquellos agentes económicos, sociales y políticos con relación directa e incluso indirecta con los eventos

de exportaciones de pisco, en particular con destino a los Estados Unidos, pudiendo incluso movilizar cámaras de comercio entre ambas naciones.

\section{Valor Teórico.}


El valor teórico del presente estudio se basa en el hecho que cada variable, dimensión e indicadores que se ha escogido para el desarrollo investigativo, se analizarán en base a metodologías estandarizadas, lo que hace que sus resultados tengan una validez teórica respecto a la realidad de lo analizado, siendo importante señalar que incluso las conclusiones $\mathrm{y}$ recomendaciones a las que se pueda llegar sean de carácter científico.

\section{Utilidad Metodológica.}

La utilidad metodológica que aporta este estudio se basa en el hecho que se ejecutará desde la obtención de datos hasta el análisis de las variables que respondan, alcancen y demuestren los diferentes problemas, objetivos e hipótesis planteadas en la presente tesis, de manera tal que, de un lado, se cumpla con la rigurosidad científica y de otro, no se desvíen los aportes teóricos que se buscan aportar.

\subsection{Marco Referencial}

\subsubsection{Antecedentes.}

Yussan y Zegarra, (2019) en su estudio titulado: Factores determinantes que influyeron en las exportaciones de pisco al mercado de Estados Unidos en el marco del tratado de libre comercio (TLC), periodo 2002-2018, busca analizar las principales causas que contribuyeron al incremento de las exportaciones de Pisco Peruano a Estados Unidos y para ello determinan investigar el sector del pisco y ver cuál ha sido su desenvolvimiento en el mercado mundial.

La tesis también propone analizar si uno de los factores del incremento de exportación del pisco ha sido la situación de conflicto con el país vecino de Chile por obtener la denominación 
Pisco como propiedad o si esta misma situación tuvo un efecto que hizo variar negativamente el nivel de exportación.

Para los autores también es de total importancia determinar cuál es el nivel de competitividad del pisco peruano ante el pisco chileno; también si el precio a la que son puestos en venta en el mercado internacional son grandes factores que influyen a la exportación del pisco peruano.

Finalmente se concluye que gracias al Tratado de Libre Comercio con Estados Unidos, la exportación del pisco peruano y el incremento propiamente dicho, ha sido muy favorable, con una participación en el mercado de Estados Unidos de manera significante, más que el pisco chileno.

Palacios y Sánchez (2017) en su investigación científica titulada: Análisis de los factores que influyeron en la internacionalización del pisco en el periodo 2013 al 2016, propone analizar las múltiples variables existentes en el sector Pisco que son factores principales de la apreciación en el mercado internacional y principalmente en el mercado estadounidense y determinar cómo es que estas variables pueden influir a la exportación del pisco peruano.

Se determina investigar si el nivel de producción de las empresas que exportan el pisco y si la calidad misma son factores positivos que contribuyen al incremento de la exportación del pisco y propone métodos eficientes para seguir exportando.

Se señala que, últimamente el tamaño de exportación del pisco peruano ha incrementado significativamente, y esta increíble situación — indica—, se debe también a los acuerdos y tratados comerciales con otros países y para ello se propone analizar estos acuerdos.

Finalmente se señala que las empresas exportadoras de pisco en nuestro país han formado asociaciones para tener un nivel de producción eficiente para que así se puedan atender los pedidos 
de exportación, y en este caso también se recomienda que haya inversión privada para llegar a ser más competitivos.

Soto (2017) realizó un estudio titulado: Exportación de pisco acholado "New imperial" a Paterson, New Jersey-Estados Unidos, señala que la exportación de pisco tiene una gran aceptación en el mercado estadounidense, y para ello propone la exportación del pisco acholado, cuyo ingrediente principal es la unificación de sabores y olores de tres diferentes tipos de uvas.

La investigación de esta tesis propone aprovechar la gran aceptación del pisco en el mercado internacional como una oportunidad de crear negocios para incrementar los ingresos de los empresarios y por ende ayudar de alguna manera en el desarrollo económico del país.

Y siendo Estados Unidos unos de los principales importadores de nuestro producto bandera, se propone producir este tipo de pisco, específicamente el pisco acholado, un producto para aquellos paladares exigentes y amantes de nuevos sabores.

Finalmente se indica que el negocio de la elaboración de este pisco cumple con los estándares de calidad y esto lo convierte en un candidato especial para incursionar en el mercado de Estados Unidos y a ello se suma la gran ventaja de pagar menos por la exportación, debido al Tratado de Libre Comercio.

Núñez (2017) en su estudio titulado: Exportación de pisco de uva Italia hacia Nueva York Estados Unidos, señala que el principal deseo que persigue esta investigación es poder participar en la comercialización del pisco, que como ya sabemos es nuestro gran apreciado producto bandera e introducirlo de forma más eficaz en el mercado de Estados Unidos. 
Para lograr el principal objetivo de esta investigación y hacerlo conocido internacionalmente, se determina introducir al mercado norteamericano el pisco de uva italiana, y esto debido al gran incremento, éxito y aceptación, propiamente dicho.

De lo anterior podemos argumentar que debido al gran éxito que está teniendo nuestro producto bandera en niveles de exportación, es de total conveniencia argumentar que realmente este sector (del Pisco) necesita ser promocionado, debido a su sola aceptación en el mercado internacional.

Finalmente es conveniente declarar que el estado promueva la inversión privada enfocada en este sector para fortalecerlo significantemente y lograr que sea más competitivo en el mercado estadounidense y a nivel mundial.

López (2018) en su proyecto de investigación titulado: La exportación de pisco a Estados Unidos y su impacto en la producción peruana en el periodo 2008 - 2017, tiene como objetivo analizar y determinar cómo es que la exportación de nuestro pisco al mercado estadounidense afectó en el nivel de producción de las empresas exportadoras de pisco, y tener como muestra los resultados para seguir incursionando en la producción del pisco.

Se determina que las empresas productoras necesitan apoyo en la adquisición de herramientas con avances tecnológicos y esto para que les permitan llegar a tener un nivel de producción eficiente, y poder cubrir los pedidos del mercado internacional.

La tesis señala que debido al incremento de las exportaciones del pisco en el mercado de Estados Unidos es que los productores deben de estar más capacitados para el cultivo de la uva pisquera para incrementar la producción y cubrir el mercado. 
Finalmente se recomienda que los productores adquieran maquinarias que les permitan aumentar sus producciones, y que siendo Estados Unidos uno de los principales clientes, las autoridades de la mano con los productores deben de realizar campañas de marketing y se den a los productores las oportunidades de regularizar sus negocios.

Lama, Martínez y Rosado (2006) realizaron un estudio titulado: Estrategia de distribución de pisco en el mercado de Estados Unidos. Caso práctico: Austin Texas, indican que, debido a los nuevos cambios en el mercado y la globalización, son razones por la cual la comercialización entre otros países debe de mejorar, mejorando los métodos u estrategias de intercambio comercial y aprovechar las oportunidades de comercialización que ofrecen los acuerdos.

Para lograr incursionar de forma eficaz en el mercado internacional, específicamente en el de Estados Unidos, debemos investigar a nuestros clientes del mercado donde queremos introducir nuestra bebida bandera y analizar cuáles son sus comportamientos y poder así tener éxito.

La tesis señala que una de las variables a investigar es la estrategia de distribución del pisco y sumado a ello, investigar las normas legales que rigen el sector licores en este país, y poder señalar el mejor modelo de penetración en el mercado norteamericano y estar a derecho con sus leyes.

Finalmente, la tesis señala que el mejor método para penetrar en el mercado estadounidense de forma exitosa es distribuir el pisco peruano en la coctelería, ya que los gustos del consumidor estadounidense son más inclinados a consumir coctele 
Tabla 4.

Resumen de antecedentes

\begin{tabular}{|c|c|c|c|c|c|c|c|c|}
\hline Título & Variable & $\begin{array}{c}\text { Tipo de } \\
\text { documento }\end{array}$ & Autor & Universidad/Entidad & Diseño & Indexada & Fuente & Aporte de tesis \\
\hline $\begin{array}{l}\text { Factores Determinantes } \\
\text { que Influyeron en las } \\
\text { Exportaciones de Pisco } \\
\text { al Mercado de Estados } \\
\text { Unidos en el Marco Del } \\
\text { Tratado de Libre } \\
\text { Comercio (TLC), } \\
\text { Periodo 2002-2018 }\end{array}$ & $\begin{array}{l}\text { Valor FOB } \\
\text { exportado }\end{array}$ & Tesis de Pregrado & $\begin{array}{l}\text { Leyla Yussan León } \\
\text { Viviano; Karina } \\
\text { Stefanny Angela y } \\
\text { Zegarra Guevara } \\
\text { (2019) }\end{array}$ & $\begin{array}{l}\text { Universidad } \\
\text { Peruana de Ciencias } \\
\text { Aplicadas }\end{array}$ & Mixta & No & $\begin{array}{l}\text { Repositorio } \\
\text { académico } \\
\text { UPC }\end{array}$ & $\begin{array}{l}\text { Analizar las } \\
\text { principales causas } \\
\text { que contribuyeron al } \\
\text { incremento de las } \\
\text { exportaciones de } \\
\text { Pisco Peruano a } \\
\text { Estados Unidos }\end{array}$ \\
\hline $\begin{array}{l}\text { Análisis de los Factores } \\
\text { que Influyeron en la } \\
\text { Internacionalización del } \\
\text { Pisco en el Periodo } \\
2013 \text { al } 2016 .\end{array}$ & $\begin{array}{l}\text { Marketing } \\
\text { Internacional }\end{array}$ & Tesis de Pregrado & $\begin{array}{l}\text { Carmen A. } \\
\text { Palacios } \\
\text { Jiménez; } \\
\text { Gabriela } \\
\text { Sánchez Porras } \\
\text { (2017) }\end{array}$ & $\begin{array}{l}\text { Universidad Privada } \\
\text { del Norte }\end{array}$ & Mixta & No & $\begin{array}{l}\text { Repositorio } \\
\text { UPN }\end{array}$ & $\begin{array}{l}\text { Propone analizar las } \\
\text { múltiples variables } \\
\text { existentes en el } \\
\text { sector Pisco que son } \\
\text { factores principales } \\
\text { de la apreciación en } \\
\text { el mercado } \\
\text { internacional }\end{array}$ \\
\hline $\begin{array}{l}\text { Exportación de Pisco } \\
\text { Acholado "New } \\
\text { Imperial” a Paterson, } \\
\text { New Jersey-Estados } \\
\text { Unidos. }\end{array}$ & $\begin{array}{l}\text { Denominación } \\
\text { origen }\end{array}$ & Tesis de Pregrado & $\begin{array}{l}\text { Elmer Emilio Soto } \\
\text { Pachao (2017) }\end{array}$ & $\begin{array}{l}\text { Universidad de San } \\
\text { Martin de Porres }\end{array}$ & Mixta & No & $\begin{array}{l}\text { Repositorio } \\
\text { USMP }\end{array}$ & $\begin{array}{l}\text { Propone la } \\
\text { exportación del } \\
\text { pisco acholado, } \\
\text { cuyo ingrediente } \\
\text { principal es la } \\
\text { unificación de } \\
\text { sabores y olores de } \\
\text { tres diferentes tipos } \\
\text { de uvas. }\end{array}$ \\
\hline
\end{tabular}


Exportación de Pisco de Uva Italia hacia Nueva

York - Estados Unidos.

La Exportación de Pisco a Estados Unidos y su

Impacto en la

Producción Peruana en

el Periodo 2008 - 2017.

\section{Estrategia de}

distribución de pisco en

el mercado de Estados

Unidos. Caso práctico:

Austin Texas

\section{Participación}

$\sqrt{2}+x^{2}$

Exportación

Exportacion

Tesis de Pregrado

Jozef Kevin López Riter (2018)

Vallejo

Universidad de San Martin de Porres

Mixta

(2017)

$\begin{array}{ll}\text { No } & \text { Repositorio } \\ \text { USMP }\end{array}$

Introducir al

mercado

norteamericano el

pisco de uva Italia

Analizar y

determinar cómo es que la exportación de nuestro pisco al mercado

estadounidense afectó en el nivel de producción de las empresas exportadoras de

pisco

$\begin{array}{lll}\text { Comercialización } & \text { Artículo de } & \text { Natali Lama, } \\ \text { investigación } & \text { Anahí Martínez } \\ & & \text { y Richard } \\ & & \text { Rosado (2006) }\end{array}$

Cualitativa No

Universidad Esan
Journal of

Economics,

finance and

administrative

science
Debemos investigar a nuestros clientes del mercado donde queremos introducir nuestra bebida bandera y analizar cuáles son sus comportamientos y poder así tener éxito.

Nota: La tabla 4 muestra los resúmenes de los antecedentes con sus respectivas variables. Autoría propia

La revisión exhaustiva de cada uno de estos antecedentes académicos, los mismos que guardan rigurosidad científica son los fundamentos para poder establecer que las variables, dimensiones e indicadores que se plantea en la presente tesis son coherentes con estudios anteriores, en donde también se establecen como parámetros de medidas y similar. 


\subsubsection{Marco Teórico.}

Las variables "Factores de Promoción" y "Exportaciones del Pisco" de la presente tesis se sustentan en teorías que a continuación se citan, las cuales se destacan debido a su relevancia científica con el estudio de la presente tesis.

\section{Teoría de la Promoción Comercial.}

Según Kotler (2003), nos menciona que las promociones de ventas o comerciales se refieren a los incentivos que se les brinda a los clientes en sus compras. El autor considera asimismo que la publicidad es una herramienta de largo plazo para persuadir la actitud y decisión del mercado o sector objetivo hacia una marca, las promociones comerciales son efectivas en el corto plazo pues desencadenan acciones de compra.

El aumento de las promociones comerciales demuestra que las empresas dan prioridad a la venta de sus productos antes que la construcción de una marca en el futuro.

Las promociones comerciales pueden estar enfocadas a distribuidores y a los clientes internos y externos. Los distribuidores realizarán arduamente su trabajo si se les brinda más descuentos, apoyo con su publicidad y medios de merchandising, así como obsequios. Los clientes externos realizarán más compras si se les brindan descuentos, cupones, ofertas 2X1 regalos, concursos, primas y garantías. Los clientes internos realizarán sus labores de ventas en función se les reconozca sus logros y objetivos alcanzados.

El autor también sostiene que, debido a las diversas herramientas de promoción comercial existentes, el área de marketing debe conocerlas para utilizar con eficiencia la mejor de todas. Algunas grandes empresas se proveen especialistas que pueden brindar consejo a los gerentes de 
marca. Otra opción es solicitar consejos de expertos en marketing sin tener necesariamente el departamento en la empresa.

En la actualidad las promociones online son masivamente utilizadas pues proveen a la marca el enriquecimiento de la imagen y a su vez añaden valor. Asimismo, estas se utilizan a la par con la publicidad pues sirven de estrategia de reconocimiento de marca.

\section{Teoría para la Promoción de bebidas.}

Esta teoría (H. H. Vivar, 2017) nos indica que el pisco es la bebida espirituosa que más se consume en el país y ello le da valor agregado, por lo que promocionarlo es esencial para penetrar en los mercados extranjeros y sobre todo en el mercado de la coctelería de Estados Unidos.

El autor declara que, los peruanos deben de conocer más a fondo la historia del pisco, cuyo conocimiento los llevará aún más a valorar este producto, considerado Patrimonio, y poder recomendarlo a otros no compatriotas su consumo.

Es a saber que existen en el mercado diferentes marcas que ofrecen este producto de diferente calidad, es por ello que es importante saber cuál es la diferencia intrínseca del producto bandera ante otros productos "similares", pero que un excelente pisco peruano supera en sabor.

También es a saber que una de las nuevas tendencias es la penetración del pisco en la coctelería; esto podría significar su ingreso a nuevos mercados internacionales y en especial en el mercado estadounidense, ya que son los más degustadores de cocteles.

Finalmente, esta teoría indica el medio por la cual se puede promocionar la bebida espirituosa como lo es el Pisco peruano es en la coctelería estadounidense, cuyo sustento es su valor histórico 
y su aceptación en el mercado de la coctelería, la cual se relaciona con nuestras variables y estrechamente a la variable Factores de Promoción.

\section{Teoría de la exportación internacional y producción.}

Esta teoría (PNUD, 2004) muestra los datos estadísticos del nivel de producción de uva de varios países y que cuyo destino principalmente es ser parte de la elaboración de bebidas espirituosas e ingrediente principal; considerándose así un nuevo elemento de intercambio comercial y de desarrollo económico regional.

Es de conocerse que en el Perú se viene acrecentando la producción de uva y cuyo resultado se muestran en ganancias muy sobresalientes, más que el de la competencia, debido a que la recolección de este producto se da mucho más temprana, convirtiéndose en su ventaja principal.

Por otro lado, se argumenta que los gustos y preferencias de los consumidores del pisco han hecho que este evolucione, ya que se señala que las nuevas tendencias de preferencia para el consumo del pisco indican que el consumidor moderno prefiere las bebidas espirituosas más suaves.

Finalmente se señala que una de las formas de promoción del pisco es la incursión de grandes empresas productoras de pisco en el extranjero ya que se han visto grandes avances para elevar su exportación al extranjero. Empero, se indica que, a pesar de tener éxito en la exportación, el precio puede jugar un papel importante y por ello se deben de canalizar nuevas formas de elaborar el pisco peruano con menos costos en la producción. 


\section{Nueva Teoría del Comercio Internacional.}

Esta teoría (Paul Krugman, 1980) es concebida debido a las nuevas demandas comerciales de economías que se encuentran actualmente reconocidas y en un gran auge en el mercado internacional en la que se llevan a cabo intercambios comerciales de bienes considerables.

La teoría señala que al ingreso de una corporación a los sectores donde las grandes industrias desarrollan sus actividades comerciales se le es muy complicado incluirse debido a que hay restricciones tales como tener grandes maquinarias e infraestructuras de punta.

La teoría también propone que en cierto grado las autoridades del gobierno por medio de sus instituciones concernientes a este sector, intervengan de cierta forma en las políticas comerciales para solucionar los inconvenientes que se dan en el mercado interno, debido a la competencia.

De lo anteriormente mencionado podemos indicar que si no tenemos un mercado en la cual haya políticas que intervengan y controlen el desenvolvimiento de la comercialización tanto interna como externa, tendremos un mercado con productividad deficiente, dependiendo de los problemas.

\section{Teoría del ciclo de vida del producto.}

Esta teoría (R., V. 1966) nos indica que los productos que son recientemente inventados en un país al cual llamaremos "X" y que son exportados al país "Y", estos llevan un proceso, un ciclo de vida, debido a que estos nuevos productos son copiados y se tiene un final peculiar.

De lo anterior se indica que son copiados por el país "Y", y son puestos en venta en el mercado internacional e incluso en el mismo país en donde fue inventado; y la teoría propone que es esta parte el 2do paso del ciclo de vida de un producto. 
Esta teoría indica que luego el producto pasa por otro momento al cual llama "madurez", en esta etapa es donde las empresas productoras mantienen sus ventas al margen de la demanda del mercado y con costos menores en la producción.

Finalmente, la teoría indica una cuarta etapa. En la cuarta etapa es donde las demandas decaen y las empresas productoras de uno de los países en competencia son capaces de producir el producto a un costo menor y por lo tanto se vuelve atractivo y conveniente para los consumidores donde se les ofrezca el mismo producto con un menor precio.

\section{Teoría de la Ventaja Comparativa.}

Esta teoría (David Ricardo, 1817) es propuesta como una opción a utilizar ante la teoría ya propuesta por Adam Smith, quien nos indica que los países deben comerciar con países que tienen ventajas absolutas en la producción de sus productos.

Esta teoría nos indica que los países deben de exportar los productos que ellos fabrican con menores costos relativos en la producción, y que debieran importar los productos que para su producción se asumen mayores costos, es así como se obtiene la ventaja comparativa.

Llevando a cabo esta idea es como un país puede incursionar en el mercado internacional, y en un futuro tener más participación en el intercambio comercial que cada vez más viene globalizándose, y obtener ventajas económicas y alianzas comerciales.

Finalmente podemos señalar que la ventaja comparativa se encuentra en la producción y exportación de bienes en la que dos países son expertos en producirlos a un coste menor, y al intercambiar, ambos países salen beneficiados. 


\section{Teoría del Comercio Internacional de Adam Smith.}

Esta propuesta teórica (Ricardo, 1997), nace en virtud de la que es la teoría clásica del comercio, la cual se encarga de analizar el comportamiento del libre comercio, de manera que esta teoría propone estudios comprobados en la actualidad y que son efectivas en la práctica.

Ante ello, la teoría del comercio internacional estudia la ventaja comparativa que tiene los países en cuanto a materia de exportación, la cual declara que, los países que tengan ventaja relativa a los costes de producción de un producto podrán ver que la exportación de ese producto es más rentable.

Esto quiere decir, en palabras más sencillas, cuando existen dos países que exportan espárragos, el país que tenga más ventaja en cuanto a menos costo en la producción de espárragos podrá competir y mejorar las expectativas de la exportación de espárragos, llegando a tener mejores oportunidades de aceptación en un mercado.

En base a esto, la teoría demuestra que los países que tienen éxito en la exportación de sus productos, es porque han mejorado sus planes de producción, haciendo que los costos de la producción de sus productos exportables sean relativamente más bajos.

Contemplando este panorama tan prometedor, se puede ver la viabilidad de la comercialización internacional de productos que los países producen en abundancia, de manera que también esto permite promover la inversión en cuanto a la mejora de la producción y tener mejores ventajas relativas con otros exportadores internacionales para ganar más mercado.

En la práctica, esta teoría es verídica, ya que declara algo que se puede comprobar y ver, ya que los países con mejores ventajas de producción utilizan tecnología más avanzada las cuales hacen 
que la producción sea menos cara y más competitiva, mejorando la exportación en cantidades exorbitantes de sus productos transables.

Finalmente, en vista de que el Perú es uno de los principales exportadores de espárragos a estados unidos, se debe de promover mejores alternativas que permitan a los productores y exportadores reducir los costos de la producción de los espárragos, para que la exportación de este producto del sector agroindustrial tenga un mercado sólido a la cual proveer.

\subsection{Objetivos e Hipótesis}

El propósito del presente trabajo de investigación titulado "Análisis de los factores de promoción que incidieron en la evolución de las exportaciones de Pisco hacia los Estados Unidos 2015 - 2019” tiene como objetivo evaluar y definir cómo la denominación de origen (pisco), los eventos de ferias y la Marca Perú influyeron en el posicionamiento del pisco en los Estados Unidos en el periodo mencionado. Así mismo, el desarrollo del presente trabajo se realizó mediante una investigación descriptiva, documental de carácter no experimental y transversal.

\subsubsection{Objetivos.}

\section{Objetivo General.}

- Analizar la incidencia de los factores de promoción en la evolución de las exportaciones de pisco hacia Estados Unidos 2015 - 2019

\section{Objetivos Específicos.}

- Determinar la incidencia de la promoción de la denominación de origen la evolución de las exportaciones de pisco hacia los Estados Unidos 2015 - 2019 
- Determinar la incidencia de la promoción de eventos de ferias en la evolución de las exportaciones de pisco hacia los Estados Unidos 2015 - 2019

- Determinar la incidencia de la promoción de la Marca Perú en la evolución de las exportaciones de pisco hacia los Estados Unidos 2015 - 2019

\subsubsection{Hipótesis:}

\section{Hipótesis General.}

- Los factores de promoción inciden positivamente en la evolución de las exportaciones de pisco hacia Estados Unidos 2015 - 2019

\section{Hipótesis Específica.}

- La promoción de la denominación de origen tiene incidencia positiva con la evolución de las exportaciones de pisco hacia Estados Unidos 2015 - 2019

- La promoción de eventos de ferias tiene incidencia positiva con la evolución de las exportaciones de pisco hacia Estados Unidos 2015 - 2019.

- La promoción de la Marca Perú tiene incidencia positiva con la evolución de las exportaciones de pisco hacia Estados Unidos 2015 - 2019 


\section{Capítulo 2}

\subsection{Método}

\subsubsection{Tipo de investigación.}

La presente tesis según (Hernández, Fernández y Baptista, 2010) será de tipo descriptiva debido a que busca señalar las características, rasgos u propiedades de personas, grupos, procesos, situaciones $\mathrm{u}$ otros factores que se expongan bajo un análisis; en otras palabras, la presente investigación busca únicamente recolectar información sobre los temas señalados a fin de poder medirlos y analizarlos.

Adicionalmente, esta tesis será correlacional porque busca conocer el grado de relación entre dos factores, variables u categorías como lo son los factores de promoción y las exportaciones del Pisco, los cuales son temas por tratar en esta búsqueda (p.p. 92-93). Asimismo, en esta investigación se puede determinar si una de las variables analizadas crea dependencia de la otra o no. Es importante señalar que los términos dependiente e independiente se utilizan para representar una relación de "causalidad" entre dos variables, siendo el caso que el valor de la variable dependiente 'depende' del valor de la variable independiente, por lo que el comportamiento de la variable dependiente se podría predecir del comportamiento de la variable independiente.

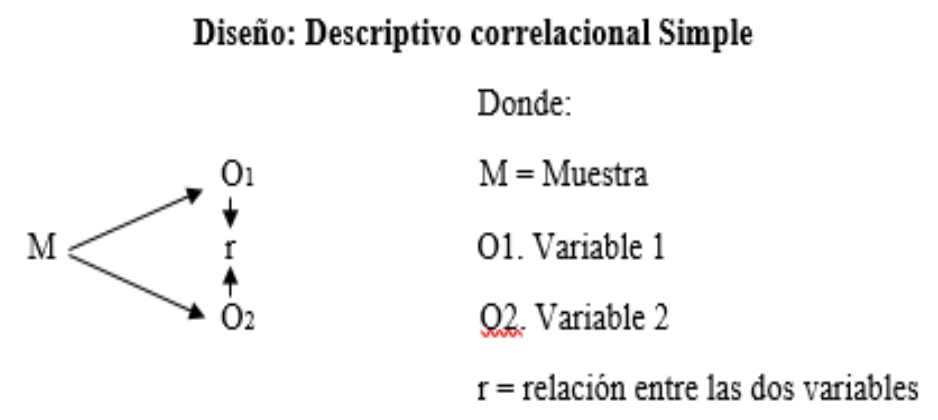


De igual manera, es una investigación de tipo transversal de acuerdo con lo que indica Hernández et al. (2010), "un estudio transversal recopila información en un rango de tiempo único" (p.152) por lo que la presente tesis tiene un tiempo de estudio comprendido del 2015 al 2019.

\subsubsection{Diseño de investigación.}

Debido a la naturaleza del objeto de estudio, se desarrollará una tesis basada en un tipo de Investigación Mixta, por consiguiente, involucra adoptar los enfoques antes mencionados.

Según Sampieri y Mendoza (2008) la investigación mixta representa una suma de métodos sistemáticos, críticos y empíricos de exploración, asimismo, implica el análisis y recolección de datos cualitativos y cuantitativos. En este sentido, se realizará este tipo de investigación ya que, las fuentes de indagación aplicadas a este trabajo fueron secundarias y primarias para realizar el soporte teórico, esto a razón de que contamos con antecedentes examinados que utilizan un enfoque mixto por lo que dicho enfoque utiliza el análisis y recolección de datos para realizar y afinar las preguntas de interés.

\subsubsection{Variables y Categorías.}

La presente tesis, al ser una investigación mixta, estudiará el tema en base a variables y categorías como se resumen en las Matrices de Operacionalización en el anexo 2 y 3.

Para la investigación cuantitativa, se hará el estudio enfocado en dos variables. Siendo considerada como la Variable Independiente $\left(\mathrm{O}_{1)}\right.$ a los Factores de Promoción los cuales según Román (2016) en su investigación "Un análisis de las promociones de ventas al consumidor" afirma: Los factores de promoción son la base para el incremento de la oferta y demanda de bienes y servicios de una economía exportadora. 
Asimismo, se considera como la Variable Dependiente $\left(\mathrm{O}_{2}\right)$ a las exportaciones del pisco (ADEX, 2010) que se sustentan en la competitividad y articulación de los actores participantes en el sector vitivinícola, por lo que se considera que la internacionalización del pisco peruano presenta un escenario favorable, ello también en base de ventajas comparativas de los campos de cultivo en comparación con su mercado de exportación.

Por otro lado, para la investigación cualitativa el enfoque se da en base a Categorías que buscan complementar el estudio de las variables de la investigación cuantitativa, por lo que a continuación detallamos la Guía de Categorías:

Tabla 5.

Guía de Categorías

\section{Categorías}

Política de Comercio Alcances de la Política de Comercio Exterior del Estado

\section{Exterior}

Acuerdo Comercial Perú - Perspectivas del Acuerdo Económico entre ambos países

\section{EEUU}

$\begin{array}{ll}\text { Mercado del Pisco } & \text { Saber la situación real de la comercialización del mercado del } \\ \text { Peruano } & \text { pisco en el ámbito nacional }\end{array}$

Estrategias Publicitarias Analizar los avances de promoción publicitaria en el mercado del pisco
Realidad Industrial Analizar la innovación de la industria del pisco en el mercado interno

Elaboración propia

De esta manera, resulta importante señalar que este tipo de análisis de contenido en base a categorías cualitativas resulta muy importante para ampliar la visión más allá de las variables de 
estudio, y poder generar análisis de informaciones para las entrevistas, ello en tanto que esta metodología se sustentan en casuísticas.

\subsubsection{Muestra.}

\section{Población de estudio.}

La población está compuesta por personal de empresas relacionadas al sector exportador y/o relacionado con el comercio internacional del pisco peruano, con conocimientos teóricos y/o de experiencia referentes a la exportación de pisco a los Estados Unidos con capacidades que permitan garantizar respuestas acordes a nuestros objetivos de investigación.

De forma tal, esta muestra recae en una población de personas que, si bien no son muy abundantes, demuestran ser representativas para obtener una mayor y mejor fuente de información para la realización de encuestas y entrevistas, siendo el caso mencionar que las experiencias de los involucrados generen altos grados de significancia a lo largo del período de análisis y permita una tabulación de tipo no probabilístico.

\section{Muestra}

Por un lado, en la parte cualitativa se ha escogido en forma analítica a 3 profesionales especializados en la actividad del sector exportador y/o relacionado con el comercio internacional del pisco peruano con experiencia entre 10 y 15 años en análisis económicos financieros del sector de esta actividad productiva, los mismos que ocupan u ocuparon puestos como empresarios, docentes de negocios internacionales, funcionarios de MINCETUR o similares.

Por otro lado, en la parte cuantitativa se aplicará un cuestionario dirigido a 50 ejecutivos relacionados con las empresas del sector exportador y/o relacionado con el comercio internacional del pisco peruano. Así mismo, detallar que esta muestra parte del enfoque en la Ley de Pareto 
(Pareto, 1986) en la que se analiza a un grupo menor de empresas pero que son responsables de generar el mayor volumen de exportaciones dentro del mercado norteamericano; es decir la conocida Regla 80/20.

A continuación, se muestran tablas que brindan a mayor detalle información de cuáles son las empresas a las que se abocará el estudio cuantitativo.

Tabla 6.

Exportación de Pisco a EEUU - participación de las marcas (\%)

$\begin{array}{llllll}\text { Marca } & 2015 & 2016 & 2017 & 2018 & 2019\end{array}$

Bodega y Viñedos Tabernero

21

11

18

12

20

Bodega San Isidro

12

9

9

16

15

Santiago Queirolo

$$
7
$$

21

9

7

15

$\begin{array}{cccccc}\text { Otros } & 60 & 59 & 64 & 65 & 50 \\ \text { TOTAL } & 100 \% & 100 \% & 100 \% & 100 \% & 100 \%\end{array}$

\section{Elaboración Propia}

Fuente: AGRODATA

En la tabla 6, se muestra las cuatro principales empresas exportadoras de mayor participación en el mercado objetivo de esta investigación. 
Tabla 7.

Principales empresas exportadoras de Pisco en los últimos años a EEUU (Variaciones Porcentual)

Empresas \%Var 18-17 \%Part. 19

\section{Bodega San Nicolás Sociedad}

Anónima

$$
19 \%
$$

$15 \%$

Anónima

Bodega San Isidro S.R.L.

$$
-16 \%
$$

$15 \%$

Destilería la Caravedo S.R.L

$-22 \%$

$10 \%$

Bodegas y Viñedos Tabernero

S.A.C.

$$
-17 \%
$$

$10 \%$

Santiago Queirolo S.A.C.

Viña Tacama S.A.

$$
-37 \%
$$

$6 \%$

Bodegas Don Luis Sociedad

Anónima...

$-25 \% \quad 6 \%$

Macchu Pisco S.A.C.

$$
-10 \%
$$

$5 \%$

Viña Ocucaje S A

$119 \%$

$5 \%$

Otras Empresas (55)

$-19 \%$

Fuente: Promperú

En la tabla 7, se puede observar con mayor claridad a las empresas que representan aproximadamente el $80 \%$ de las exportaciones a los Estados unidos y representan aproximadamente el $20 \%$ de total existentes. Son éstas las que, por resultados de su proceso de 
comercialización, las que nos ayudarán a explicar cómo los factores de promoción que aplican inciden en el comportamiento de las exportaciones de Pisco en EEUU y son parte de la materia de estudio de la presente tesis.

Asimismo, es importante señalar que en lo referente a nuestro mercado objetivo en los Estados Unidos nos dirigiremos a intermediarios que nos permita mejores y mayores facilidades en encontrar canales de distribución del pisco peruano de manera masiva, tales como licorerías, supermercados y hoteles. Como ejemplo podemos mencionar intermediarios localizados en las zonas de New Jersey y Pattersson que son condados donde se concentra la mayor cantidad de peruanos y por ende de eventos relacionados con nuestros productos bandera (ver anexo 10).

\subsubsection{Instrumentos de investigación.}

\section{Investigación Cuantitativa.}

Para esta investigación se generará encuestas dirigidas a 50 ejecutivos especializados y relacionados a empresas del sector Pisquero, las cuales se describieron a mayor detalle en los párrafos anteriores.

Es importante precisar que, si bien el parámetro de estudio son las exportaciones de pisco en Estados Unidos, se asume que los analistas del mercado interno también son conocedores de las bondades de este producto y testigos directos de los efectos de la promoción de este producto tanto por los esfuerzos privados como estatales para estos fines.

Con esta información obtenida mediante nuestras encuestas, se podrá construir análisis de los resultados, de forma tal que permita hacer comparaciones, cruces de información, comprobación y validación de las variables que están registradas en la presente tesis con la finalidad de garantizar 
un conocimiento más riguroso de la realidad investigada. Considerando lo anteriormente mencionado, es que el inventario de preguntas de la Encuesta fue sometido a un proceso de validación de expertos (Anexo 10), los cuales brindaron sus opiniones que sirvieron de base para las adaptaciones del instrumento.

Asimismo, mencionar que se usa los estándares necesarios en términos de modelos y formatos que son científicamente exigidos, en vista que ello permita darle una seriedad que es científicamente exigida; así como también, permita darles una seriedad metodológica a las encuestas y los tipos de preguntas que estarán presentes en este estudio, siendo el caso que se asegure que estas preguntas estén relacionadas con las variables, dimensiones e indicadores del objeto del presente estudio, con mayor razón si el tipo de preguntas en las encuestas son de naturaleza cerrada y multivariables.

\section{Investigación Cuantitativa.}

Se contará con (03) expertos del sector exportador de pisco a los Estados Unidos, los mismos que pueden ser incluso emprendedores de algunas marcas emblemáticas de este tipo de licor que tengan vasto conocimiento de la realidad exportadora del pisco peruano hacia el exterior, docentes de negocios internacionales, funcionarios de MINCETUR o similares, de manera tal que puedan aportar datos comerciales que aporten al análisis del objeto de estudio que perseguimos.

En este sentido, cabe indicar que nuestra intención investigativa se orienta en el hecho de obtener información relevante para conocer aquellos factores como los referidos a los esfuerzos de promoción tanto privado como estatal que sean de incidencia directa con el comportamiento de los volúmenes de exportación de pisco en particular hacia los Estados Unidos. 
De lo anterior, es importante señalar que los entrevistados contarán con alrededor de 10 y 15 años de experiencia en el mercado exportador de pisco, quienes, por esta calidad profesional, estarán en condiciones de proporcionar la data requerida por nuestra investigación.

A continuación, se detalla las características más importantes sobre el cómo se ha diseñado las preguntas.

\section{Preguntas Abiertas.}

Respecto a este tipo de preguntas, mencionamos que cada una de las preguntas son en casi todos los casos de manera abierta con la finalidad de generar confianza y amplitud de las respuestas por parte de los entrevistados y, siendo ello un factor que ayuda al cruce de información con las informaciones del análisis de contenido.

\section{Re-preguntas.}

Este tipo de preguntas se pueden suscitar en base a las preguntas ya planificadas y generan nuevas informaciones por parte del entrevistado. Es importante destacar el hecho que también las re-preguntas de alguna manera fueron previstas antes de realizar las entrevistas ya que ello ayudaría en aprovechar la mayor información posible en rangos de tiempo más eficientemente trabajados.

Finalmente, se indica que estos instrumentos de entrevistas en profundidad son realizados con estándares de formatos y similares (Anexo 6). Adicional, a continuación, se presenta los datos de los entrevistados: 
Tabla 8 .

Datos de Control

\section{Datos de Control}

\begin{tabular}{llll}
\hline & Contacto 1 & Contacto 2 & Contacto 3 \\
\hline Nombre & $\begin{array}{l}\text { Nilsa Sifuentes } \\
\text { Beingolea }\end{array}$ & José Bazán Briceño & Fernando Ochoa Torres \\
Cargo & Ex Funcionaria & $\begin{array}{l}\text { Docente de Negocios } \\
\text { Internacionales }\end{array}$ & Ex Gerencia de Exportaciones \\
Profesión & $\begin{array}{l}\text { Dra. En Proyectos de } \\
\text { Inversión } \\
\text { Exportadora }\end{array}$ & $\begin{array}{l}\text { MBA en Administración } \\
\text { de Negocios }\end{array}$ & $\begin{array}{l}\text { Master en Proyectos de } \\
\text { Inversión }\end{array}$ \\
Empresa & Mincetur & UNFV & Tabernero SAC \\
País & Perú & Perú & Perú \\
\hline Elaboración propia & &
\end{tabular}

\subsubsection{Procedimientos de recolección de datos.}

Para esta investigación mixta, tanto para la parte de la investigación cuantitativa como cualitativa, a continuación, se esboza los principales procedimientos y herramientas metodológicas que se aplicará para la recolección de datos relevantes:

\section{Empleo del Software Microsoft Excel.}

Con ello se generará los distintos cálculos de procesamiento de datos, así como la tabulación de data numérica y gráfica.

\section{Empleo del Software IBM SPSS.}

Con ello se aplicará un procesamiento cuantitativo a la data obtenida mediante encuestas, asimismo permitirá la validación estadística de la data procesada en esta investigación. 
Finalmente, cabe destacar que esta investigación al basarse en estas técnicas de procesamiento de recolección de datos para la parte cuantitativa, como en la referida al análisis de contenido para la parte cualitativa, permitirá cumplir con las exigencias metodológicas mínimas exigidas para posicionar la presente tesis con estándares científicos acordes a la naturaleza del objeto de estudio, reflejando todo ello mediante gráficos, tablas estadísticas y/o de frecuencia que buscan demostrar las hipótesis planteadas. 


\section{Capítulo 3}

\subsection{Presentación de Resultados}

\section{Resultados de las Entrevistas de Profundidad.}

Respecto a las entrevistas de profundidad dirigidas a especialistas en el análisis de factores de promoción que tienen incidencia a lo largo de la cadena de exportaciones de pisco hacia los Estados Unidos, destacaron los siguientes profesionales:

- $\quad$ SIFUENTES BEINGOLEA, Nilsa, quien es Doctora en Proyectos de Inversión Exportadora, Ex Funcionaria Mincetur con 25 años de experiencia

- BAZAN BRICEÑO, José, MBA en Administración de Negocios, Docente de Negocios Internacionales en la UNFV con 30 años de experiencia

- OCHOA TORRES, Fernando, Master en Proyectos de Inversión, Ex Gerencia de Exportaciones con 22 años de experiencia.

De estas entrevistas a profundidad dirigidas a los especialistas mencionados se determinaron que los factores de promoción tienen una importante incidencia en la evolución de las exportaciones de pisco hacia Estados Unidos en los últimos años.

Ello en vista que, en base a la experiencia de estos profesionales los factores con mayor incidencia en las exportaciones del pisco peruano hacia los Estados Unidos son hasta el momento la denominación de origen, eventos de ferias internacionales y el trabajo de una marca Perú en el exterior. Es en esta perspectiva que los esfuerzos del sector público y privado deben de continuar en horizontes de largo plazo con la finalidad de que un mejor posicionamiento de nuestro pisco 
reditúe en múltiples beneficios para los productores, exportadores, consumidores y demás agentes involucrados en este sector.

Los aportes de estos profesionales cobran importancia en la medida que tienen años de experiencia exitosa en el análisis de la evolución del pisco peruano en las exportaciones hacia los Estados Unidos y cuyas conclusiones aportadas por ellos, nos sirven para contextualizar de manera adecuada la demostración de los objetivos e hipótesis planteadas en la presente tesis.

\section{Resultados de las Encuestas.}

\section{Cuestionario de Encuesta.}

Se presenta a continuación el cuestionario que ayudará a analizar, interpretar y tabular los resultados de medir el Análisis de Factores de Promoción que incidieron en la evolución de las Exportaciones de Pisco Hacia Estados Unidos 2015 - 2019.

Pregunta 1: ¿Considera que la denominación de origen del pisco peruano incide en recomendaciones internacionales dentro del mercado de los Estados Unidos?

Tabla 9.

Pregunta 1

\begin{tabular}{llcc}
\hline & & Frecuencia & Porcentaje válido \\
\hline Válido & Muy de acuerdo & 35 & 70.00 \\
& De acuerdo & 14 & 28.00 \\
& Indiferente & 0 & 0.00 \\
En desacuerdo & 1 & 2.00 \\
Muy en desacuerdo & 0 & 0.00 \\
Total & 50 & 100.00
\end{tabular}




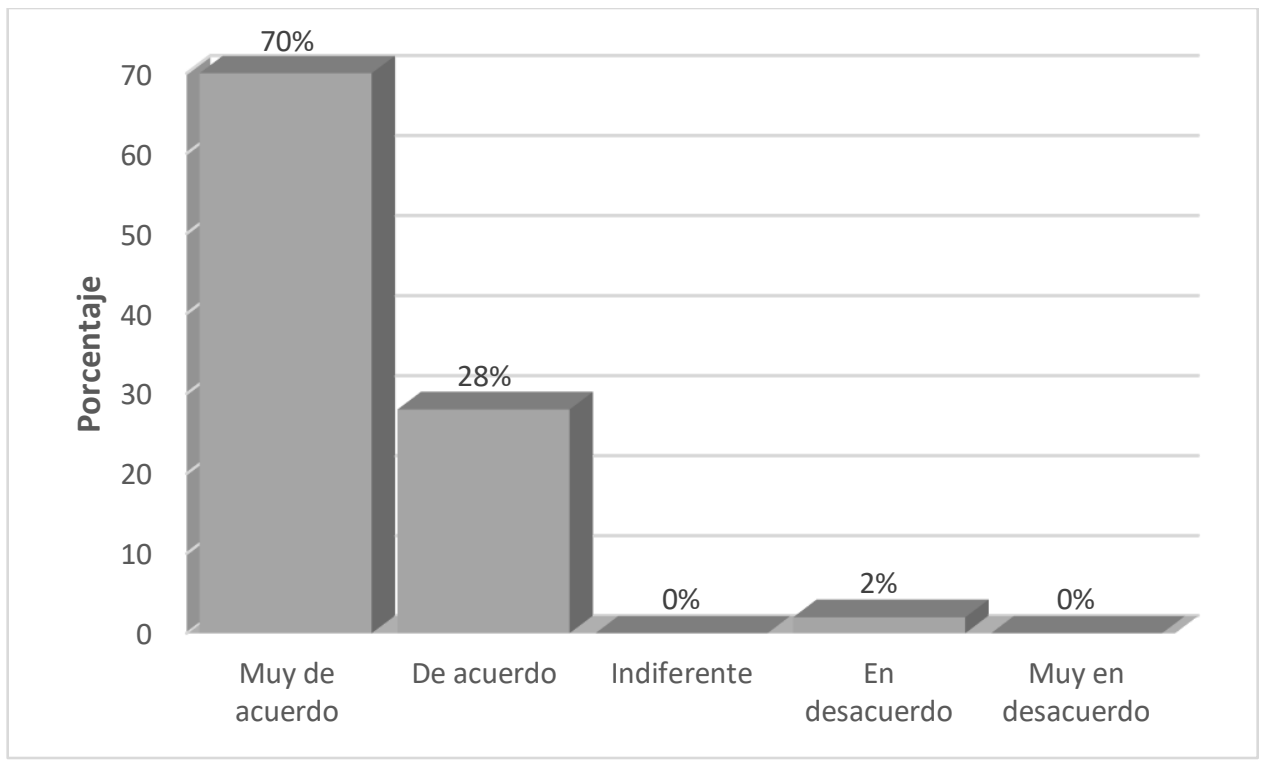

Figura 1. Pregunta 1

¿Considera que la denominación de origen del pisco peruano incide en recomendaciones internacionales dentro del mercado de los Estados Unidos? Adaptado de encuesta, por fuente propia, 2020

\section{Interpretación:}

En la figura 1, se observa, que el resultado de la encuesta nos muestra que el $70 \%$ de los encuestados están muy de acuerdo y el $28 \%$ están de acuerdo, por lo cual podemos deducir que la mayoría de los encuestados indican positivamente con respecto a que el pisco peruano incide en recomendaciones internacionales dentro del mercado de los Estados Unidos. 
Pregunta 2: ¿Asume que la denominación de origen del pisco peruano ayuda al comercio exterior, en particular a los volúmenes de exportación de este producto a los Estados Unidos?

Tabla 10.

Pregunta 2

\begin{tabular}{llcc}
\hline & Frecuencia & $\begin{array}{c}\text { Porcentaje } \\
\text { válido }\end{array}$ \\
\hline Válido & Muy de acuerdo & 28 & 56.00 \\
& De acuerdo & 20 & 40.00 \\
& Indiferente & 2 & 4.00 \\
En desacuerdo & 0 & 0.00 \\
Muy en desacuerdo & 0 & 0.00 \\
Total & 50 & 100.00 \\
\hline
\end{tabular}

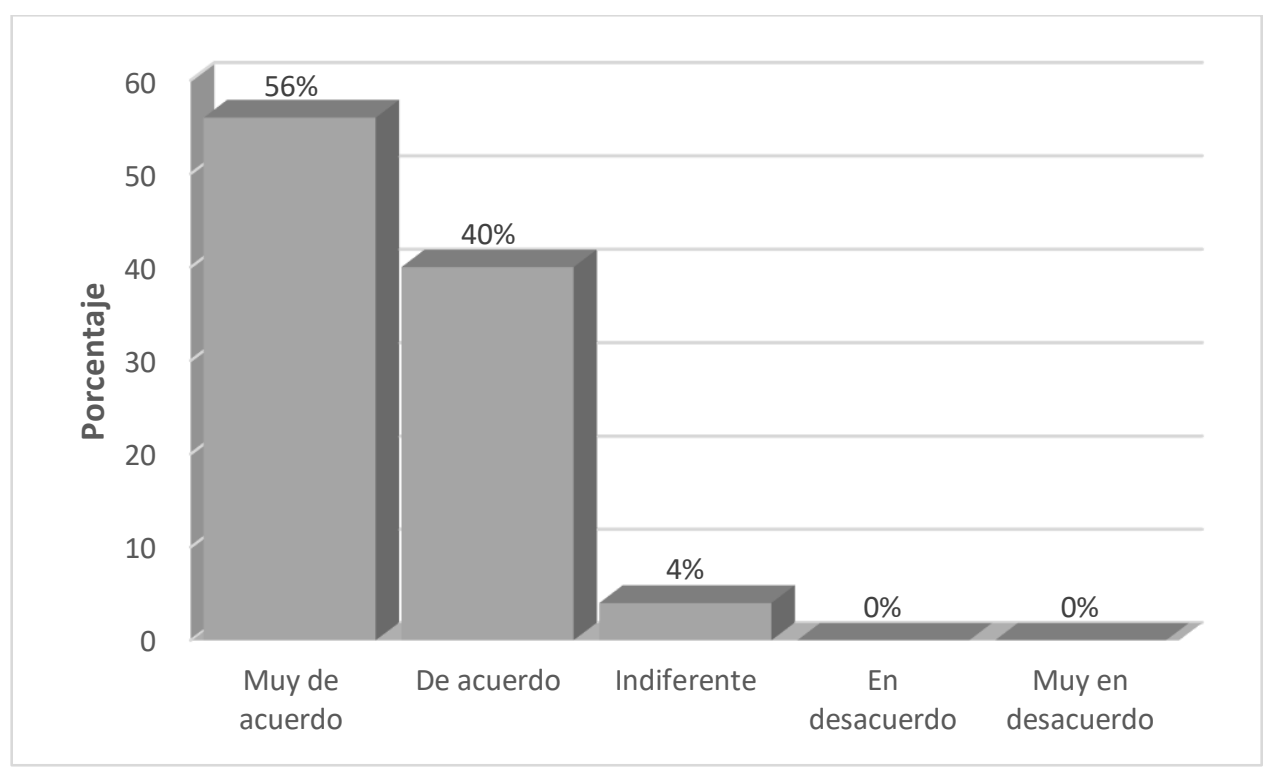

Figura 2. Pregunta 2

¿Asume que la denominación de origen del pisco peruano ayuda al comercio exterior, en particular a los volúmenes de exportación de este producto a los Estados Unidos? Adaptado de encuesta, por fuente propia, 2020 


\section{Interpretación:}

En la figura 2, con relación a que la denominación de origen del pisco peruano ayuda al comercio exterior, en particular a los volúmenes de exportación de este producto a los Estados Unidos, se observa que el $56 \%$ de los encuestados están muy de acuerdo y el 40\% están de acuerdo, con ello podemos inferir que la gran parte de los encuestados afirman positivamente la importancia sobre la denominación de origen del pisco hacia el comercio exterior.

Pregunta 3: ¿A su juicio, la denominación de origen del pisco peruano incide en mayores mercados dentro de los Estados Unidos?

Tabla 11.

Pregunta 3

\begin{tabular}{llcc}
\hline & & Frecuencia & Porcentaje válido \\
\hline Válido & Muy de acuerdo & 32 & 64.00 \\
& De acuerdo & 17 & 34.00 \\
Indiferente & 1 & 2.00 \\
En desacuerdo & 0 & 0.00 \\
Muy en desacuerdo & 0 & 0.00 \\
Total & 50 & 100.00 \\
\hline
\end{tabular}




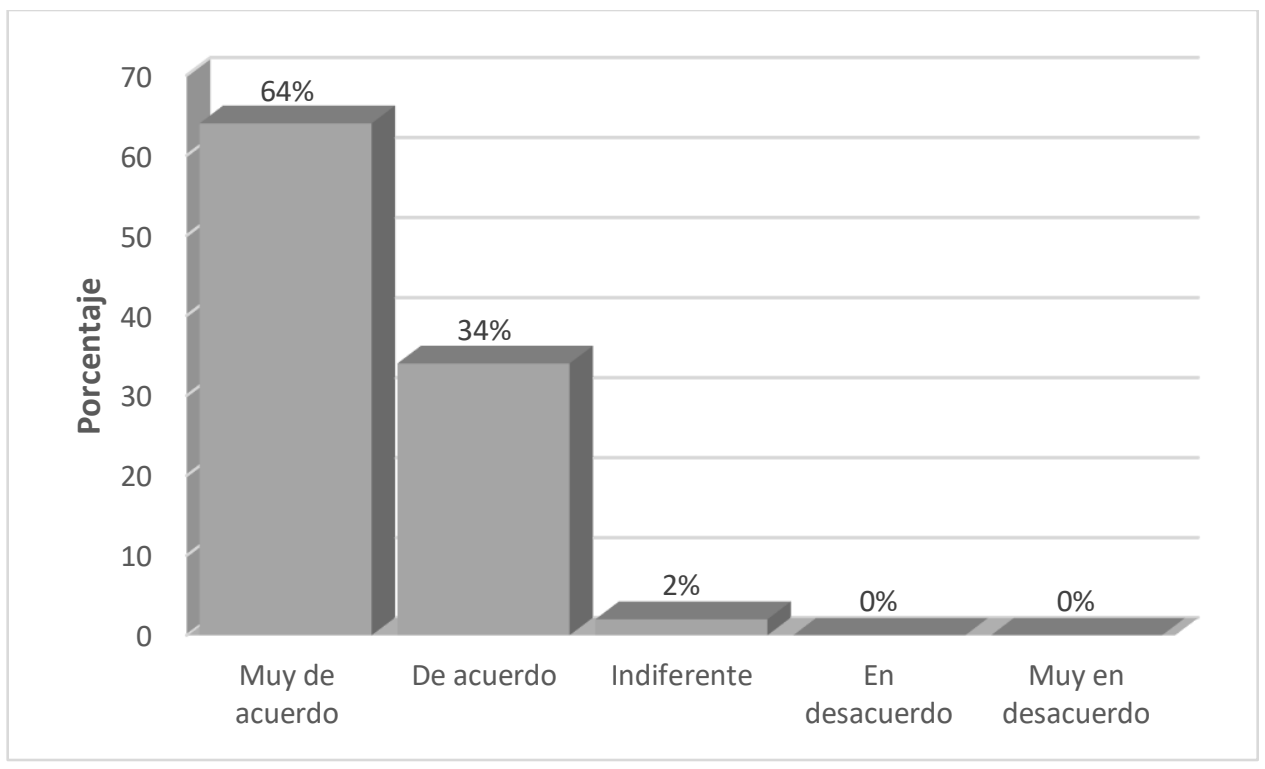

Figura 3. Pregunta 3

¿A su juicio, la denominación de origen del pisco peruano incide en mayores mercados dentro de los Estados Unidos? Adaptado de encuesta, por fuente propia, 2020

\section{Interpretación:}

En la figura 3. Respecto a si la denominación de origen del pisco peruano incide en mayores mercados dentro de los Estados Unidos, se obtuvo un resultado positivo. Se puede observar que el $64 \%$ de encuestados están muy de acuerdo; por el contrario de ello solo el $2 \%$ le es indiferente, por estos datos podemos deducir que la denominación de origen del pisco repercute en mayores mercados dentro de los Estados Unidos. 
Pregunta 4: ¿Considera que la denominación de origen del pisco peruano ayuda al reconocimiento internacional de este producto en los Estados Unidos?

Tabla 12.

Pregunta 4

Frecuencia

Porcentaje válido

\begin{tabular}{lccc}
\hline Válido & Muy de acuerdo & 30 & 60.00 \\
De acuerdo & 18 & 36.00 \\
Indiferente & 1 & 2.00 \\
En desacuerdo & 1 & 2.00 \\
Muy en desacuerdo & 0 & 0.00 \\
Total & 50 & 100.00 \\
\hline
\end{tabular}

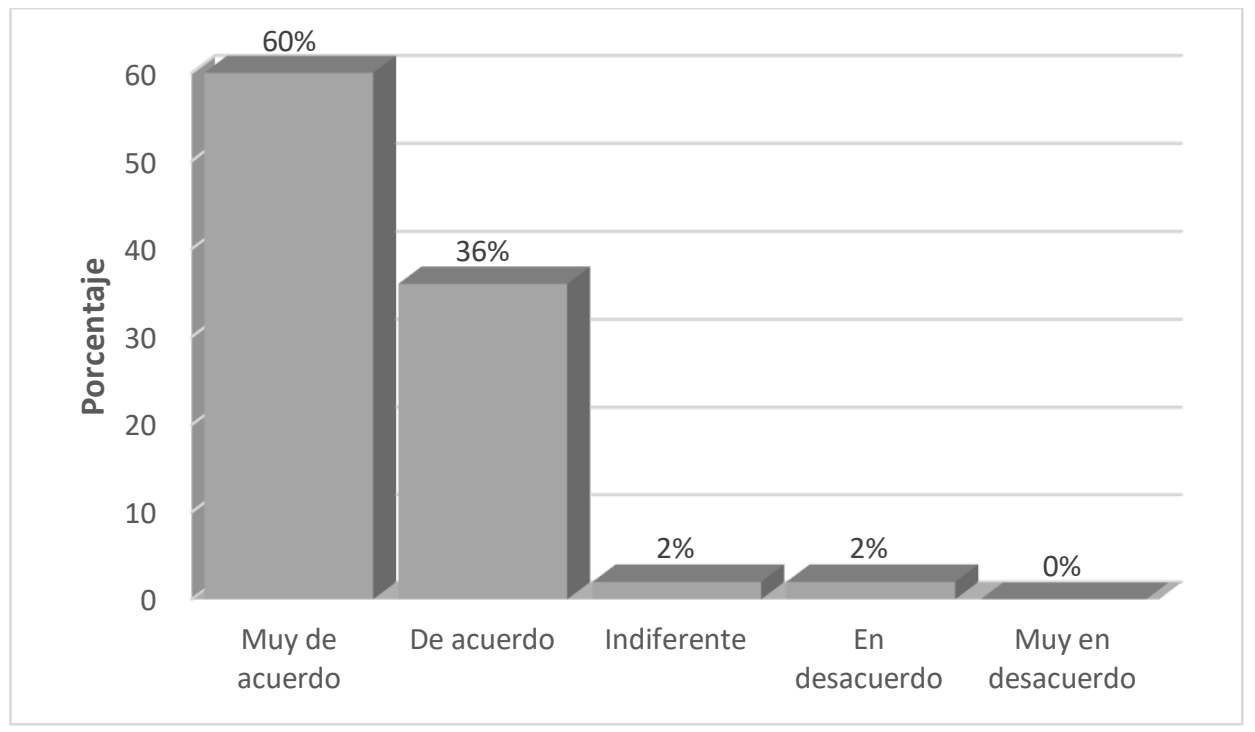

Figura 4. Pregunta 4

¿Considera que la denominación de origen del pisco peruano ayuda al reconocimiento internacional de este producto en los Estados Unidos? Adaptado de encuesta, por fuente propia, 2020 


\section{Interpretación:}

En la figura 4, referente a los resultados de esta pregunta los encuestados mostraron que un $60 \%$ están muy de acuerdo en que la denominación del pisco peruano ayuda al reconocimiento internacional en los Estados Unidos y, por lo contrario, el $0.00 \%$ de los encuestados optan por estar muy en desacuerdo.

Pregunta 5: ¿Asume, que la denominación de origen del pisco peruano incide en las exportaciones de este producto hacia los Estados Unidos?

Tabla 13.

Pregunta 5

\begin{tabular}{llcc}
\hline & Frecuencia & Porcentaje válido \\
\hline Válido & Muy de acuerdo & 26 & 52.00 \\
& De acuerdo & 21 & 42.00 \\
& Indiferente & 2 & 4.00 \\
& En desacuerdo & 1 & 2.00 \\
Muy en desacuerdo & 0 & 0.00 \\
Total & 50 & 100.00 \\
\hline
\end{tabular}




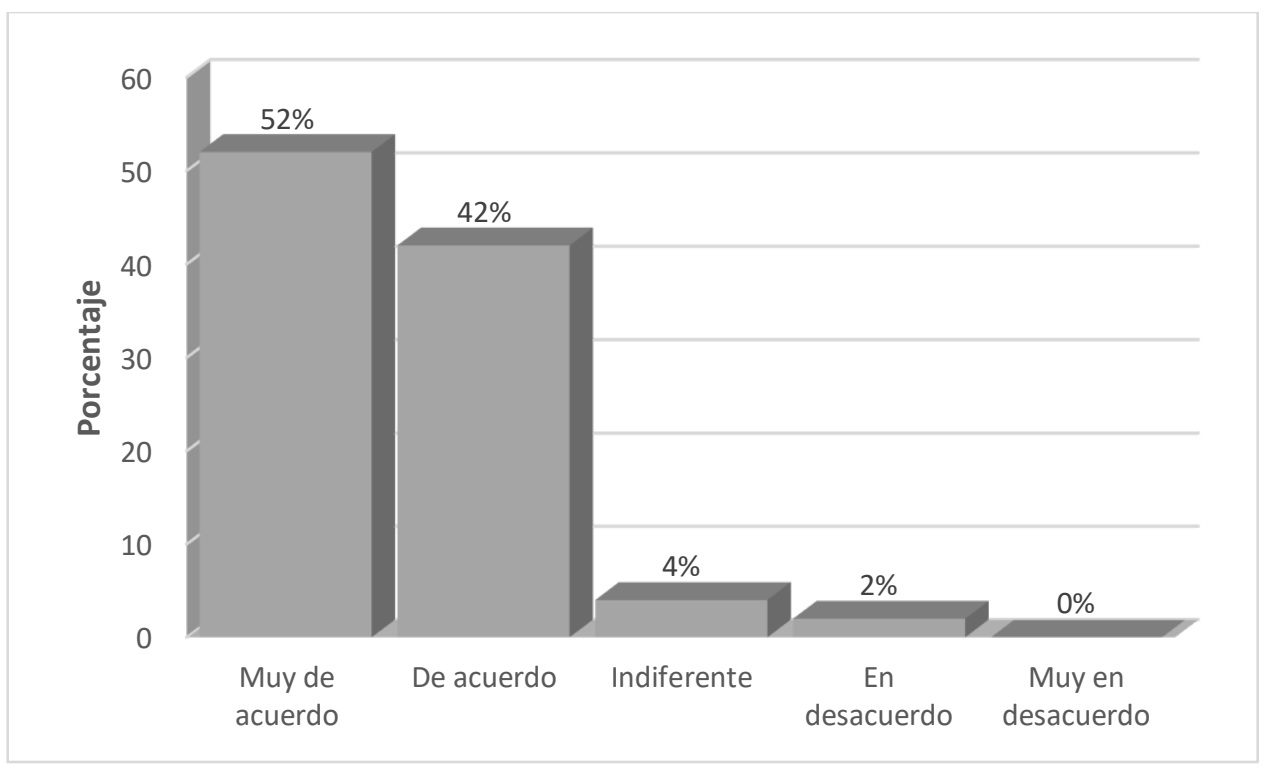

Figura 5. Pregunta 5

¿Asume, que la denominación de origen del pisco peruano incide en las exportaciones de este producto hacia los Estados Unidos? Adaptado de encuesta, por fuente propia, 2020

\section{Interpretación:}

En la figura 5, el 52\% de los encuestados están en muy de acuerdo y solamente el $4 \%$ indican indiferencia. El 2\% fueron en desacuerdo y por último el $0.00 \%$ muy en desacuerdo. Por ende, estos resultados nos permiten resaltar que la denominación de origen del pisco peruano influye en las exportaciones hacia los Estados Unidos. 
Pregunta 6: ¿A su juicio, los eventos de feria del pisco peruano inciden en nuevos eventos al interior de los Estados Unidos?

Tabla 14.

Pregunta 6

\begin{tabular}{llcc}
\hline & Frecuencia & Porcentaje válido \\
\hline Válido & Muy de acuerdo & 24 & 48.00 \\
& De acuerdo & 24 & 48.00 \\
Indiferente & 2 & 4.00 \\
En desacuerdo & 0 & 0.00 \\
Muy en desacuerdo & 0 & 0.00 \\
Total & 50 & 100.00 \\
\hline
\end{tabular}

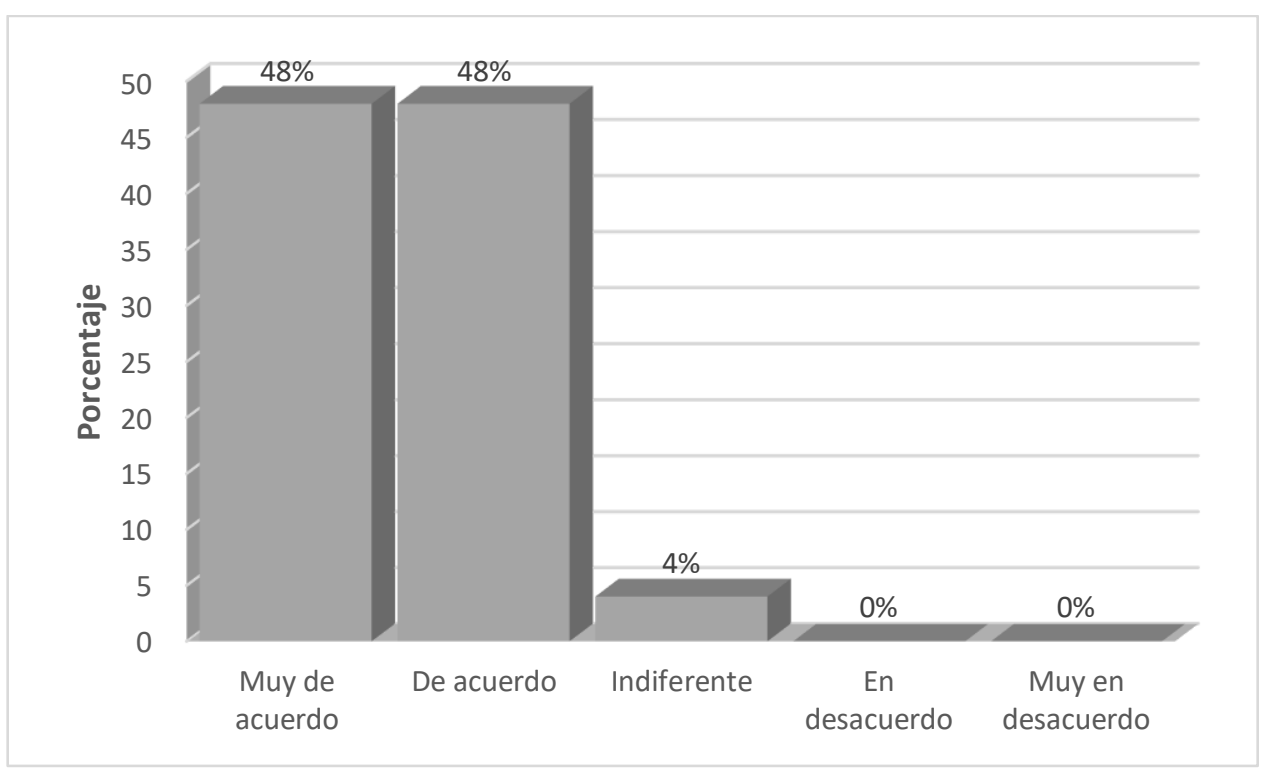

Figura 6. Pregunta 6

¿A su juicio, los eventos de feria del pisco peruano inciden en nuevos eventos al interior de los Estados Unidos? Adaptado de encuesta, por fuente propia, 2020.

\section{Interpretación:}

En la figura 6, Respecto al impacto de los eventos de feria del pisco peruano se obtuvo un resultado favorable ya que el $48 \%$ de los encuestados mencionaron estar totalmente muy de 
acuerdo y de acuerdo, por el contrario, el $4 \%$ mostraron indiferencia. Por eso podemos decir que los eventos de feria influyen a generar nuevos eventos al interior de los Estados Unidos.

Pregunta 7: ¿Considera, que los eventos de feria del pisco peruano ayuda al comercio exterior, en particular al mercado de los Estados Unidos?

Tabla 15.

Pregunta 7

Frecuencia

Porcentaje válido

\begin{tabular}{llcc}
\hline Válido & Muy de acuerdo & 23 & 46.00 \\
& De acuerdo & 26 & 52.00 \\
Indiferente & 1 & 2.00 \\
En desacuerdo & 0 & 0.00 \\
Muy en desacuerdo & 0 & 0.00 \\
Total & 50 & 100.00 \\
\hline
\end{tabular}

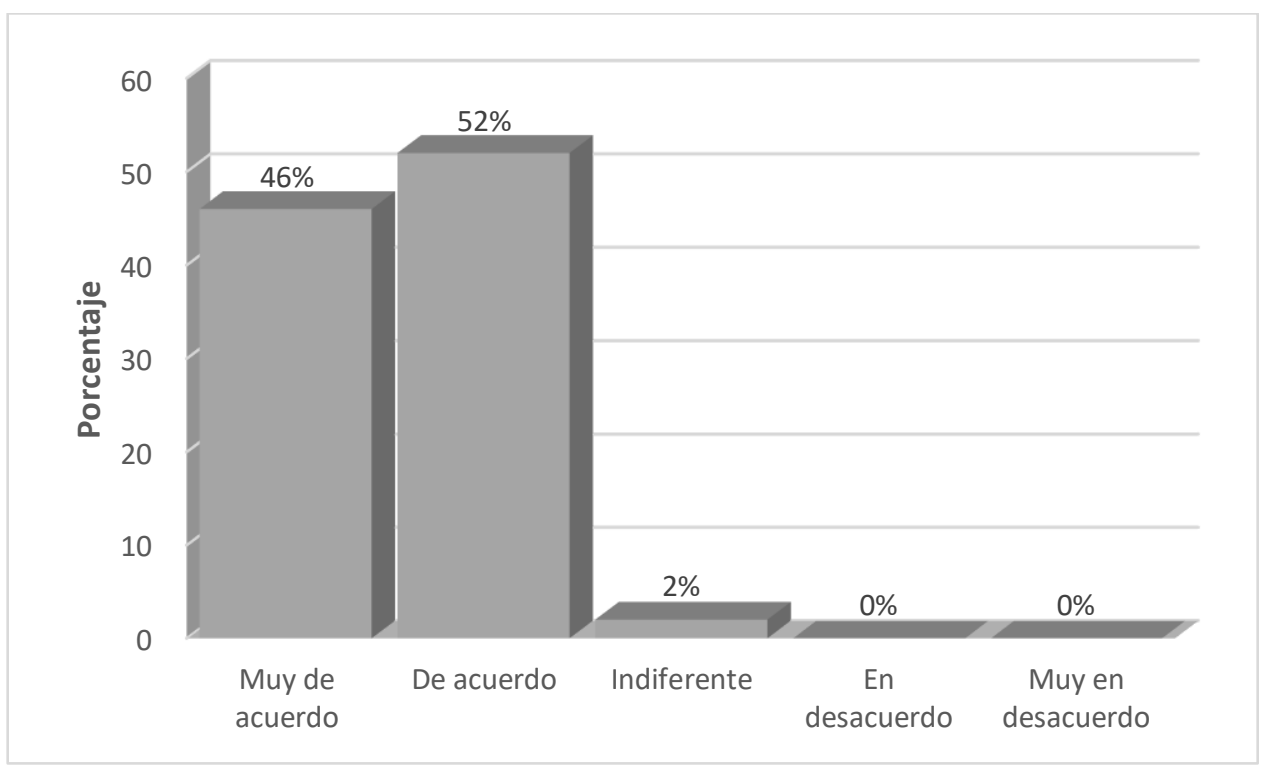

Figura 7. Pregunta 7

¿Considera, que los eventos de feria del pisco peruano ayuda al comercio exterior, en particular al mercado de los Estados Unidos? Adaptado de encuesta, por fuente propia, 2020 


\section{Interpretación:}

En la figura 7, tal como se observa referente a los eventos de feria y el comercio exterior, el $46 \%$ indicaron estar muy de acuerdo, el $2 \%$ mostraron una postura indiferente. Estos resultados nos permiten resaltar que los eventos de feria del pisco peruano influyen en el comercio exterior particularmente en Estados Unidos de tal manera que es una gran ventaja para este producto.

Pregunta 8: ¿Asumen, que los eventos de feria del pisco peruano inciden en mayores mercados dentro de los Estados Unidos?

Tabla 16.

Pregunta 8

\begin{tabular}{llcc}
\hline & Frecuencia & Porcentaje válido \\
\hline Válido & Muy de acuerdo & 19 & 38.00 \\
& De acuerdo & 28 & 56.00 \\
& Indiferente & 3 & 6.00 \\
& En desacuerdo & 0 & 0.00 \\
& Muy en desacuerdo & 0 & 0.00 \\
& Total & 50 & 100.00 \\
\hline
\end{tabular}




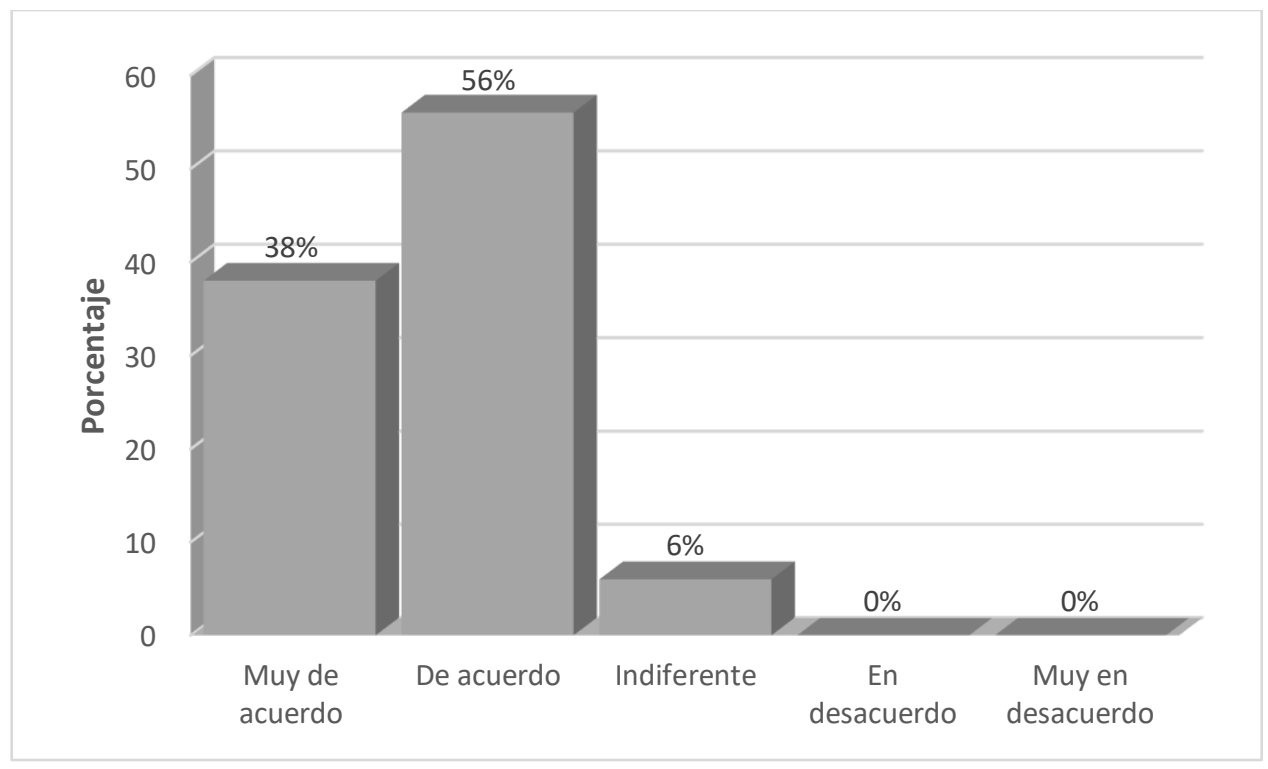

Figura 8. Pregunta 8

¿Asumen, que los eventos de feria del pisco peruano inciden en mayores mercados dentro de los Estados Unidos? Adaptado de encuesta, por fuente propia, 2020

\section{Interpretación:}

En la figura 8, con respecto a los eventos de feria del pisco peruano inciden en mayores mercados dentro de los Estados Unidos. El resultado de las encuestas evidencia que el 38\% están muy de acuerdo y el $56 \%$ de los encuestados se muestran de acuerdo, esto es un indicador de que efectivamente el pisco peruano tiene grandes ventajas en otros mercados dentro de los Estados Unidos. 
Pregunta 9: ¿A su juicio, los eventos de feria del pisco peruano ayuda al reconocimiento internacional de este producto en los Estados Unidos?

Tabla 17.

Pregunta 9

Frecuencia

Porcentaje válido

\begin{tabular}{llcc}
\hline Válido & Muy de acuerdo & 24 & 48.00 \\
De acuerdo & 24 & 48.00 \\
Indiferente & 2 & 4.00 \\
En desacuerdo & 0 & 0.00 \\
Muy en desacuerdo & 0 & 0.00 \\
Total & 50 & 100.00 \\
\hline
\end{tabular}

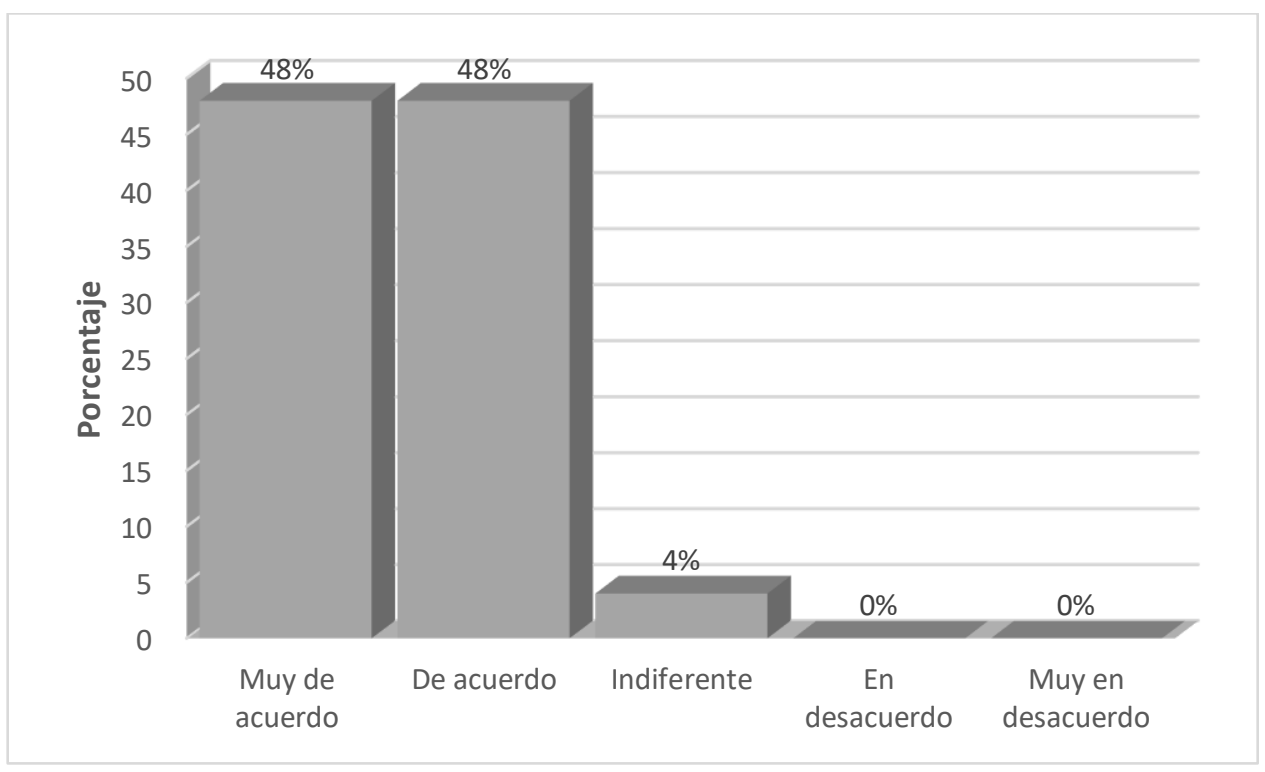

Figura 9. Pregunta 9

¿A su juicio, los eventos de feria del pisco peruano ayuda al reconocimiento internacional de este producto en los Estados Unidos? Adaptado de encuesta, por fuente propia, 2020 


\section{Interpretación:}

En la figura 9, como se aprecia el $2 \%$ se mostraron indiferentes, mientras que el $48 \%$ mencionaron estar muy de acuerdo y de acuerdo. Acorde a la opinión de los expertos podemos concluir que los eventos de feria ayudan al reconocimiento internacional de este producto en los Estados Unidos.

Pregunta 10: ¿Considera, que los eventos de feria del pisco peruano inciden en las exportaciones de este producto hacia los estados unidos?

Tabla 18.

Pregunta 10

\begin{tabular}{llcc}
\hline & & Frecuencia & Porcentaje válido \\
\hline Válido & Muy de acuerdo & 22 & 44.00 \\
& De acuerdo & 26 & 52.00 \\
& Indiferente & 2 & 4.00 \\
& En desacuerdo & 0 & 0.00 \\
Muy en desacuerdo & 0 & 0.00 \\
& Total & 50 & 100.00 \\
\hline
\end{tabular}




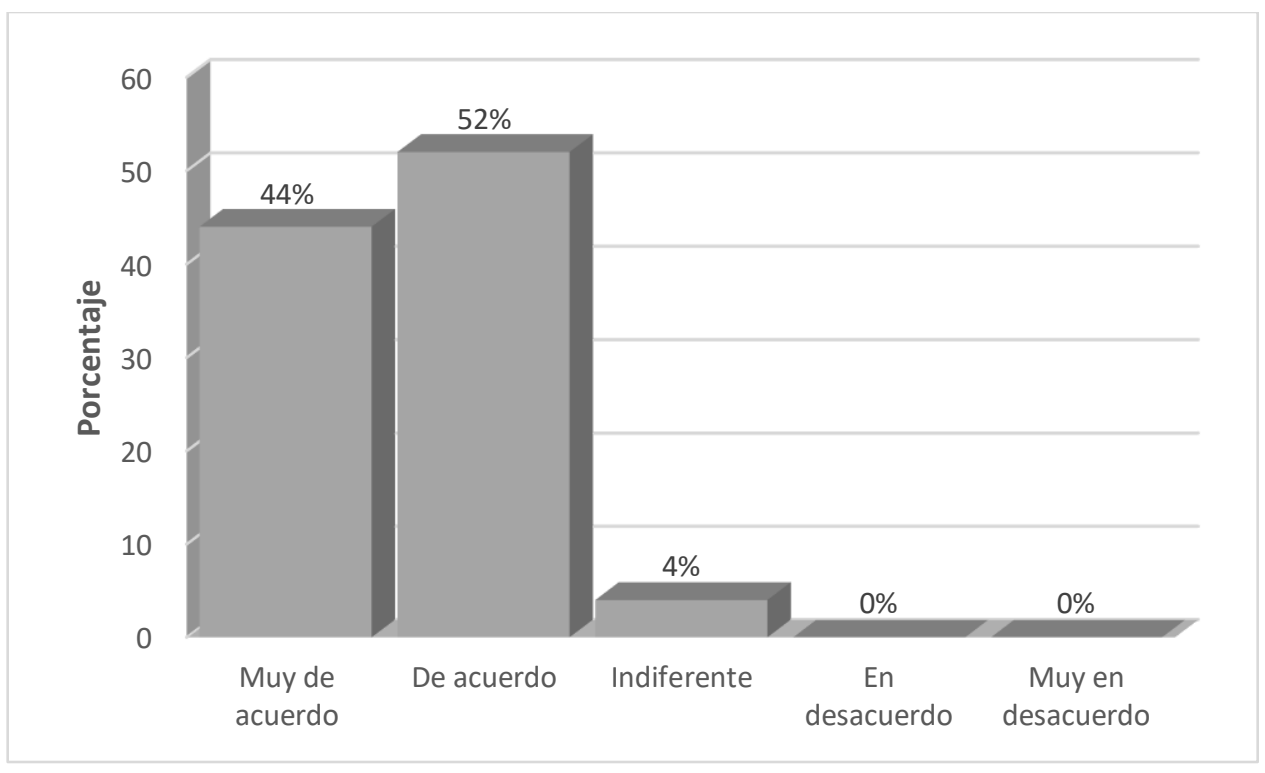

Figura 10. Pregunta 10

¿Considera, que los eventos de feria del pisco peruano inciden en las exportaciones de este producto hacia los estados unidos? Adaptado de encuesta, por fuente propia, 2020

\section{Interpretación:}

En la figura 10, el $44 \%$ de los encuestados indican estar muy de acuerdo, el $52 \%$ estar de acuerdo y por otro lado el $0.00 \%$ indican estar en desacuerdo y muy en desacuerdo. Finalmente, podemos indicar que gracias a las ferias este producto incide en las exportaciones hacia los EE.UU. 
Pregunta 11: ¿A su juicio, la Marca Perú genera incidencia en recomendaciones del pisco peruano en el mercado de los Estados Unidos?

Tabla 19.

Pregunta 11

Frecuencia

Porcentaje válido

\begin{tabular}{llcc}
\hline Válido & Muy de acuerdo & 30 & 60.00 \\
De acuerdo & 19 & 38.00 \\
Indiferente & 1 & 2.00 \\
En desacuerdo & 0 & 0.00 \\
Muy en desacuerdo & 0 & 0.00 \\
Total & 50 & 100.00
\end{tabular}

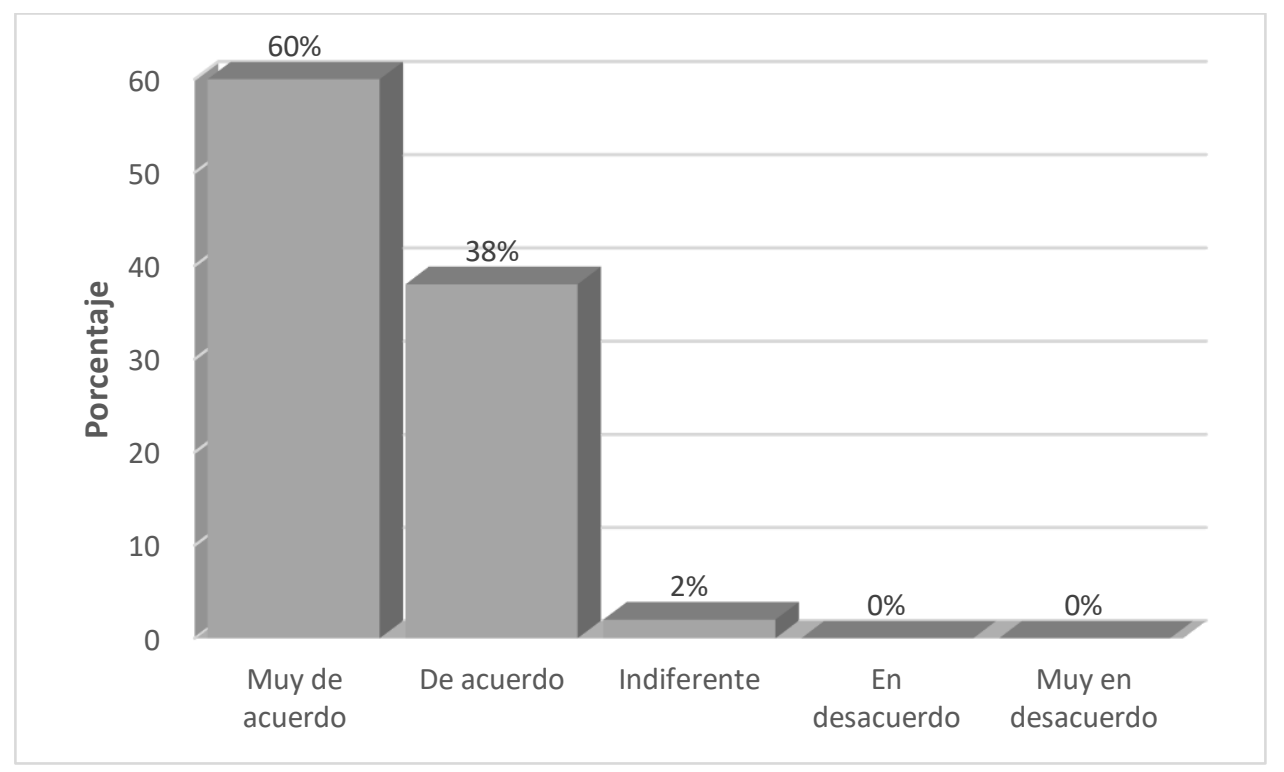

Figura 11. Pregunta 11

¿A su juicio, la Marca Perú genera incidencia en recomendaciones del pisco peruano en el mercado de los Estados Unidos? Adaptado de encuesta, por fuente propia, 2020 


\section{Interpretación:}

En la figura 11, se puede observar que la marca Perú genera incidencia en recomendaciones del pisco peruano. De los cuales el $60 \%$ indicaron estar muy de acuerdo, en cambio el $0.00 \%$ mencionaron estar en desacuerdo. De tal manera podemos finalizar que la marca Perú es parte de una influencia atractiva a favor de las exportaciones del pisco peruano hacia el mercado estadounidense.

Pregunta 12: ¿Asume que la marca Perú genera ayuda al comercio exterior del pisco peruano con los Estados Unidos?

Tabla 20.

Pregunta 12

\begin{tabular}{llcc}
\hline & Frecuencia & Porcentaje válido \\
\hline Válido & Muy de acuerdo & 23 & 46.00 \\
& De acuerdo & 25 & 50.00 \\
& Indiferente & 2 & 4.00 \\
En desacuerdo & 0 & 0.00 \\
Muy en desacuerdo & 0 & 0.00 \\
& Total & 50 & 100.00 \\
\hline
\end{tabular}




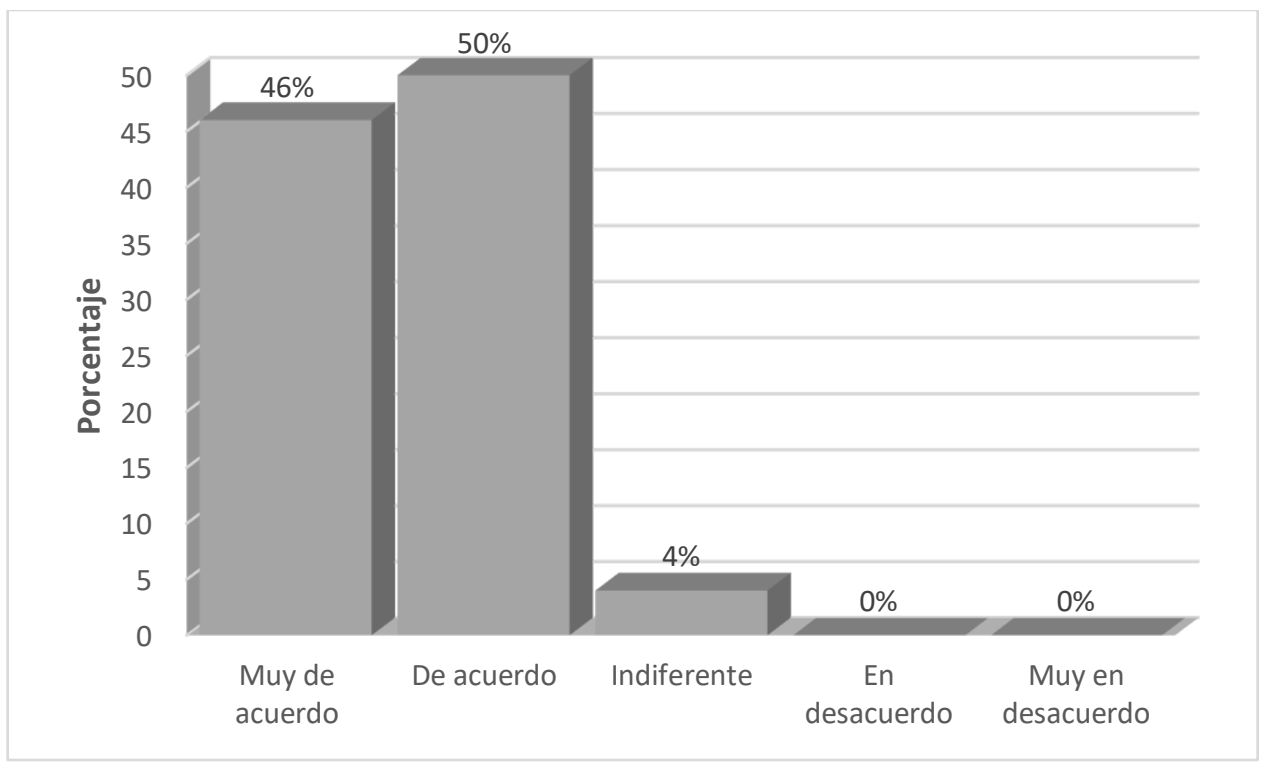

Figura 12. Pregunta 12

¿Asume que la marca Perú genera ayuda al comercio exterior del pisco peruano con los Estados Unidos? Adaptado de encuesta, por fuente propia, 2020

\section{Interpretación:}

En la figura 12, podemos observar que el $46 \%$ de lo los encuestados están muy de acuerdo y el 50\% están de acuerdo que la marca Perú genera ayuda al comercio exterior del pisco peruano con los Estados Unidos. Se concluye que la marca Perú tiene gran posicionamiento en el mercado exterior. 
Pregunta 13: ¿Considera que la mara Perú genera incidencia en mayores mercados del pisco peruano al interior de los Estados Unidos?

Tabla 21.

Pregunta 13

Frecuencia

\begin{tabular}{|c|c|c|c|}
\hline \multirow[t]{6}{*}{ Válido } & Muy de acuerdo & 29 & 58.00 \\
\hline & De acuerdo & 20 & 40.00 \\
\hline & Indiferente & 0 & 0.00 \\
\hline & En desacuerdo & 1 & 2.00 \\
\hline & Muy en desacuerdo & 0 & 0.00 \\
\hline & Total & 50 & 100.00 \\
\hline
\end{tabular}

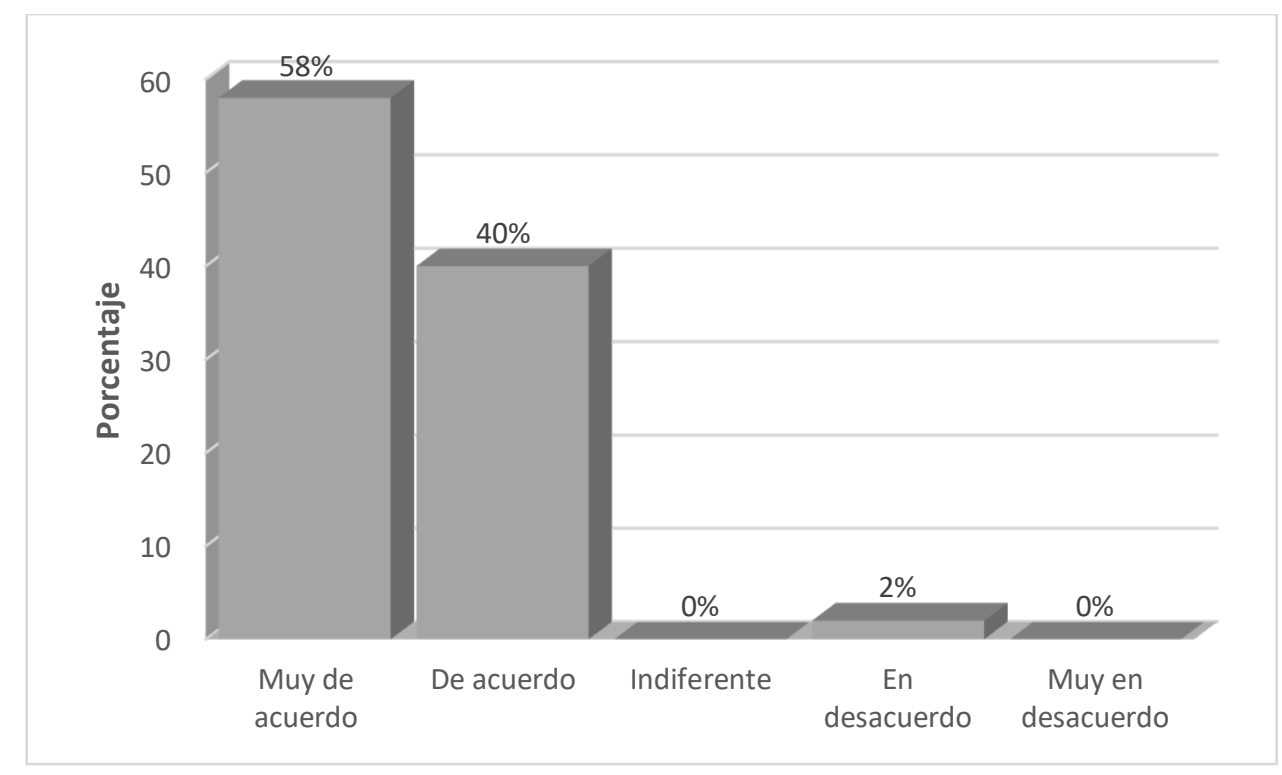

Figura 13. Pregunta 13

¿Considera que la mara Perú genera incidencia en mayores mercados del pisco peruano al interior de los Estados Unidos?_Adaptado de encuesta, por fuente propia, 2020 


\section{Interpretación:}

En la figura 13, los encuestados respondieron positivamente sobre la marca Perú ya que genera incidencia en mayores mercados del pisco peruano al interior de los Estados Unidos, como podemos observar el 58\% mencionaron estar muy de acuerdo, en cambio el $2 \%$ se mostraron estar en desacuerdo.

Pregunta 14: ¿A su juicio, la marca Perú genera ayuda al reconocimiento del pisco peruano en el mercado de los Estados Unidos?

Tabla 22.

Pregunta 14

\begin{tabular}{llcc}
\hline & & Frecuencia & Porcentaje válido \\
\hline Válido & Muy de acuerdo & 28 & 56.00 \\
& De acuerdo & 21 & 42.00 \\
& Indiferente & 0 & 0.00 \\
& En desacuerdo & 1 & 2.00 \\
& Muy en desacuerdo & 0 & 0.00 \\
& Total & 50 & 100.00 \\
\hline
\end{tabular}




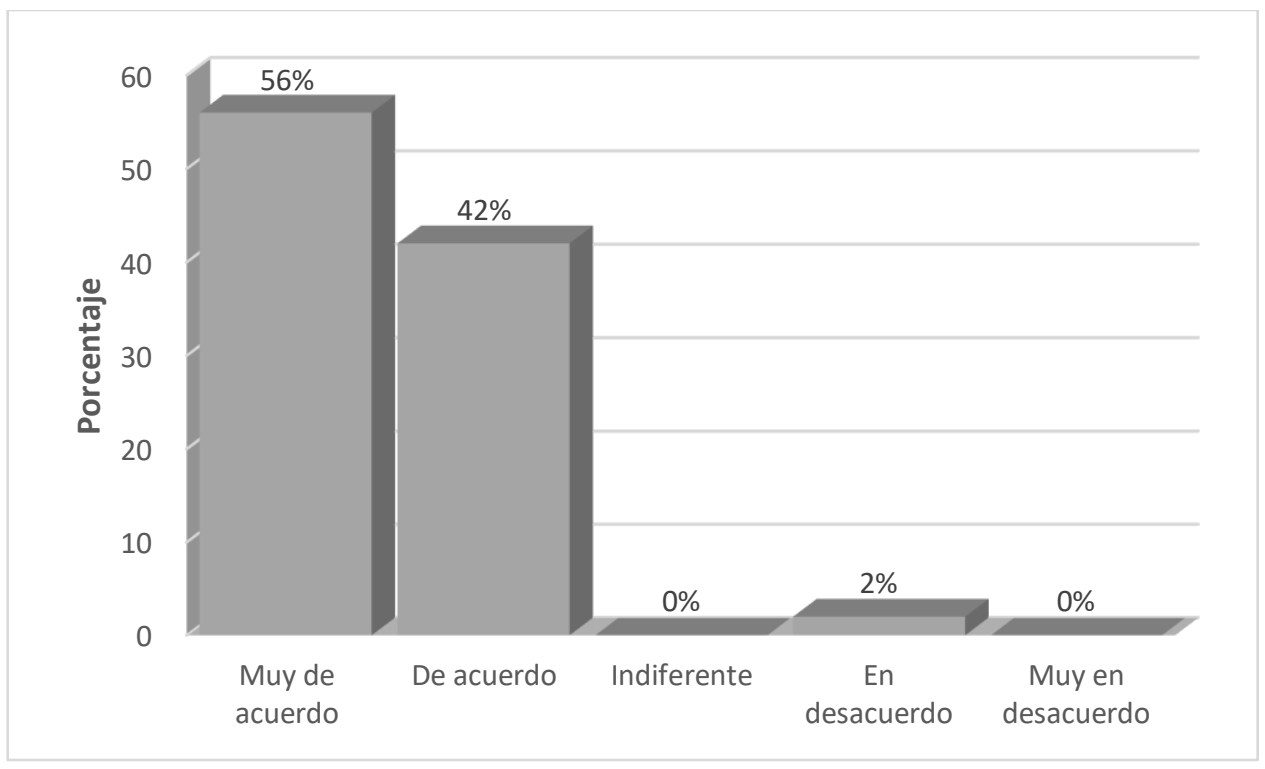

Figura 14. Pregunta 14

¿A su juicio, la marca Perú genera ayuda al reconocimiento del pisco peruano en el mercado de los Estados Unidos? Adaptado de encuesta, por fuente propia, 2020

\section{Interpretación:}

En la figura 14, se puede apreciar el juicio de las personas sobre la marca Perú en donde el 56\% del total de los encuestados indicaron estar muy de acuerdo y que solo el $2 \%$ se mostraron en desacuerdo, por ello, se puede concluir que la marca Perú genera ayuda al reconocimiento del pisco peruano en el mercado de los Estados Unidos. 
Pregunta 15: ¿Asume que la marca Perú genera incidencia en las exportaciones del pisco peruano hacia los Estados Unidos?

Tabla 23.

Pregunta 15

Frecuencia

$\begin{array}{llcc}\text { Válido } & \text { Muy de acuerdo } & 25 & 50.00 \\ \text { De acuerdo } & 24 & 48.00 \\ \text { Indiferente } & 0 & 0.00 \\ \text { En desacuerdo } & 1 & 2.00 \\ \text { Muy en desacuerdo } & 0 & 0.00 \\ \text { Total } & 50 & 100.00\end{array}$

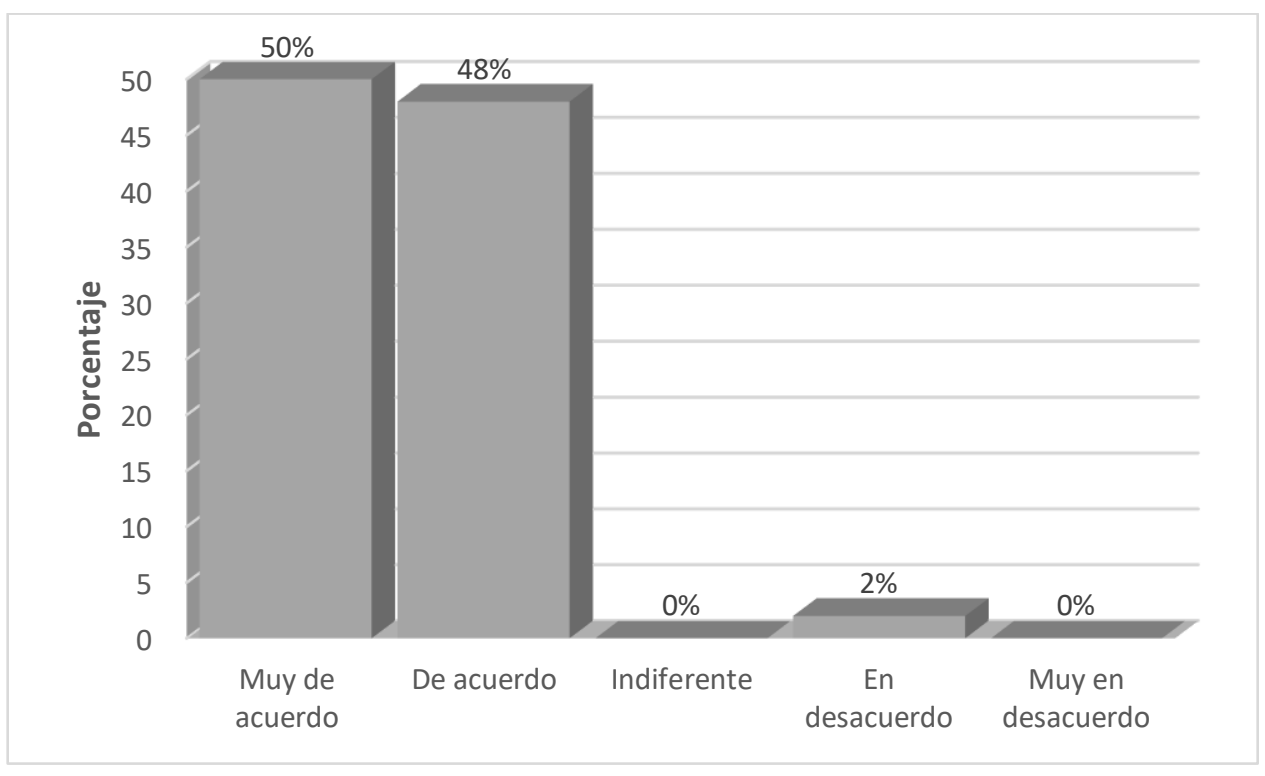

Figura 15. Pregunta 15

¿Asume que la marca Perú genera incidencia en las exportaciones del pisco peruano hacia los Estados Unidos? Adaptado de encuesta, por fuente propia, 2020 


\section{Interpretación:}

En la figura 15, como podemos observar el 50\% mencionaron estar muy de acuerdo, en cambio el $2 \%$ se mostraron estar en desacuerdo. A raíz de los resultados podemos finalizar que efectivamente la marca Perú tiene un gran impacto a favor de las exportaciones del pisco hacia los Estados Unidos.

Pregunta 16: ¿Considera que los términos de intercambio son positivos para el pisco peruano hacia los Estados Unidos?

Tabla 24.

Pregunta 16

\begin{tabular}{llcc}
\hline & Frecuencia & Porcentaje válido \\
\hline Válido & Muy de acuerdo & 20 & 40.00 \\
& De acuerdo & 29 & 58.00 \\
& Indiferente & 1 & 2.00 \\
En desacuerdo & 0 & 0.00 \\
Muy en desacuerdo & 0 & 0.00 \\
Total & 50 & 100.00 \\
\hline
\end{tabular}

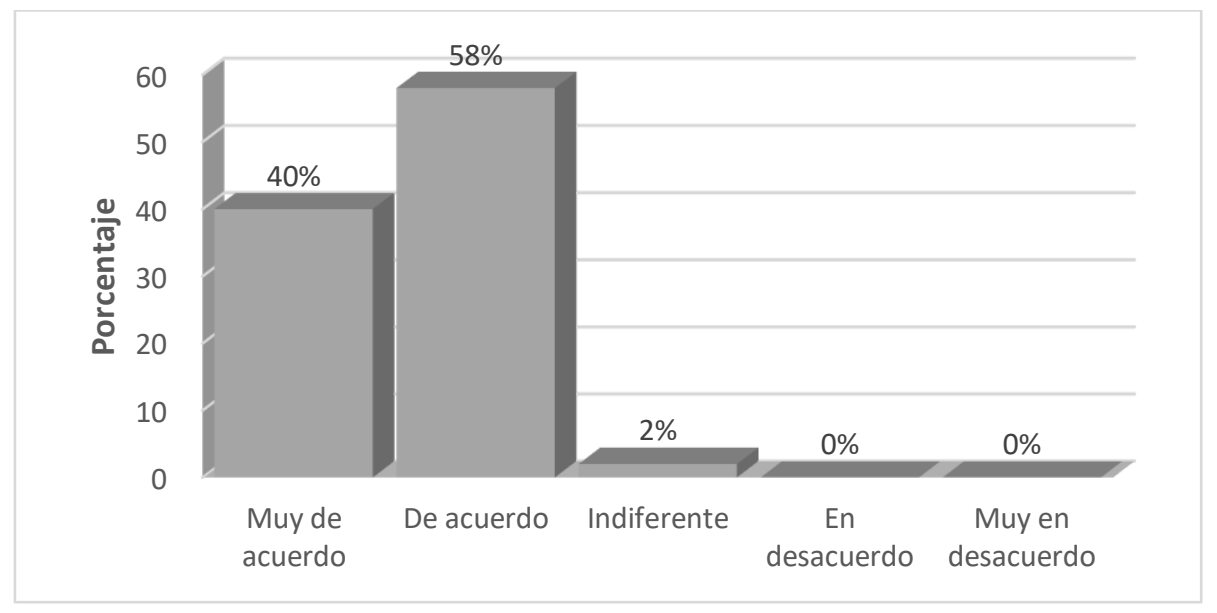

Figura 16. Pregunta 16

¿Considera que los términos de intercambio son positivos para el pisco peruano hacia los Estados Unidos? Adaptado de encuesta, por fuente propia, 2020 


\section{Interpretación:}

En la figura 16, podemos observar que los términos de intercambio son positivos para el pisco peruano hacia los Estados Unidos ya que el $40 \%$ de los encuestados respondieron estar muy de acuerdo y el $2 \%$ indiferente. Por lo tanto, se puede concluir que efectivamente esta metodología de intercambio es favorable para este producto.

Pegunta 17: ¿A su juicio, los términos de intercambio del pisco peruano son estratégicos hacia los Estados Unidos?

Tabla 25.

Pregunta 17

\begin{tabular}{llcc}
\hline & & Frecuencia & Porcentaje válido \\
\hline Válido & Muy de acuerdo & 24 & 48.00 \\
& De acuerdo & 25 & 50.00 \\
& Indiferente & 1 & 2.00 \\
En desacuerdo & 0 & 0.00 \\
Muy en desacuerdo & 0 & 0.00 \\
& Total & 50 & 100.00 \\
\hline
\end{tabular}




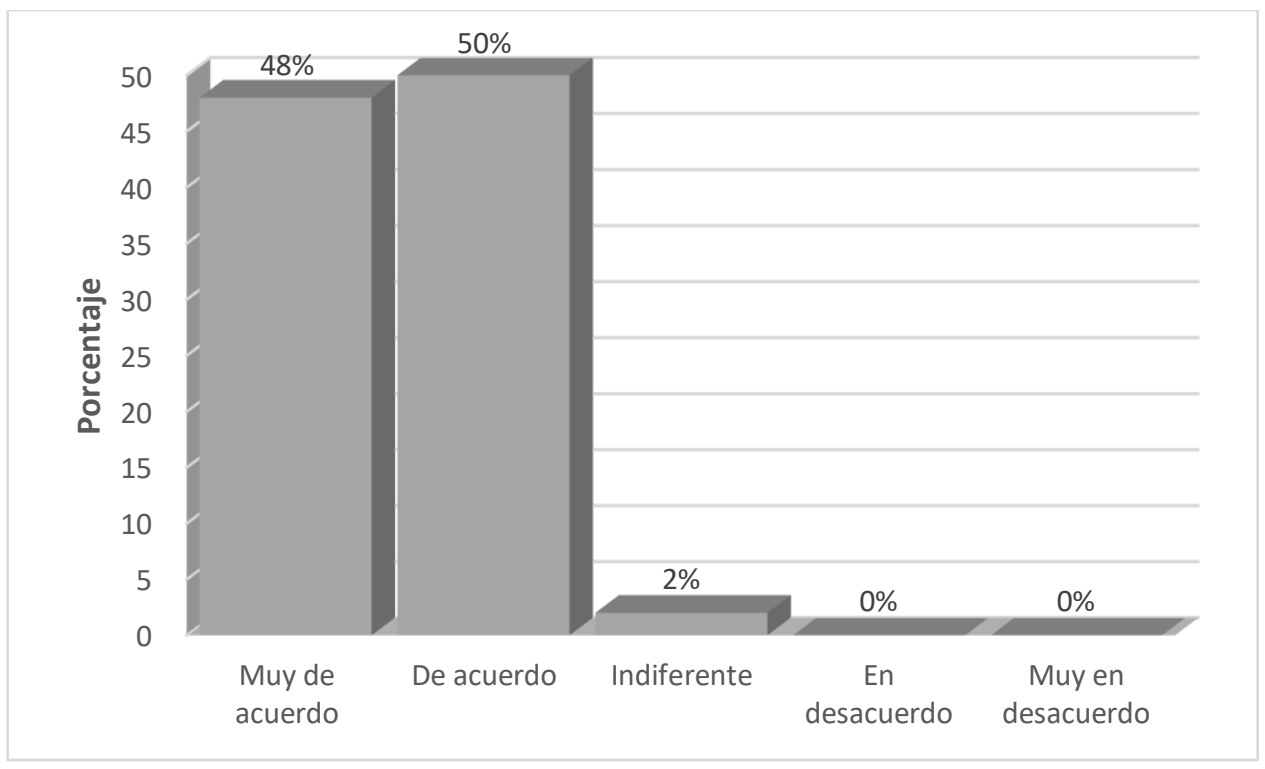

Figura 17. Pregunta 17

¿A su juicio, los términos de intercambio del pisco peruano son estratégicos hacia los Estados Unidos? Adaptado de encuesta, por fuente propia, 2020

\section{Interpretación:}

En la figura 17, se puede visualizar con respecto a los términos de intercambio del pisco peruano, los siguientes resultados donde observamos que el $48 \%$ de las personas encuestadas se inclinaron a estar muy de acuerdo en que esta situación es estratégica en el mercado de los Estados Unidos, pero el 2\% mencionaron estar indiferente con la pregunta. 
Pregunta 18: ¿Asume que los términos de intercambio del pisco peruano tenderán a crecer en el mercado de los Estados Unidos?

Tabla 26.

Pregunta 18

Frecuencia

\begin{tabular}{|c|c|c|c|}
\hline \multirow[t]{6}{*}{ Válido } & Muy de acuerdo & 28 & 56.00 \\
\hline & De acuerdo & 20 & 40.00 \\
\hline & Indiferente & 1 & 2.00 \\
\hline & En desacuerdo & 1 & 2.00 \\
\hline & Muy en desacuerdo & 0 & 0.00 \\
\hline & Total & 50 & 100.00 \\
\hline
\end{tabular}

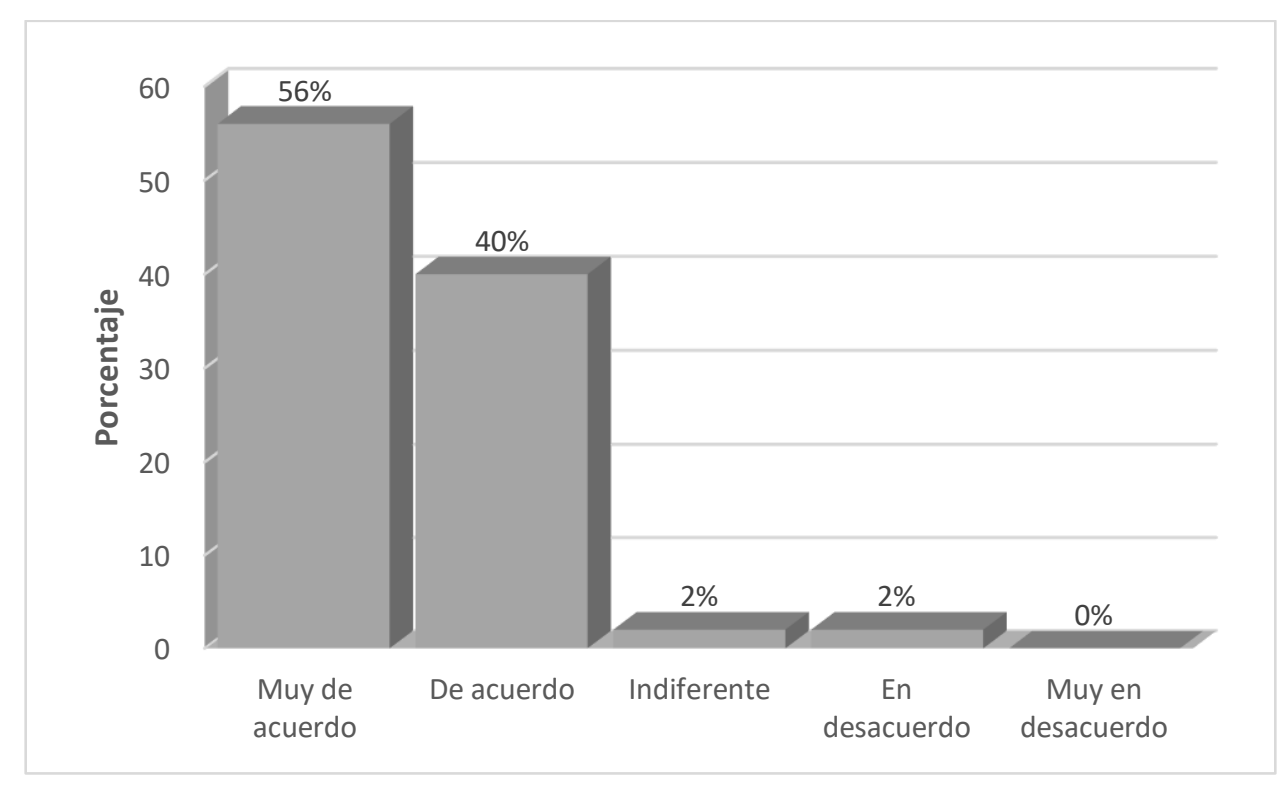

Figura 18. Pregunta 18

¿Asume que los términos de intercambio del pisco peruano tenderán a crecer en el mercado de los Estados Unidos? Adaptado de encuesta, por fuente propia, 2020 


\section{Interpretación:}

En la figura 18, se aprecia que los términos de intercambio del pisco peruano tenderán a crecer en el mercado de los Estados Unidos ya que los porcentajes que podemos observar son muy favorables. El 56\% de los encuestados indicaron estar muy de acuerdo y el $40 \%$ mostraron estar de acuerdo ante la pregunta; solo el $2 \%$ señalaron estar en desacuerdo.

Pregunta 19: ¿Considera que los términos de intercambio del pisco peruano contribuyen con la balanza comercial de forma positiva con los Estados Unidos?

Tabla 27.

Pregunta 19

Frecuencia

Válido

Muy de acuerdo

De acuerdo

Indiferente

En desacuerdo

Muy en desacuerdo

Total

29

19

1

0

1

50
Porcentaje válido

58.00

38.00

2.00

0.00

2.00

100.00 


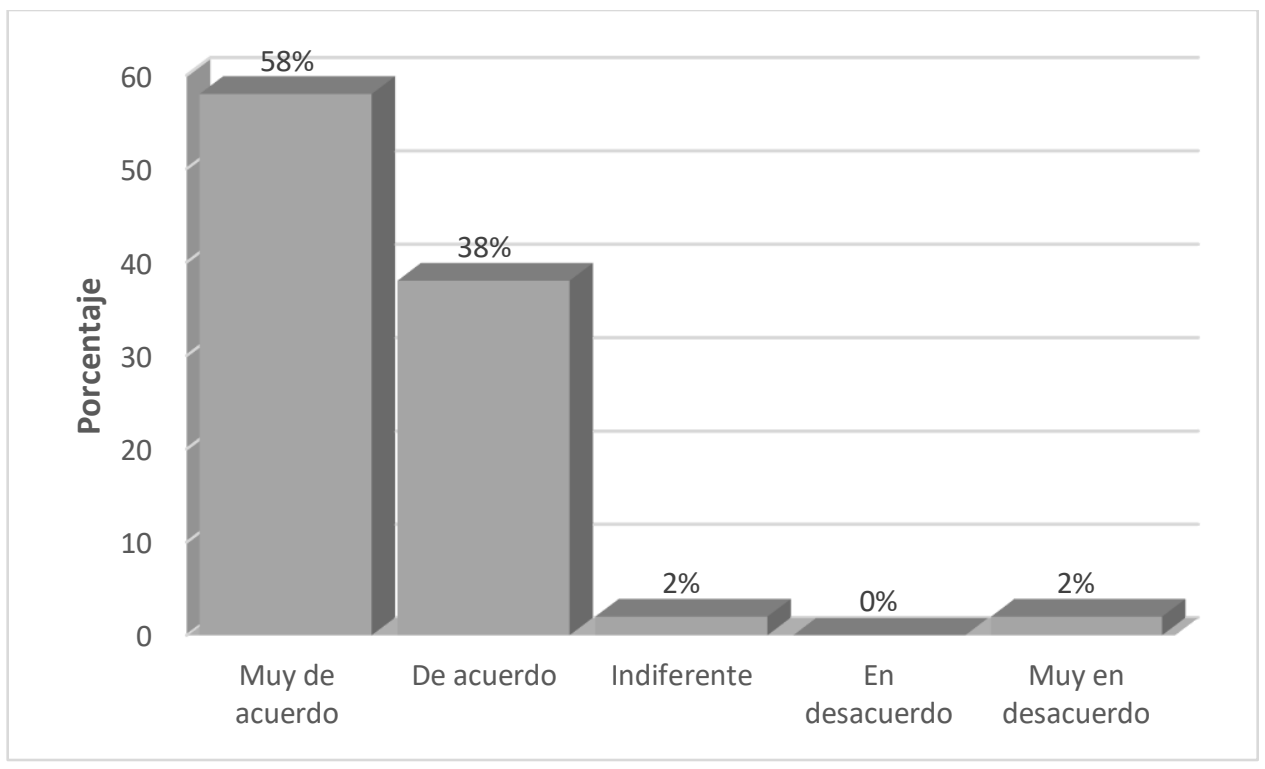

Figura 19. Pregunta 19

¿Considera que los términos de intercambio del pisco peruano contribuyen con la balanza comercial de forma positiva con los Estados Unidos? Adaptado de encuesta, por fuente propia, 2020

\section{Interpretación:}

En la figura 19, en relación así los términos de intercambio del pisco peruano contribuyen con la balanza comercial de forma positiva con los Estados Unidos, el 58\% de los encuestados están muy de acuerdo, el $38 \%$ están de acuerdo, en cambio el $2 \%$ le ha parecido indiferente y muy en desacuerdo. 
Pregunta 20: ¿A su juicio, los términos de intercambio mantendrán al pisco peruano como producto bandera?

Tabla 28.

Pregunta 20

Frecuencia Muy de acuerdo

De acuerdo

Indiferente

En desacuerdo

Muy en desacuerdo

Total

31

18

0

1

0

50

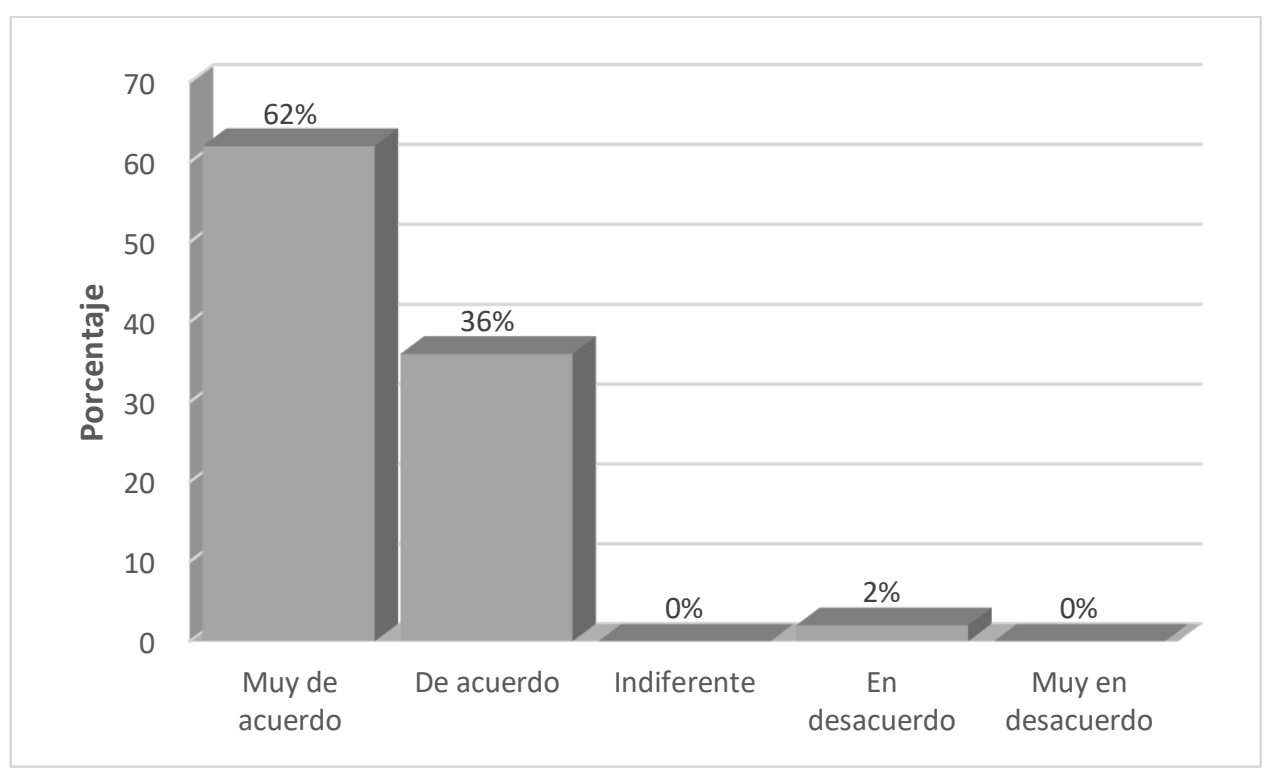

Porcentaje válido

62.00

36.00

0.00

2.00

0.00

100.00

Figura 20. Pregunta 20

¿A su juicio, los términos de intercambio mantendrán al pisco peruano como producto bandera? Adaptado de encuesta, por fuente propia, 2020 


\section{Interpretación:}

En la figura 20, se puede apreciar un resultado positivo que fue obtenido en base al juicio de los encuestados sobre si los términos de intercambio mantendrán al pisco peruano como producto bandera. El $62 \%$ están muy de acuerdo, pero el $2 \%$ se mostraron estar en desacuerdo. Dado estos resultados se puede concluir que, con estos términos de intercambio el pisco se mantendrá como producto bandera.

\subsubsection{Prueba de normalidad.}

El primer paso a realizar para poder saber qué tipo de prueba estadística utilizar es aplicar una prueba de normalidad. En este caso se hace para cada variable cuantitativa de manera independiente, ya que no presente dimensiones por grupos.

\section{Para la variable Factores de Promoción.}

i) Planteamiento de las Hipótesis.

$\mathrm{H}_{0}$ : La variable Factores de Promoción tiene una distribución Normal.

$\mathrm{H}_{1}$ : La variable Factores de Promoción no tiene una distribución Normal.

ii) Nivel de Significancia.

El nivel de significancia para la hipótesis es de $\alpha=0.05$

iii) Prueba estadística a emplear.

Emplearemos la prueba de Shapiro-Wilk: 
Tabla 29.

Prueba d normalidad - variable factores de promoción

Pruebas de normalidad

\begin{tabular}{|c|r|r|r|r|r|c|}
\hline & \multicolumn{3}{|c|}{ Kolmogorov-Smirnov $^{\text {a }}$} & \multicolumn{3}{c|}{ Shapiro-Wilk } \\
\cline { 2 - 7 } & Estadístico & gl & \multicolumn{1}{c|}{ Sig. } & Estadístico & gl & Sig. \\
\hline Factores de Promoción &, 253 & 50 &, 000 &, 701 & 50 &, 000 \\
\hline
\end{tabular}

a. Corrección de la significación de Lilliefors

Nota: La tabla 29 muestra la prueba de normalidad y el factor de promoción obtenidos del SPSS. Por fuente propia, 2020

\section{iv) Decisión.}

Con la prueba de Shapiro-Wilk, la cual se utiliza en muestras de hasta 50 datos, se puede decir que con un $95 \%$ de nivel de confianza se acepta la hipótesis alterna y, por lo tanto, los datos de la variable Factores de Promoción no tienen una distribución normal.

\section{Para la variable Exportaciones del Pisco.}

i) Planteamiento de las Hipótesis.

$\mathrm{H}_{0}$ : La variable Exportaciones del Pisco tiene una distribución Normal.

$\mathrm{H}_{1}$ : La variable Exportaciones del Pisco no tiene una distribución Normal.

ii) Nivel de Significancia.

El nivel de significancia para la hipótesis es de $\alpha=0.05$

iii) Prueba estadística a emplear.

Emplearemos la prueba de Shapiro-Wilk: 
Tabla 30.

Prueba de normalidad - exportación del pisco

Pruebas de normalidad

\begin{tabular}{|l|r|r|r|r|r|r|}
\hline & \multicolumn{3}{|c|}{ Kolmogorov-Smirnov $^{\text {a }}$} & \multicolumn{3}{c|}{ Shapiro-Wilk } \\
\cline { 2 - 7 } & Estadístico & \multicolumn{1}{c|}{$\mathrm{gl}$} & Sig. & Estadístico & \multicolumn{1}{c|}{$\mathrm{gl}$} & Sig. \\
\hline Exportaciones del Pisco &, 247 & 50 &, 000 &, 754 & 50 &, 000 \\
\hline
\end{tabular}

a. Corrección de la significación de Lilliefors

Nota: La tabla 30 muestra la prueba de normalidad y la exportación del pisco obtenidos del SPSS. Por fuente propia, 2020

\section{iv) Decisión.}

Con la prueba de Shapiro-Wilk, la cual se utiliza en muestras de hasta 50 datos, se puede decir que con un $95 \%$ de nivel de confianza se acepta la hipótesis alterna y, por lo tanto, los datos de la variable Factores de Promoción no tienen una distribución normal.

\section{Para la variable Denominación de origen.}

i) Planteamiento de las Hipótesis.

$\mathrm{H}_{0}$ : La variable Denominación de origen tiene una distribución Normal.

$\mathrm{H}_{1}$ : La variable Denominación de origen no tiene una distribución Normal.

ii) Nivel de Significancia.

El nivel de significancia para la hipótesis es de $\alpha=0.05$

iii) Prueba estadística a emplear.

Emplearemos la prueba de Shapiro-Wilk: 
Tabla 31.

Prueba de normalidad - denominación de origen

Pruebas de normalidad

\begin{tabular}{|l|r|r|r|r|r|r|}
\hline \multirow{2}{*}{} & \multicolumn{3}{|c|}{ Kolmogorov-Smirnov $^{\mathrm{a}}$} & \multicolumn{3}{c|}{ Shapiro-Wilk } \\
\cline { 2 - 7 } & Estadístico & $\mathrm{gl}$ & Sig. & Estadístico & $\mathrm{gl}$ & Sig. \\
\hline Denominación de origen &, 218 & 50 &, 000 &, 780 & 50 &, 000 \\
\hline
\end{tabular}

a. Corrección de la significación de Lilliefors

Nota: La tabla 31 muestra la prueba de normalidad y la denominación de origen obtenidos del SPSS. Por fuente propia, 2020

\section{iv) Decisión.}

Con la prueba de Shapiro-Wilk, la cual se utiliza en muestras de hasta 50 datos, se puede decir que con un $95 \%$ de nivel de confianza se acepta la hipótesis alterna y, por lo tanto, los datos de la variable Denominación de origen no tienen una distribución normal.

\section{Para la variable Eventos de feria.}

i) Planteamiento de las Hipótesis.

$\mathrm{H}_{0}$ : La variable Eventos de feria tiene una distribución Normal.

$\mathrm{H}_{1}$ : La variable Eventos de feria no tiene una distribución Normal.

ii) Nivel de Significancia.

El nivel de significancia para la hipótesis es de $\alpha=0.05$

iii) Prueba estadística a emplear.

Emplearemos la prueba de Shapiro-Wilk: 
Tabla 32.

Pruebas de normalidad - eventos de feria

\section{Pruebas de normalidad}

\begin{tabular}{|l|r|r|r|r|r|r|}
\hline \multirow{2}{*}{} & \multicolumn{4}{|c|}{ Kolmogorov-Smirnov $^{\text {a }}$} & \multicolumn{3}{c|}{ Shapiro-Wilk } \\
\cline { 2 - 7 } & Estadístico & gl & Sig. & Estadístico & \multicolumn{1}{c|}{ gl } & Sig. \\
\hline Eventos de feria &, 191 & 50 &, 000 &, 884 & 50 &, 000 \\
\hline
\end{tabular}

a. Corrección de la significación de Lilliefors

Nota: La tabla 32 muestra la prueba de normalidad y los eventos de feria obtenidos del SPSS. Por fuente propia, 2020

\section{iv) Decisión.}

Con la prueba de Shapiro-Wilk, la cual se utiliza en muestras de hasta 50 datos, se puede decir que con un $95 \%$ de nivel de confianza se acepta la hipótesis alterna y, por lo tanto, los datos de la variable Eventos de feria no tienen una distribución normal.

\section{Para la variable Marca Perú.}

i) Planteamiento de las Hipótesis.

$\mathrm{H}_{0}$ : La variable Marca Perú tiene una distribución Normal.

$\mathrm{H}_{1}$ : La variable Marca Perú no tiene una distribución Normal.

ii) Nivel de Significancia.

El nivel de significancia para la hipótesis es de $\alpha=0.05$

iii) Prueba estadística a emplear.

Emplearemos la prueba de Shapiro-Wilk: 
Tabla 33.

Prueba de normalidad - marca Perú

Pruebas de normalidad

\begin{tabular}{|c|r|r|r|r|r|c|}
\hline & \multicolumn{3}{|c|}{ Kolmogorov-Smirnov $^{\text {a }}$} & \multicolumn{3}{c|}{ Shapiro-Wilk } \\
\cline { 2 - 7 } & Estadístico & gl & Sig. & Estadístico & gl & Sig. \\
\hline Marca Perú &, 199 & 50 &, 000 &, 741 & 50 &, 000 \\
\hline
\end{tabular}

a. Corrección de la significación de Lilliefors

Nota: La tabla 33 muestra la prueba de normalidad y la marca Perú obtenidos del SPSS. Por fuente propia, 2020

iv) Decisión.

Con la prueba de Shapiro-Wilk, la cual se utiliza en muestras de hasta 50 datos, se puede decir que con un $95 \%$ de nivel de confianza se acepta la hipótesis alterna y, por lo tanto, los datos de la variable Marca Perú no tienen una distribución normal.

Para la variable Términos de intercambio.

i) Planteamiento de las Hipótesis.

$\mathrm{H}_{0}$ : La variable Términos de intercambio tiene una distribución Normal.

$\mathrm{H}_{1}$ : La variable Términos de intercambio no tiene una distribución Normal.

ii) Nivel de Significancia.

El nivel de significancia para la hipótesis es de $\alpha=0.05$

iii) Prueba estadística a emplear.

Emplearemos la prueba de Shapiro-Wilk: 
Tabla 34.

Prueba de normalidad - términos de intercambio

Pruebas de normalidad

\begin{tabular}{|c|c|c|c|c|c|c|}
\hline & \multicolumn{3}{|c|}{ Kolmogorov-Smirnov ${ }^{a}$} & \multicolumn{3}{|c|}{ Shapiro-Wilk } \\
\hline & Estadístico & $\mathrm{gl}$ & Sig. & Estadístico & $\mathrm{gl}$ & Sig. \\
\hline Términos de intercambio & 247 & 50 &, 000 & 754 & 50 &, 000 \\
\hline
\end{tabular}

a. Corrección de la significación de Lilliefors

Nota: La tabla 34 muestra la prueba de normalidad y los términos de intercambio obtenidos del SPSS. Por fuente propia, 2020

\section{iv) Decisión.}

Con la prueba de Shapiro-Wilk, la cual se utiliza en muestras de hasta 50 datos, se puede decir que con un $95 \%$ de nivel de confianza se acepta la hipótesis alterna y, por lo tanto, los datos de la variable Términos de intercambio no tienen una distribución normal.

\subsubsection{Prueba de correlación.}

En esta investigación se aplicará el coeficiente de correlación de Spearman para verificar la validez de las hipótesis planteadas.

\section{Para la hipótesis específica 1.}

\section{Hipótesis.}

$\mathrm{H}_{0}$ : La promoción de la denominación de origen no tiene incidencia positiva con la evolución de las exportaciones de pisco.

$\mathrm{H}_{1}$ : La promoción de la denominación de origen tiene incidencia positiva con la evolución de las exportaciones de pisco.

Nivel de significancia.

El nivel de significancia para la hipótesis es de $\alpha=0.05$

Estadístico de prueba.

Para esta prueba se evalúa el Rho de Spearman 
Tabla 35.

Prueba de correlación - Hipótesis especifica 1

\begin{tabular}{|c|c|c|c|c|}
\hline \multicolumn{5}{|c|}{ Correlaciones } \\
\hline & & & $\begin{array}{c}\text { Denominació } \\
\mathrm{n} \text { de origen }\end{array}$ & $\begin{array}{c}\text { Términos de } \\
\text { intercambio }\end{array}$ \\
\hline \multirow[t]{6}{*}{ Rho de Spearman } & \multirow[t]{3}{*}{ Denominación de origen } & $\begin{array}{l}\text { Coeficiente de } \\
\text { correlación }\end{array}$ & 1,000 & $.481^{\prime}$ \\
\hline & & Sig. (bilateral) & . &, 000 \\
\hline & & $N$ & 50 & 50 \\
\hline & \multirow[t]{3}{*}{ Términos de intercambio } & $\begin{array}{l}\text { Coeficiente de } \\
\text { correlación }\end{array}$ & $.481^{m}$ & 1,000 \\
\hline & & Sig. (bilateral) &, 000 & . \\
\hline & & $N$ & 50 & 50 \\
\hline
\end{tabular}

**. La correlación es significativa al nivel 0,01 (bilateral).

Nota: La tabla 35 muestra la prueba de correlación en la hipótesis especifica 1. obtenido del SPSS. Por fuente propia, 2020

\section{Decisión.}

Una vez realizada la prueba de correlación de Spearman para estadísticas no-paramétricas, se revisa el "r" estimador de correlación y se verifica su nivel de significancia.

En este caso, se presenta una correlación positiva entre la Denominación de origen y los Términos de intercambio. Además, se concluye que con un nivel de significancia de 0.01 hay evidencia estadística para el Rho de Spearman que la correlación entre la Denominación de origen y los Términos de intercambio es significativa y, por lo tanto, la hipótesis alterna se acepta.

\section{Para la hipótesis específica 2.}

\section{Hipótesis.}

$\mathrm{H}_{0}$ : La promoción de eventos de ferias no tiene incidencia positiva con la evolución de las exportaciones de pisco.

$\mathrm{H}_{1}$ : La promoción de eventos de ferias tiene incidencia positiva con la evolución de las exportaciones de pisco. 


\section{Nivel de significancia.}

El nivel de significancia para la hipótesis es de $\alpha=0.05$

\section{Estadístico de prueba.}

Para esta prueba se evalúa el Rho de Spearman

Tabla 36.

Prueba de correlación - hipótesis especifica 2

Correlaciones

\begin{tabular}{|c|c|c|c|c|}
\hline & & & $\begin{array}{c}\text { Eventos de } \\
\text { feria }\end{array}$ & $\begin{array}{l}\text { Términos de } \\
\text { intercambio }\end{array}$ \\
\hline \multirow[t]{6}{*}{ Rho de Spearman } & \multirow[t]{3}{*}{ Eventos de feria } & $\begin{array}{l}\text { Coeficiente de } \\
\text { correlación }\end{array}$ & 1,000 & 356 \\
\hline & & Sig. (bilateral) & &, 011 \\
\hline & & N & 50 & 50 \\
\hline & \multirow[t]{3}{*}{ Términos de intercambio } & $\begin{array}{l}\text { Coeficiente de } \\
\text { correlación }\end{array}$ & $356^{x}$ & 1,000 \\
\hline & & Sig. (bilateral) & ,011 & \\
\hline & & N & 50 & 50 \\
\hline
\end{tabular}

*. La correlación es significativa al nivel 0,05 (bilateral).

Nota: La tabla 36 muestra la prueba de correlación en la hipótesis especifica 2. obtenido del SPSS. Por fuente propia, 2020

\section{Decisión.}

Una vez realizada la prueba de correlación de Spearman para estadísticas no-paramétricas, se revisa el "r" estimador de correlación y se verifica su nivel de significancia.

En este caso, se presenta una correlación positiva entre los Eventos de feria y los Términos de intercambio. Además, se concluye que con un nivel de significancia de 0.05 hay evidencia estadística para el Rho de Spearman que la correlación entre los Eventos de feria y los Términos de intercambio es significativa y, por lo tanto, la hipótesis alterna se acepta. 


\section{Para la hipótesis específica 3.}

\section{Hipótesis.}

$\mathrm{H}_{0}$ : La promoción la Marca Perú no tiene incidencia positiva con la evolución de las exportaciones de pisco.

$\mathrm{H}_{1}$ : La promoción la Marca Perú tiene incidencia positiva con la evolución de las exportaciones de pisco.

Nivel de significancia.

El nivel de significancia para la hipótesis es de $\alpha=0.05$

\section{Estadístico de prueba.}

Para esta prueba se evalúa el Rho de Spearman

Tabla 37.

Prueba de correlación - hipótesis especifica 3

Correlaciones

\begin{tabular}{|c|c|c|c|c|}
\hline & & & Marca Perú & $\begin{array}{l}\text { Términos de } \\
\text { intercambio }\end{array}$ \\
\hline \multirow[t]{6}{*}{ Rho de Spearman } & \multirow[t]{3}{*}{ Marca Perú } & $\begin{array}{l}\text { Coeficiente de } \\
\text { correlación }\end{array}$ & 1,000 &, $402^{m}$ \\
\hline & & Sig. (bilateral) & . &, 004 \\
\hline & & $N$ & 50 & 50 \\
\hline & \multirow[t]{3}{*}{ Términos de intercambio } & $\begin{array}{l}\text { Coeficiente de } \\
\text { correlación }\end{array}$ & $402^{n \pi}$ & 1,000 \\
\hline & & Sig. (bilateral) &, 004 & . \\
\hline & & $\mathrm{N}$ & 50 & 50 \\
\hline
\end{tabular}

**. La correlación es significativa al nivel 0,01 (bilateral).

Nota: La tabla 37 muestra la prueba de correlación en la hipótesis especifica 3 obtenido del SPSS. Por fuente propia, 2020 


\section{Decisión.}

Una vez realizada la prueba de correlación de Spearman para estadísticas no-paramétricas, se revisa el "r" estimador de correlación y se verifica su nivel de significancia.

En este caso, se presenta una correlación positiva entre la Marca Perú y los Términos de intercambio. Además, se concluye que con un nivel de significancia de 0.01 hay evidencia estadística para el Rho de Spearman que la correlación entre la Marca Perú y los Términos de intercambio es significativa y, por lo tanto, la hipótesis alterna se acepta.

\section{Para la hipótesis general.}

Hipótesis.

$\mathrm{H}_{0}$ : Los factores de promoción no inciden en la evolución de las exportaciones de pisco.

$\mathrm{H}_{1}$ : Los factores de promoción inciden en la evolución de las exportaciones de pisco.

Nivel de significancia.

El nivel de significancia para la hipótesis es de $\alpha=0.05$

Estadístico de prueba.

Para esta prueba se evalúa el Rho de Spearman 
Tabla 38.

Prueba de correlación - hipótesis general

Correlaciones

\begin{tabular}{|c|c|c|c|c|}
\hline & & & $\begin{array}{l}\text { Factores de } \\
\text { Promoción }\end{array}$ & $\begin{array}{c}\text { Exportaciones } \\
\text { del Pisco }\end{array}$ \\
\hline \multirow[t]{6}{*}{ Rho de Spearman } & \multirow[t]{3}{*}{ Factores de Promoción } & $\begin{array}{l}\text { Coeficiente de } \\
\text { correlación }\end{array}$ & 1,000 &, $445^{n}$ \\
\hline & & Sig. (bilateral) & $\cdot$ & 001 \\
\hline & & $N$ & 50 & 50 \\
\hline & \multirow[t]{3}{*}{ Exportaciones del Pisco } & $\begin{array}{l}\text { Coeficiente de } \\
\text { correlación }\end{array}$ & $445^{m-1}$ & 1,000 \\
\hline & & Sig. (bilateral) & 001 & . \\
\hline & & $N$ & 50 & 50 \\
\hline
\end{tabular}

**. La correlación es significativa al nivel 0,01 (bilateral).

Nota: La tabla 39 muestra la prueba de correlación en la hipótesis especifica general obtenido del SPSS. Por fuente propia, 2020

\section{Decisión.}

Una vez realizada la prueba de correlación de Spearman para estadísticas no-paramétricas, se revisa el "r" estimador de correlación y se verifica su nivel de significancia.

En este caso, se presenta una correlación positiva entre los Factores de promoción y las Exportaciones de Pisco. Además, se concluye que con un nivel de significancia de 0.01 hay evidencia estadística para el Rho de Spearman que la correlación entre los Factores de promoción y las Exportaciones de Pisco es significativa y, por lo tanto, la hipótesis alterna se acepta.

\section{Análisis}

Siendo la significancia bilateral inferior a 0.01 , se acepta la hipótesis de que los factores de promoción inciden en la evolución de las exportaciones de pisco. Además, siendo el coeficiente de correlación de Spearman 0.445, las variables se encuentran directamente relacionadas. 
En la Tabla 39, se puede apreciar la tabla de contingencia de la variable Factores de promoción y de la variable Exportaciones de Pisco, en términos absolutos y relativos. Finalmente, en la Figura 21 se puede observar el gráfico de barras con el resultado de la investigación.

Tabla 39.

Tabla de contingencia con los resultados de la investigación

Tabla de contingencia Factores de Promoción (agrupado) * Exportaciones del Pisco (agrupado)

\begin{tabular}{|c|c|c|c|c|c|c|c|}
\hline & & & \multicolumn{4}{|c|}{ Exportaciones del Pisco (agrupado) } & \multirow[b]{2}{*}{ Total } \\
\hline & & & Bajo & Regular & Bueno & Excelente & \\
\hline \multirow{8}{*}{$\begin{array}{l}\text { Factores de Promoción } \\
\text { (agrupado) }\end{array}$} & Bajo & Recuento & 4 & 0 & 0 & 0 & 4 \\
\hline & & $\%$ del total & $8,0 \%$ & $0,0 \%$ & $0,0 \%$ & $0,0 \%$ & $8,0 \%$ \\
\hline & Regular & Recuento & 0 & 10 & 6 & 3 & 19 \\
\hline & & $\%$ del total & $0,0 \%$ & $20,0 \%$ & $12,0 \%$ & $6,0 \%$ & $38,0 \%$ \\
\hline & Bueno & Recuento & 4 & 3 & 15 & 2 & 24 \\
\hline & & $\%$ del total & $8,0 \%$ & $6,0 \%$ & $30,0 \%$ & $4,0 \%$ & $48,0 \%$ \\
\hline & Excelente & Recuento & 0 & 0 & 0 & 3 & 3 \\
\hline & & $\%$ del total & $0,0 \%$ & $0,0 \%$ & $0,0 \%$ & $6,0 \%$ & $6,0 \%$ \\
\hline \multirow[t]{2}{*}{ Total } & & Recuento & 8 & 13 & 21 & 8 & 50 \\
\hline & & $\%$ del total & $16,0 \%$ & $26,0 \%$ & $42,0 \%$ & $16,0 \%$ & $100,0 \%$ \\
\hline
\end{tabular}

Nota: La tabla 41 muestra las exportaciones del Pisco con sus respectivas variables obtenido del SPSS. Por fuente propia, 2020

\subsection{Discusión}

En la presente tesis se investigó los factores de promoción que inciden en la evolución de las exportaciones de pisco hacia los Estados Unidos y, en función con la metodología de recolección de datos planteada, expresada en entrevistas y encuestas realizadas, estamos en la posición de afirmar que los resultados obtenidos confirmaron nuestra hipótesis general y nuestras hipótesis específicas, así como los objetivos de la presente tesis se pudieron alcanzar. 


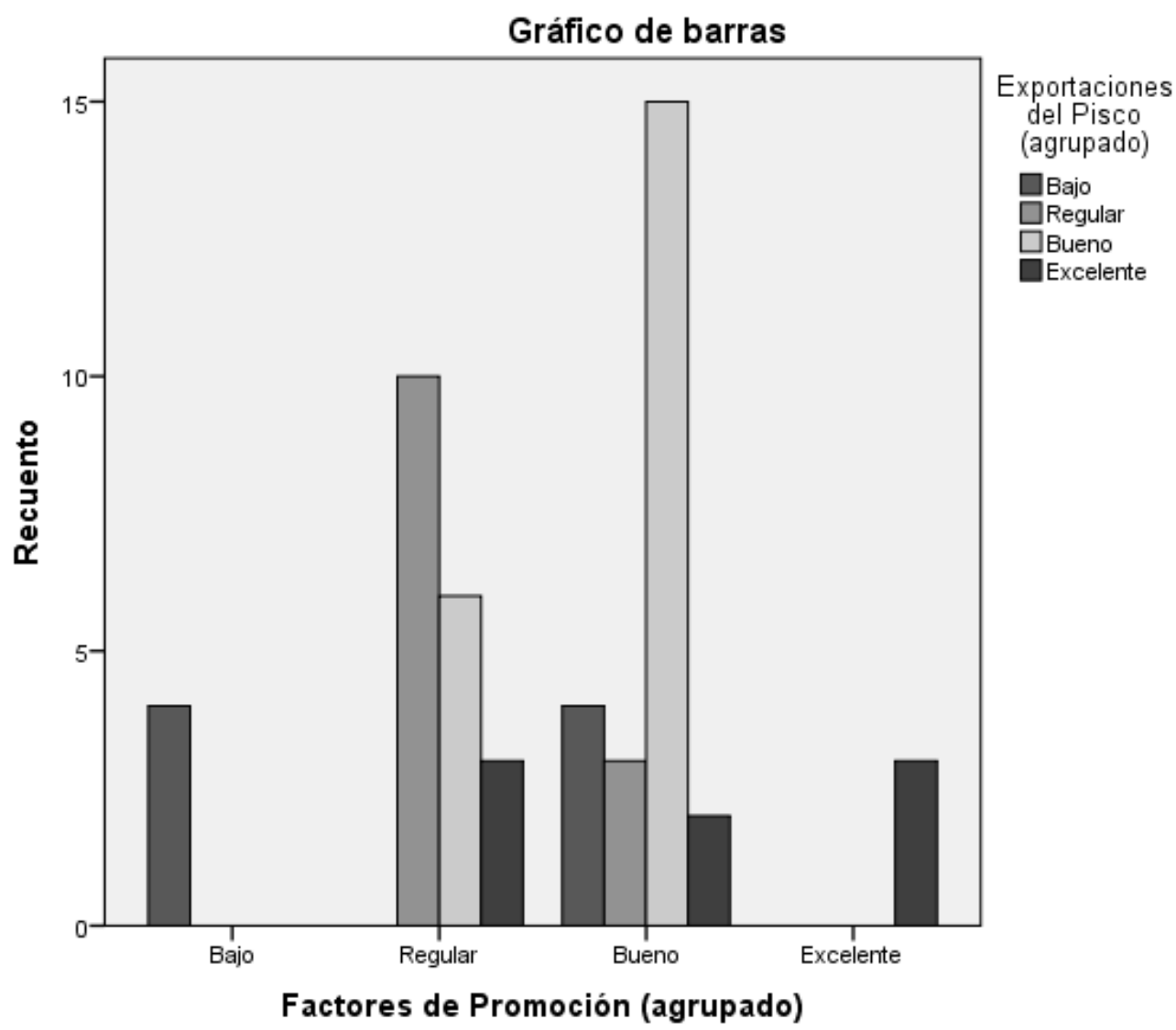

Figura 21. Resultados de los factores de promoción obtenido del SPSS. Por fuente propia, 2020

De lo anterior y, en función a los resultados hallados en esta tesis se puede establecer que los factores de promoción inciden positivamente en la evolución de las exportaciones de pisco hacia los Estados Unidos, siendo el caso que se evidencia una correlación entre las variables de Factores de Promoción y Exportaciones de Pisco, lo que muestra que a mayor y mejores formas de promoción hace que ello incida en las exportaciones del pisco peruano al mercado norte americano.

Resulta importante señalar que nuestro principal aporte con la tesis es abrir brechas y nuevos espacios para generar conocimientos sobre la manera efectiva de promocionar el pisco peruano en el mercado de los Estados Unidos de manera tal que ello sirva de apoyo y soporte en la toma 
de decisiones de todos aquellos actores vinculados con el mercado exportador hacia Norteamérica.

En este sentido, cobran importancia los factores analizados como son la denominación de origen, eventos de ferias internacionales y la marca Perú, como aquellas dimensiones que nos permiten contrastar las hipótesis planteadas en la presente investigación.

Los resultados que se encontraron en lo referente a la hipótesis general de que los factores de promoción inciden en la evolución de las exportaciones de pisco hacia Estados Unidos, mostraron resultados significativos para afirmar que existe correlación positiva entre las variables 0 de pisco, tal como lo demuestran las respuestas de los entrevistados y encuestados de las entidades y empresas vinculadas al sector.

Este hallazgo, nos permite aseverar que encontramos coincidencia con la teoría de la promoción comercial (Kotler 2003), la misma que nos menciona la importancia de las promociones de venta se sustentan en los beneficios que se les brinda a los clientes a la hora que estos últimos hacen sus decisiones de compra en función también al trabajo de una marca posicionada, lo que trasluce de forma analítica la incidencia de los factores de promoción en las actividades exportadoras de un producto en particular.

En lo concerniente a la hipótesis específica referida a que la promoción de la denominación de origen tiene incidencia positiva con la evolución de las exportaciones de pisco hacia Estados Unidos, expusieron resultados significativos para confirmar que existe correlación positiva entre el factor de denominación de origen con las exportaciones de pisco, ello también sustentado en las resultantes de las entrevistas y encuestas realizadas en el trabajo de campo. 
Asimismo, resulta importante señalar que en lo referente a las encuestas realizadas para medir los objetivos planteados en esta tesis las respuestas oscilaron entre el rango de $40 \%$ y el $70 \%$ de los encuestados en responder muy de acuerdo con la correlación positiva de las variables, dimensiones e indicadores planteadas como parte de la metodología de la presente tesis, siendo el caso que estos resultados con las definiciones relacionadas con los análisis de las promociones de ventas al consumidor (Román, 2016).

De otro lado, con respecto a la hipótesis específica alusiva a la promoción de eventos de ferias tiene incidencia positiva con la evolución de las exportaciones de pisco hacia Estados Unidos, revelaron resultados significativos para aseverar que existe correlación positiva entre el factor de eventos de ferias con las exportaciones de pisco, todo esto traslucido en las respuestas obtenidas en el proceso de recolección de datos de los actores involucrados que son personas muy relacionadas con entidades y empresas del sector.

Referente a la hipótesis específica concerniente a la promoción de la Marca Perú tiene incidencia positiva con la evolución de las exportaciones de pisco hacia Estados Unidos, expresaron resultados significativos para afirmar que existe correlación positiva entre el factor marca Perú con las exportaciones de pisco, tal como lo sustenta los resultados obtenidos a través de los instrumentos de las entrevistas y encuestas realizadas para esta finalidad.

Asimismo, resulta importante señalar que las hipótesis específicas analizadas y validadas encuentran coincidencia con la teoría para la promoción de bebidas (H. H. Vivar, 2017), la cual nos afirma que el pisco al guardar una relación con la historia, conlleva a ser aún más valorado, por lo que ello, en nuestra perspectiva de análisis, las dimensiones de denominación de origen, promoción de eventos y marca Perú, cobra una relevancia correlacional científica. 


\subsection{Conclusiones}

En base a la investigación realizada se han encontrado las siguientes conclusiones:

En primer lugar, teniendo como objetivo principal determinar los factores de promoción que incidieron en la evolución de las exportaciones de pisco hacia los Estados Unidos 2015 -2019.

Se concluye que existen factores de promoción como denominación de origen, eventos de feria y marca Perú que guardan una relación directa con las exportaciones del pisco peruano hacia el mercado norteamericano en los últimos años.

En segundo lugar, el análisis respecto a la incidencia de la denominación de origen en la evolución de las exportaciones de pisco hacia los Estados Unidos ha sido validado al lograrse el nivel de significancia exigido para la presente investigación, en tanto que se enfatiza a manera de conclusión que los niveles de reconocimiento del pisco como un producto peruano es uno de los factores que crece en el mercado de destino con efectos positivos para su reconocimiento como tal.

En tercer lugar, se concluye que los factores referidos a la promoción de eventos de ferias internacionales como de la marca Perú también han obtenido un nivel de significancia dentro del rango aceptable. De esta manera, los factores en mención tienen incidencia directa con la evolución de las exportaciones del pisco peruano hacia los Estados Unidos en la actualidad.

Esto debido a que la promoción de eventos de ferias internacionales resultar ser principales canales para generar cada vez mayor mercado dentro de los Estados Unidos, en tanto que son muy 
buenas oportunidades de promoción que contribuyen de forma directa al reconocimiento de nuestro pisco peruano en el mercado mencionado.

Es de destacar que el factor marca Perú también ha sido valido por haber obtenido el nivel de significancia requerido, lo que nos permite decir que los esfuerzos de promoción de principales productos bandera, entre ellos el pisco peruano resulta muy importante para incidir en los volúmenes de exportación al mercado norteamericano.

Finalmente, los factores analizados cobran importancia porque se relacionan con las teorías del comercio internacional planteadas en este estudio, lo que nos permite tener sustento teórico a las conclusiones vertidas y, por ende, aplicables principalmente a las empresas que están esbozadas en la Ley de Pareto aplicada a nuestras tesis, como también a las empresas intermediarias ubicadas en los Estados Unidos.

\subsection{Recomendaciones}

Como primer punto, en el factor de denominación de origen se identificó que su incidencia es relevante en las exportaciones del pisco peruano en los Estados Unidos, para ello se recomienda que los esfuerzos para consolidar un posicionamiento de este producto bandera en el mercado norteamericano sean de manera combinada entre el sector público como privado, en vista que los resultados de un mejor y mayor reconocimiento de las exportaciones de pisco en ese país de destino así lo sigue ameritando.

A ello se suma, el hecho que la denominación de origen se enmarca dentro de los distintivos del pisco peruano en los Estados Unidos, por lo que es recomendable que los esfuerzos mencionados en el párrafo anterior se encaminen a considerar a este factor como estratégico para 
las proyecciones de crecimiento en los volúmenes de exportaciones de este e inclusive de otros productos bandera del país.

Como segundo punto, en el factor referido a eventos de ferias internacionales se ha identificado que ello resulta uno de los mejores canales de promoción del pisco peruano en los Estados Unidos, por lo que se recomienda que este tipo de eventos de un lado, continúen creciendo dentro del gran mercado norteamericano logrando así cada vez mayor presencia del pisco peruano en diferentes ciudades de ese país de destino lo que contribuirá con un mercado cada vez mayor para nuestro producto bandera, incluso pudiendo ser extensible a otros productos bandera similares de nuestro país.

Como tercer punto, en el factor concerniente a la marca Perú se identificó su importancia de un lado en la promoción del pisco peruano en los Estados Unidos y, de otro lado, incluso en términos de posicionamiento internacional, esto último como un hecho interpretativo de nuestros análisis, por lo que se recomienda que las distintas marcas de los piscos peruanos con la marca Perú no se separen, en términos de promoción conjunta y de esa manera juntar los esfuerzos publicitarios en uno solo para hacer crecer su presencia en el mercado norteamericano.

Finalmente, también se recomienda que los sectores públicos y privados, mediante instituciones como PROMPERU, gremios empresariales como ADEX, COMEX y similares aumenten su inversión publicitaria y de promoción del pisco peruano en los Estados Unidos, en particular las empresas que están esbozadas en la Ley de Pareto aplicada a nuestras tesis y a las empresas intermediarias en Estados Unidos como las mencionadas en el anexo 10 que se refieren a establecimientos de distribución del pisco peruano en los condados de New Jersey y Patterson, en 
tanto que ello serían inversiones bien dirigidas con retornos de cada vez mayor reconocimiento y posicionamiento de nuestro producto bandera en el exterior. 


\section{Referencias}

Aguirre, C. Implicaciones del comercio internacional desde la teoría de Adam Smith y David. Ricardo.Economía y Finanzas Internacionales. Recuperado el 5 septiembre, 2017 de http://puceae.puce.edu.ec/efi/index.php/economiainternacional/12-teoria-clasica/242-comercio-internacional-adam-smith-davidricardo

Classical theories of international trade. Universitatea din Craiova. Recuperado el 5 septiembre, 2017 de cis01.central.ucv.ro

Ferri, J. (2017). Iniciarse en la exportación: Una aproximación a los mercados internacionales. España: Independently published.

Garita, R. (2006). Teoría económica del comercio internacional. Gestiópolis. Recuperado el 5 septiembre, 2017 de https://www.gestiopolis.com/teoria-economica-delcomercio-internacional/

Godínez, H. Teorías del comercio internacional. Universidad Autónoma Metropolitana. Recuperado el 5 septiembre, 2017 de sgpwe.izt.uam.mx

Hans Hilburg (2017). Perú la tierra del pisco: La nueva coctelería peruana. Lima: Universidad de San Martín de Porres.

Harrington, J. (2013) International Trade Theory. University of Washington. Recuperado el 5 septiembre, 2017 de washington.edu

Hernández, G. (2009) La Nueva Teoría del Comercio Internacional en la posmodernización de la economía global. Universidad Tecnológica de la Mixteca. Recuperado el 5 septiembre, 2017 de utm.mx

Ibarra, D. (2016) Crítica a la Teoría Clásica del Comercio Internacional, un enfoque de equilibrio general entre país grande y país pequeño. Science Direct. Recuperado el 5 septiembre, 2017 de sciencedirect.com

Kothler, P. (2003). Mercadotecnia. México: Pearson Presentice Hall. 
Kouzmine, V. (2000). Exportaciones no tradicionales latinoamericanas. Un enfoque no tradicional. Santiago: CEPAL - ECLAC.

Krugman, p. (1980). Economía Internacional. Madrid: McGraw-Hill.

Lama, N., Martínez, A. Y Rosado, R. (2007) Estrategia de distribución del pisco peruano en el mercado de Estados Unidos: El caso de Texas (Tesis de pregrado). Universidad Esan, Lima, Perú.

Lavados, H. (2016) Teorías del comercio internacional. Modelos y algunas evidencias empíricas: una revisión bibliográfica. Universidad de Chile. Recuperado el 5 septiembre, 2017 de econ.uchile.cl

León, L. y Zegarra, K. (2019). Factores determinantes que influyeron en las exportaciones de Pisco al mercado de Estados Unidos en el marco del TLC, periodo 2002-2018 (Tesis de pregrado). Recuperado de https://repositorioacademico.upc.edu.pe/bitstream/handle/10757/626052/Leon_V L.pdf?sequence $=1 \&$ is Allowed $=\mathrm{y}$

López, J. (2018). La exportación de pisco a Estados Unidos y su impacto en la producción peruana en el periodo 2008 - 2017 (Tesis de pregrado). Recuperado de

http://repositorio.ucv.edu.pe/bitstream/handle/20.500.12692/32243/Lopez_RJK.p df? sequence $=1 \&$ is Allowed $=y$

Morales, C. (2018). Exportación para pymes. Cómo detectar, analizar y planear negocios de exportación. Recuperado de https://issuu.com/angiecmt/docs/exportaci_n_para_pymes_versi_n_el

Morgan, R. y Katsikeas, C. (1997) Theories of international trade, foreign direct investment and firm internationalization: a critique. University of St Andrews. Recuperado el 5 septiembre, 2017 de st-andrews.ac.uk

Nelson, C (2009). Manual De Importaciones y Exportaciones (Cuarta Edición). Recuperado de https://es.calameo.com/read/005989382c6aa5af1a9a8 
Núñez, M. (2017). Exportación de pisco de uva Italia hacia Nueva York - Estados Unidos (Tesis de pregrado). Recuperado de http://repositorio.usmp.edu.pe/bitstream/handle/20.500.12727/2938/nunez_sme.pd f?sequence $=1 \&$ is Allowed $=\mathrm{y}$

Palacios, C. y Sánchez, G. (2017). Análisis de los factores que influyeron en la internacionalización del pisco en el periodo 2013 al 2016 (Tesis de Pregrado). Universidad Privada del Norte, Lima, Perú.

Quiroz, L. (2012) Fundamentos del modelo económico H-O (Modelo Heckscher-Ohlin). Economía y Finanzas Internacionales. Recuperado el 5 septiembre, 2017 de puce.edu.ec

Ricardo, D. (1817). Ventaja Comparativa. Inglaterra: John Murray.

Sen, S. (2010) International Trade Theory and Policy: A Review of the Literature. Levy Economics Institute. Recuperado el 5 septiembre, 2017 de levyinstitute.org

Smith, A. (1817). La teoría universal del comercio exportador internacional. México, s.e

Soto, E. (2017). Exportación de pisco acholado "New Imperial" a Paterson, New jerseyEstados Unidos (Tesis de pregrado). Universidad San Martin de Porres, Lima, Perú.

The Imitation Lag Hypothesis. Wright State University. Recuperado el 5 septiembre 2017 de wright.com.

United Nations Development Programme. Oficina del Perú, Centro de Innovación Tecnológica Vitivinícola - Perú (2004). La Uva y el pisco: Potencialidades Productivas [versión electrónica], 1-62. 


\section{ANEXOS}

Anexo 1. Matriz de Consistencia

\section{TÍTULO: ANÁLISIS DE FACTORES DE PROMOCIÓN QUE INCIDIERON EN LA EVOLUCIÓN DE LAS EXPORTACIONES HACIA EEUU 2015 - 2019}

\begin{tabular}{|c|c|c|c|c|}
\hline PROBLEMA & OBJETIVO & HIPÓTESIS & VARIABLE & METODOLOGÍA \\
\hline Problema general & Objetivo general & Hipótesis general & Variable 01 & Tipo de estudio \\
\hline $\begin{array}{l}\text { ¿Cómo inciden los factores de } \\
\text { promoción en la evolución de las } \\
\text { exportaciones de pisco hacia } \\
\text { Estados Unidos 2015-2019? }\end{array}$ & $\begin{array}{l}\text { Analizar la incidencia de los } \\
\text { factores de promoción en la } \\
\text { evolución de las exportaciones } \\
\text { de pisco hacia Estados Unidos } \\
2015 \text { - } 2019\end{array}$ & $\begin{array}{l}\text { Los factores de promoción inciden } \\
\text { positivamente en la evolución de las } \\
\text { exportaciones de pisco hacia Estados } \\
\text { Unidos } 2015 \text { - } 2019\end{array}$ & Factores de Promoción & Cualitativo: Descriptivo - Correlacional. \\
\hline Problemas específicos & Objetivos específicos & & $\begin{array}{l}\text { Número de } \\
\text { Reconocimientos }\end{array}$ & $\begin{array}{l}\text { Cuadros estadísticos de fuentes oficiales y } \\
\text { secundarias. }\end{array}$ \\
\hline $\begin{array}{l}\text { ¿Cómo incide la promoción de la } \\
\text { denominación de origen en la } \\
\text { evolución de las exportaciones } \\
\text { de pisco hacia los Estados } \\
\text { Unidos } 2015 \text { - 2019? }\end{array}$ & $\begin{array}{l}\text { Determinar la incidencia de la } \\
\text { promoción de la denominación } \\
\text { de origen en la evolución de las } \\
\text { exportaciones de pisco hacia los } \\
\text { Estados Unidos } 2015 \text { - } 2019\end{array}$ & $\begin{array}{l}\text { Hipótesis específicas } \\
\text { La promoción de la denominación de } \\
\text { origen tiene incidencia positiva con la } \\
\text { evolución de las exportaciones de pisco } \\
\text { hacia Estados Unidos } 2015 \text { - } 2019\end{array}$ & $\begin{array}{l}\text { Número de Eventos } \\
\text { Porcentaje de } \\
\text { Posicionamiento }\end{array}$ & $\begin{array}{l}\text { Instrumentos } \\
\text { Encuestas, entrevista estructurada de } \\
\text { profundidad y guía de análisis de contenido. }\end{array}$ \\
\hline $\begin{array}{l}\text { ¿Cómo incide la promoción de } \\
\text { eventos de ferias en la evolución } \\
\text { de las exportaciones de pisco } \\
\text { hacia los Estados Unidos } 2015 \text { - } \\
2019 \text { ? }\end{array}$ & $\begin{array}{l}\text { Determinar la incidencia de la } \\
\text { promoción de eventos de ferias } \\
\text { en la evolución de las } \\
\text { exportaciones de pisco hacia los }\end{array}$ & $\begin{array}{l}\text { La promoción de eventos de ferias tiene } \\
\text { incidencia positiva con la evolución de } \\
\text { las exportaciones de pisco hacia } \\
\text { Estados Unidos } 2015 \text { - } 2019 \text {. }\end{array}$ & $\begin{array}{l}\text { Variable } 02 \\
\text { Exportaciones del Pisco }\end{array}$ & $\begin{array}{l}\text { Recolección de datos } \\
\text { IBM SPSS, Microsoft Excel y Word. }\end{array}$ \\
\hline $\begin{array}{l}\text { ¿Cómo incide la promoción de la } \\
\text { Marca Perú en la evolución de } \\
\text { las exportaciones de pisco hacia } \\
\text { los Estados Unidos } 2015 \text { - 2019? }\end{array}$ & $\begin{array}{l}\text { Determinar la incidencia de la } \\
\text { promoción de la Marca Perú en } \\
\text { la evolución de las exportaciones } \\
\text { de pisco hacia los Estados } \\
\text { Unidos } 2015-2019\end{array}$ & $\begin{array}{l}\text { La promoción de la Marca Perú tiene } \\
\text { incidencia positiva con la evolución de } \\
\text { las exportaciones de pisco hacia } \\
\text { Estados Unidos } 2015 \text { - } 2019\end{array}$ & $\begin{array}{l}\text { Volumen de } \\
\text { Exportaciones del Pisco }\end{array}$ & \\
\hline
\end{tabular}


Anexo 2. Matriz Operacional (Cuantitativa)

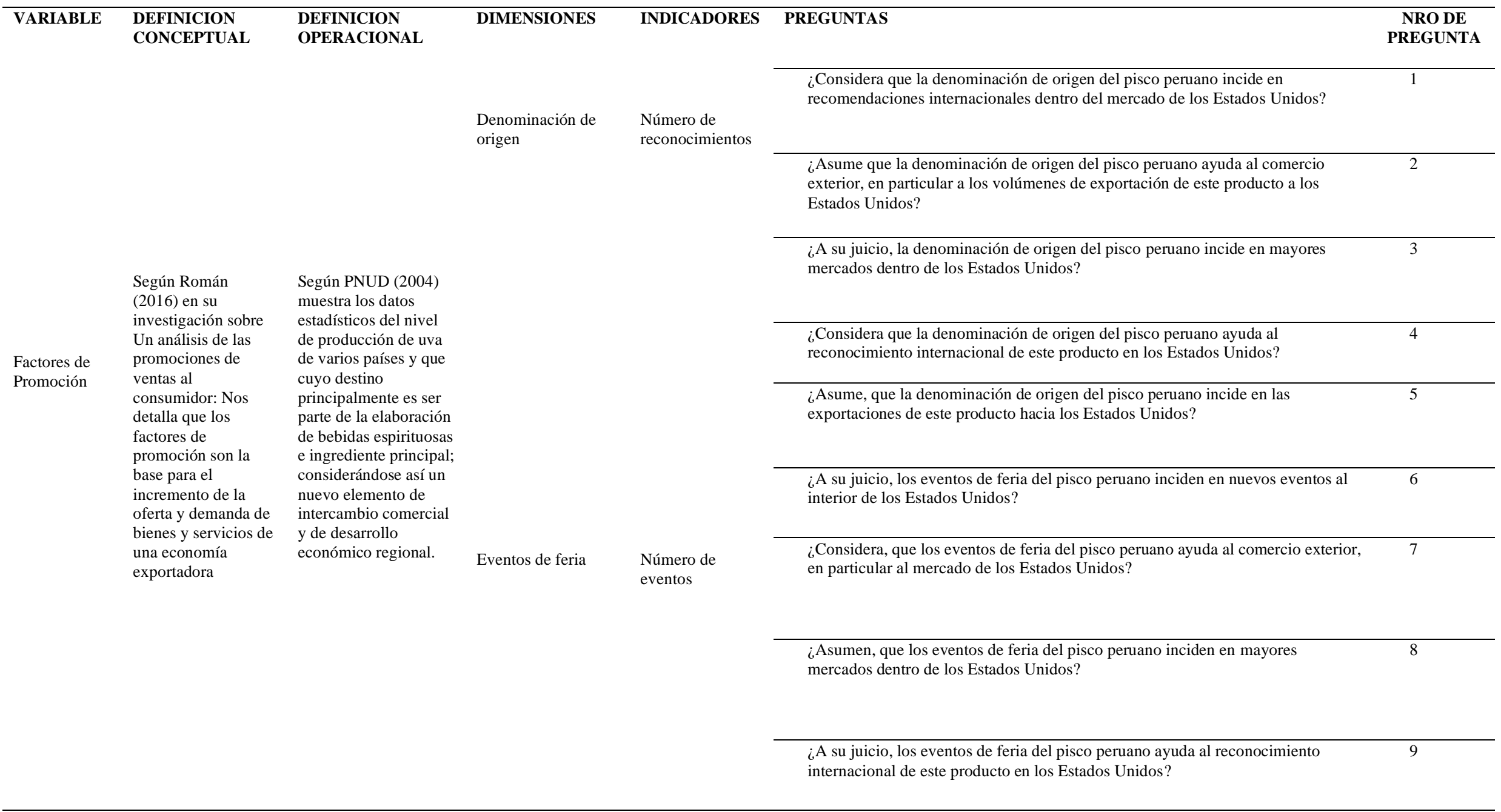




\begin{tabular}{|c|c|c|c|c|c|c|}
\hline & & & & & $\begin{array}{l}\text { ¿Considera, que los eventos de feria del pisco peruano inciden en las } \\
\text { exportaciones de este producto hacia los estados unidos? }\end{array}$ & 10 \\
\hline & & & \multirow{5}{*}{ Marca Perú } & \multirow{5}{*}{$\begin{array}{l}\text { Porcentaje de } \\
\text { posicionamiento }\end{array}$} & $\begin{array}{l}\text { ¿A su juicio, la Marca Perú genera incidencia en recomendaciones del pisco } \\
\text { peruano en el mercado de los Estados Unidos? }\end{array}$ & 11 \\
\hline & & & & & $\begin{array}{l}\text { ¿Asume que la marca Perú genera ayuda al comercio exterior del pisco peruano } \\
\text { con los Estados Unidos? }\end{array}$ & 12 \\
\hline & & & & & $\begin{array}{l}\text { ¿Considera que la marca Perú genera incidencia en mayores mercados del pisco } \\
\text { peruano al interior de los Estados Unidos? }\end{array}$ & 13 \\
\hline & & & & & $\begin{array}{l}\text { ¿A su juicio, la marca Perú genera ayuda al reconocimiento del pisco peruano en } \\
\text { el mercado de los Estados Unidos? }\end{array}$ & 14 \\
\hline & & & & & $\begin{array}{l}\text { ¿Asume que la marca Perú genera incidencia en las exportaciones del pisco } \\
\text { peruano hacia los Estados Unidos? }\end{array}$ & 15 \\
\hline \multirow{6}{*}{$\begin{array}{l}\text { Exportaciones } \\
\text { del Pisco }\end{array}$} & \multirow{6}{*}{$\begin{array}{l}\text { Las exportaciones } \\
\text { del pisco (Adex, } \\
\text { 2010) se sustentan } \\
\text { en la competitividad } \\
\text { y articulación de los } \\
\text { actores participantes } \\
\text { en el sector } \\
\text { vitivinícola, por lo } \\
\text { que se considera que } \\
\text { la } \\
\text { internacionalización } \\
\text { del pisco peruano } \\
\text { presenta un } \\
\text { escenario favorable, } \\
\text { ello también en base } \\
\text { de ventajas } \\
\text { comparativas de los } \\
\text { campos de cultivo } \\
\text { en comparación con } \\
\text { su mercado de } \\
\text { exportación. }\end{array}$} & \multirow{6}{*}{$\begin{array}{l}\text { Según H. H. Vivar } \\
\text { (2013) nos indica el } \\
\text { pisco es la bebida } \\
\text { espirituosa que más se } \\
\text { consume en el país y } \\
\text { ello le da valor } \\
\text { agregado, por lo que } \\
\text { promocionarlo es } \\
\text { esencial para penetrar } \\
\text { en los mercados } \\
\text { extranjeros y sobre } \\
\text { todo en el mercado de } \\
\text { la coctelería de estados } \\
\text { unidos. }\end{array}$} & \multirow{6}{*}{$\begin{array}{l}\text { Términos de } \\
\text { intercambio }\end{array}$} & \multirow{6}{*}{$\begin{array}{l}\text { Volúmenes de } \\
\text { exportación de } \\
\text { Pisco }\end{array}$} & $\begin{array}{l}\text { ¿Considera que los términos de intercambio son positivos para el pisco peruano } \\
\text { hacia los Estados Unidos? }\end{array}$ & 16 \\
\hline & & & & & & \\
\hline & & & & & $\begin{array}{l}\text { ¿A su juicio, los términos de intercambio del pisco peruano son estratégicos hacia } \\
\text { los Estados Unidos? }\end{array}$ & 17 \\
\hline & & & & & $\begin{array}{l}\text { ¿Asume que los términos de intercambio del pisco peruano tenderán a crecer en el } \\
\text { mercado de los Estados Unidos? }\end{array}$ & 18 \\
\hline & & & & & $\begin{array}{l}\text { ¿Considera que los términos de intercambio del pisco peruano contribuyen con la } \\
\text { balanza comercial de forma positiva con los Estados Unidos? }\end{array}$ & 19 \\
\hline & & & & & $\begin{array}{l}\text { ¿A su juicio, los términos de intercambio mantendrán al pisco peruano como } \\
\text { producto bandera? }\end{array}$ & 20 \\
\hline
\end{tabular}




\section{Anexo 3. Matriz Operacional (Cualitativa)}

Categorías

Concepto

Preguntas

1. ¿Qué opina a la afirmación que la política de comercio exterior contribuye con los factores de promoción que explican la incidencia en la evolución de las exportaciones de pisco hacia los Estados Unidos en los últimos cinco años?

\section{Política de Comercio Exterior}

Alcances de la Política de Comercio Exterior del Estado
2. ¿Cuál es su posición al respecto?

3. iDe qué manera el acuerdo comercial Perú - EEUU contribuye con la promoción de la denominación de origen que incide a su vez en la evolución de las exportaciones de pisco hacia los Estados Unidos en los últimos cinco años?
Acuerdo Comercial Perú - EEUU Perspectivas del Acuerdo Económico entre Países
4. ¿Cuál es su posición al respecto?

5. ¿De qué manera el mercado del pisco peruano resulta ser la base para la promoción de eventos de ferias que incidan a su vez en la evolución de las exportaciones de pisco hacia los Estados Unidos en los últimos cinco?
Mercado del Pisco Peruano
Situación real de la comercialización del mercado del pisco peruano en el ámbito nacional
6. ¿Cuál es su posición al respecto?

7. ¿De qué manera las estrategias publicitarias ayudan a que la promoción de la marca Perú incida en la evolución de las exportaciones de pisco hacia los Estados Unidos en los últimos cinco años?

8. ¿Cuál es su posición al respecto?

9. ¿En qué medida la actual realidad industrial, hace que la promoción de la denominación de origen, eventos de feria y de la Marca Peru, sean factores estratégicos para seguir continuando con ello y así hacer que las exportaciones de pisco a los Estados Unidos en los próximos años puedan seguir mejorando?

10. ¿Cuál es su posición al respecto? 
Anexo 4. Exportación de Pisco en US\$

Exportación de Pisco (US\$ - FOB)

\begin{tabular}{ccccc}
\hline 2015 & 2016 & 2017 & 2018 & 2019 \\
& & & & \\
\hline $7,912,523$ & $8,297,132$ & $6,700,123$ & $5,598,869$ & $6,980,879$ \\
\hline
\end{tabular}

Elaboración Propia

Fuente: SUNAT

Anexo 5. Exportación de pisco por destino

Exportación de Pisco por destino (US\$ - FOB)

\begin{tabular}{cccccc}
\hline País & 2015 & 2016 & 2017 & 2018 & 2019 \\
\hline Chile & 2,784 & 2,922 & 1,282 & 1,800 & 3,230 \\
EE. UU & 2,849 & 2,549 & 2,299 & 1,672 & 1,555 \\
España & 339 & 461 & 766 & 750 & 990 \\
U. K & 409 & 340 & 257 & 291 & 512 \\
TOTAL & 6,381 & 6,272 & 4,604 & 4,513 & 6,287 \\
\hline
\end{tabular}

Elaboración Propia

Fuente: AGRODATA 
Anexo 6. Cuestionario de Entrevista

\section{Cuestionario de Entrevista}

Vamos a contactar con tres (3) Ejecutivos especializados, como empresarios, docentes de negocios internacionales, funcionarios de mincetur o similares, relacionados con las actividades vinculadas con el sector exportador y/o relacionado con el comercio internacional del pisco peruano con experiencia en análisis económicos financieros de la evolución de este licor en el mercado norteamericano.

\section{Preguntas}

\section{Respuestas}

1. ¿Qué opina a la afirmación que la política de comercio exterior contribuye con los factores de promoción que explican la incidencia en la evolución de las exportaciones de pisco hacia los Estados Unidos en los últimos cinco años?

2. ¿Cuál es su posición al respecto?

3. ¿De qué manera el acuerdo comercial Perú - EEUU contribuye con la promoción de la denominación de origen que incide a su vez en la evolución de las exportaciones de pisco hacia los Estados Unidos en los últimos cinco años?

4. ¿Cuál es su posición al respecto?

5. ¿De qué manera el mercado del pisco peruano resulta ser la base para la promoción de eventos de ferias que incidan a su vez en la evolución de las exportaciones de pisco hacia los Estados Unidos en los últimos cinco?

6. ¿Cuál es su posición al respecto?

7. ¿De qué manera las estrategias publicitarias ayudan a que la promoción de la marca Perú incida en la evolución de las exportaciones de pisco hacia los Estados Unidos en los últimos cinco años? 
8. ¿Cuál es su posición al respecto?

9. ¿En qué medida la actual realidad industrial, hace que la promoción de la denominación de origen, eventos de feria y de la Marca Peru, sean factores estratégicos para seguir continuando con ello y así hacer que las exportaciones de pisco a los Estados Unidos en los próximos años puedan seguir mejorando?

10. ¿Qué nos aporta al respecto?

Cuestionario de la Entrevista:

¿Qué opina a la afirmación que la política de comercio exterior contribuye con los factores de promoción que explican la incidencia en la evolución de las exportaciones de pisco hacia los Estados Unidos en los últimos cinco años?

¿Cuál es su posición al respecto?

¿De qué manera el acuerdo comercial Perú - EEUU contribuye con la promoción de la denominación de origen que incide a su vez en la evolución de las exportaciones de pisco hacia los Estados Unidos en los últimos cinco años?

¿Cuál es su posición al respecto? 
¿De qué manera el mercado del pisco peruano resulta ser la base para la promoción de eventos de ferias que incidan a su vez en la evolución de las exportaciones de pisco hacia los Estados Unidos en los últimos cinco?

¿Cuál es su posición al respecto?

¿De qué manera las estrategias publicitarias ayudan a que la promoción de la marca Perú incida en la evolución de las exportaciones de pisco hacia los Estados Unidos en los últimos cinco años?

¿Cuál es su posición al respecto?

¿En qué medida la actual realidad industrial, hace que la promoción de la denominación de origen, eventos de feria y de la Marca Peru, sean factores estratégicos para seguir continuando con ello y así hacer que las exportaciones de pisco a los Estados Unidos en los próximos años puedan seguir mejorando? 
¿Qué nos aporta al respecto?

\section{Entrevista 1:}

\section{SIFUENTES BEINGOLEA, Nilsa}

\section{Cuestionario de Entrevista}

1. ¿Qué opina a la afirmación que la política de comercio exterior contribuye con los factores de promoción que explican la incidencia en la evolución de las exportaciones de Pisco hacia los Estados Unidos en los últimos cinco años?

Gracias por la entrevista, bueno mi opinión es que, en los últimos años, nuestra política de comercio exterior viene teniendo un gran impacto directo en los volúmenes de las exportaciones, con mayor razón en aquellos productos que nos representan y nos hacen conocidos en el mercado de los Estados Unidos, tal es el caso del pisco peruano, siendo así que es muy importante señalar que nuestra política de comercio exterior debe continuar en la dirección de potenciar sus estrategias año tras año.

2. ¿Cuál es su enfoque personal y profesional al respecto?

Desde mi perspectiva, toda política de comercio exterior que apunte a seguir apoyando a las exportaciones del pisco peruano tendrá un futuro muy favorable y un amplio desarrollo en el 
mercado de los Estados Unidos siempre en cuando este directamente relacionado con lograr ser reconocido y así obtener un nuevo posicionamiento.

3. ¿De qué manera el acuerdo comercial Perú - EEUU contribuye con la promoción de la denominación de origen que incide a su vez en la evolución de las exportaciones de pisco hacia los Estados Unidos en los últimos cinco años?

Este acuerdo ha generado nuevas oportunidades para los peruanos y a su vez está resaltando las raíces del pisco en cuanto a su origen y proceso de elaboración de tal forma que fomenta la evolución de las exportaciones y también el reconocimiento del país en el mercado estadounidense.

Asimismo, permíteme comentar como un enfoque complementario que la competencia que tenemos con chile en cuanto a la denominación de origen, esa rivalidad ayuda a que el mercado extranjero, en particular en los Estados Unidos, empiece a probar y comparar nuestro pisco, con eso ya estamos atrayendo al nuevo mercado, como es el caso de muchos extranjeros que han llegado a Perú y lo han hecho de su bebida favorita.

4. ¿Cuál es su enfoque personal y profesional al respecto?

Bueno, vamos por el buen camino, como persona en el ámbito personal y profesional siempre busco lo mejor para nuestro país y con este acuerdo que se hizo se están abriendo nuevas oportunidades a las pequeñas y grandes empresas generando trabajo.

5. ¿De qué manera el mercado del pisco peruano resulta ser la base para la promoción de eventos de ferias que incidan a su vez en la evolución de las exportaciones de pisco hacia los Estados Unidos en los últimos cinco años? 
El pisco peruano, gracias a los esfuerzos privados y estatales en términos de promoción y publicidad de los productos bandera, en los últimos años viene experimentando un gran posicionamiento en el mercado nacional por ende ya tiene ese plus y oportunidad de incursionar en el mercado extranjero, e particular en los Estados Unidos y es, mediante actividades de eventos de ferias donde nuestra oferta de pisco se conecta con la demanda de nuevos consumidores estadounidenses.

6. ¿Cuál es su enfoque personal y profesional al respecto?

Desde mi punto de vista, el mercado del pisco peruano está creciendo en un promedio de $18 \%$ en los últimos 5 años, de tal forma que al ser un producto originario del Perú influye en la promoción de eventos tipo ferias tanto en el mercado nacional como en el extranjero por ende como resultado es el posicionamiento y desarrollo creciente y actual en el mercado estadounidense.

7. ¿De qué manera las estrategias publicitarias ayudan a que la promoción de la marca Perú incida en la evolución de las exportaciones de pisco hacia los Estados Unidos en los últimos cinco años?

Como bien sabemos una campaña publicitaria es una estrategia que lleva a cabo difundir un producto como por ejemplo el pisco peruano y su objetivo de fijarla en la mente de los consumidores potenciales de una forma adecuada y exitosa. Y así incidir en la evolución de las exportaciones de pisco. 
8. ¿Cuál es su enfoque personal y profesional al respecto?

Desde mi punto de vista, en cuanto al enfoque de las estrategias publicitarias tenemos la publicidad pull, la publicidad de contenido o como el alcohol advertising y entre otras, estas estrategias publicitarias son herramientas fundamentales para llegar al consumidor final.

9. ¿En qué medida la actual realidad industrial, hace que la promoción de la denominación de origen, eventos de feria y de la Marca Perú, sean factores estratégicos para seguir continuando con ello y así hacer que las exportaciones de pisco a los Estados Unidos en los próximos años puedan seguir mejorando?

Como bien sabemos la marca Perú cuenta con estrategias diferenciadas para diferentes ámbitos, inicio su campaña de internacionalización con mayor fuerza obteniendo una impresión sumamente positiva y así convirtiéndose en un producto atractivo. Por otro lado, los eventos de feria como las promociones también son estrategias que llevan al éxito.

10. ¿Cuál es su enfoque personal y profesional al respecto?

Bueno, desde mi enfoque personal y profesional las exportaciones del pisco peruanos permiten aumentar la rentabilidad de las empresas y por lo tanto la denominación no solo se enfoca en una publicidad si no que más bien engloba todo como: la marca, promoción, las ferias y el origen.

\section{Entrevista 2:}

BAZAN BRICEÑO, José

\section{Cuestionario de Entrevista}


1. ¿Qué opina a la afirmación que la política de comercio exterior contribuye con los factores de promoción que explican la incidencia en la evolución de las exportaciones de Pisco hacia los Estados Unidos en los últimos cinco años?

Claro con gusto, mi experiencia en el análisis del impacto de nuestra política de comercio exterior en apoyo a las exportaciones del pisco peruano es sumamente positiva, siendo el mejor de nuestros mercados de destino el de los Estados Unidos, en tanto que considero a este mercado como un destino natural del nuestro pisco como de otros productos banderas de nuestro país por un tema de cercanía geográfica y la mucha presencia de peruanos que viven en varias ciudades norte americanas.

2. ¿Cuál es su enfoque personal y profesional al respecto?

En mi enfoque personal y profesional Perú, mediante su política de comercio exterior del pisco peruano hizo un gran esfuerzo de marketing para su promoción en base a la consideración de esta bebida como originario de Perú, aun cuando se está en disputa con Chile, por consiguiente, esto a su vez incide con la evolución de las exportaciones y el posicionamiento del mercado estadounidense.

3. ¿De qué manera el acuerdo comercial Perú - EEUU contribuye con la promoción de la denominación de origen que incide a su vez en la evolución de las exportaciones de pisco hacia los Estados Unidos en los últimos cinco años?

Uno de los impactos positivos que fue gracias a este acuerdo es para los productores y sectores vinculados al pisco, por la incorporación del pisco Perú como producto distintivo de tal forma que influye en la promoción de la denominación del origen del pisco y a su vez en la evolución de las exportaciones hacia el mercado estadounidense. 
4. ¿Cuál es su enfoque personal y profesional al respecto?

Desde mi enfoque personal y profesional el tratado entre Perú y Estados Unidos atrae flujos de inversión privada nacional y extranjera, propiciando el desarrollo de economía y a su vez contribuye con la expansión de la oferta de empleo.

5. ¿De qué manera el mercado del pisco peruano resulta ser la base para la promoción de eventos de ferias que incidan a su vez en la evolución de las exportaciones de pisco hacia los Estados Unidos en los últimos cinco años?

En mi experiencia en cuanto al mercado del pisco peruano una de sus principales estrategias de publicidad es la participación de eventos de ferias y así poder captar y desarrollar el mercado estadounidense, bueno es la base de esta promoción ya que su atractivo es la degustación como estrategia de exportaciones a este mercado de destino

Asimismo, permíteme resaltar que el pisco peruano fue denominado una bebida espirituosa es como hablar de nuestras tierras, como el futbol, la gastronomía entre otros. El origen genera pasión he ahí donde nos enfocamos del pisco como base para la promoción de eventos de feria en donde se destacan sus orígenes e impulsar en el mercado norte americano.

6. ¿Cuál es su enfoque personal y profesional al respecto?

Mi enfoque personal y profesional destaca, que el pisco es una bebida que se debe explotar al máximo y en cuanto a la promoción de eventos de ferias contamos con varias estrategias que impulse este producto, hasta contamos con un día festivo. En la actualidad destacamos en varios países como por ejemplo en Alemania como un segundo mercado además del norte americano. 
7. ¿De qué manera las estrategias publicitarias ayudan a que la promoción de la marca Perú incida en la evolución de las exportaciones de pisco hacia los Estados Unidos en los últimos cinco años?

En cuanto a la publicidad todos tenemos claros que es una pieza clave para llevar nuestra marca hacia el consumidor final ya que su objetivo es aumentar las ventas, atraer clientes, reconocimiento del producto, mejorar la identidad de la marca, etc. Y es ahí donde nuestra marca evoluciona a nivel nacional e internacional y obviamente ligada a otras estrategias.

8. ¿Cuál es su enfoque personal y profesional al respecto?

Mi perspectiva en cuanto a la estrategia de publicidad es positiva, pero todo depende de cómo lo manejan ya que hay publicidades que te pueden llevar a la cima como también te pueden llevar al olvido y es ahí donde nuestra marca tiene una identidad.

9. ¿En qué medida la actual realidad industrial, hace que la promoción de la denominación de origen, eventos de feria y de la Marca Perú, sean factores estratégicos para seguir continuando con ello y así hacer que las exportaciones de pisco a los Estados Unidos en los próximos años puedan seguir mejorando?

El espíritu empresarial es una de las fuerzas más importantes gracias a ello se aumenta la eficiencia del mercado, encontrando retos y oportunidades. La promoción de la denominación de origen juega un papel importante y en cuanto a las exportaciones la marca y los eventos son nuestra presentación hacia el cliente por ende cada año se ha estado buscado nuevas estrategias para seguir mejorando. 
10. ¿Cuál es su enfoque personal y profesional al respecto?

Desde mi punto de vista enfocándome en lo personal y profesional las exportaciones del pisco peruano han tenido buena acogida en el mercado estadounidense gracias a las promociones, los eventos, el espíritu emprendedor que se tiene en esta industria del pisco.

\section{Entrevista 3:}

OCHOA TORRES, Fernando

\section{Cuestionario de Entrevista}

1. ¿Qué opina a la afirmación que la política de comercio exterior contribuye con los factores de promoción que explican la incidencia en la evolución de las exportaciones de Pisco hacia los Estados Unidos en los últimos cinco años?

Es un placer, soy fiel creyente que la actual política de comercio exterior se puede seguir mejorando en apoyo a las ventas del pisco peruano en el exterior, con mayor énfasis en aquellos mercados donde nuestro pisco es bien aceptado y con un cada vez mayor posicionamiento, siendo el caso que en este enfoque resulta el mercado de los Estados Unidos como el de mayor participación y por ende donde deben seguir elevándose los volúmenes de exportaciones en los próximos años.

2. ¿Cuál es su enfoque personal y profesional al respecto?

A mi parecer la industria del pisco peruano está entrelazada con nuestra cultura y eso la hace muy importante para que se continúe con el apoyo la actual política de comercio exterior por parte del Estado en la promoción y el proceso de comercialización hacia el mercado de los Estados Unidos y así seguir evolucionando. 
3. ¿De qué manera el acuerdo comercial Perú - EEUU contribuye con la promoción de la denominación de origen que incide a su vez en la evolución de las exportaciones de pisco hacia los Estados Unidos en los últimos cinco años?

El acuerdo que se trató entre Perú y Estados Unidos trajo ventajas. Uno de los beneficios es la reducción de las barreras arancelarias y no arancelarias al comercio, la competitividad del pisco peruano también nos facilita el incremento del flujo de inversión extranjera y así genera una evolución positiva en cuanto a las exportaciones de pisco hacia los Estados Unidos.

4. ¿Cuál es su enfoque personal y profesional al respecto?

A mi parecer, Perú cuenta con un mercado interno reducido que necesita ser desarrollado y gracias a este tratado contamos con sectores que son beneficiados como: agroindustria, textil, joyería, artesanales, entre otros. El origen de nuestros productos es un factor clave para el mercado extranjero.

5. ¿De qué manera el mercado del pisco peruano resulta ser la base para la promoción de eventos de ferias que incidan a su vez en la evolución de las exportaciones de pisco hacia los Estados Unidos en los últimos cinco años?

El mercado de pisco peruano ya cuenta con un buen posicionamiento en estos últimos 5 años, ello como consecuencia de la promoción de eventos de feria y otras actividades que inciden con la exportación de pisco hacia los Estados Unidos, de tal forma que continuará evolucionando de manera progresiva y constante.

El pisco viene posicionándose cada vez más en el consumo de licores en los peruanos y de la misma manera está marcando territorio en los mercados internacionales, pero para ser la base para 
la promoción de eventos de feria, primero tenemos que trabajar en conjunto con los productores para fomentar con mayor fuerza la categoría de pisco o coctelera.

6. ¿Cuál es su enfoque personal y profesional al respecto?

Bueno, desde mi punto de vista el pisco peruano es un gran producto que necesita apoyo continuo por parte del gobierno para también aumentar la producción ya que chile produce 10 veces más que nosotros, de tal forma que aún hay esa guerra comercial no solamente en función de la denominación de origen del pisco sino también en contar con mayor presencia en las ferias que se dan en el mercado estadounidense y es ahí donde no podemos quedarnos atrás en continuar con la estrategia de la promoción mediante este tipo de eventos.

7. ¿De qué manera las estrategias publicitarias ayudan a que la promoción de la marca Perú incida en la evolución de las exportaciones de pisco hacia los Estados Unidos en los últimos cinco años?

Como bien sabemos la marca Perú es vendida como una marca publicitaria y es la estrategia de marketing y promoción turística por el gobierno peruano de tal forma que buscan atraer al turista como a la inversión privada y en ella resalta la gastronomía, el futbol, el pisco, el tejido y el arte textil, entro otros. Por ende, incide en la evolución de las exportaciones de pisco hacia los Estados Unidos y otros países.

8. ¿Cuál es su enfoque personal y profesional al respecto?

Hoy en día la marca es un signo distintivo que busca diferenciar a empresas, gobiernos, grupos, países, etcétera. Y es ahí donde un producto puede obtener beneficios al ser promocionado con la marca país ya que tiene un gran peso lo que le permite entrar al mercado extranjero. 
9. ¿En qué medida la actual realidad industrial, hace que la promoción de la denominación de origen, eventos de feria y de la Marca Perú, sean factores estratégicos para seguir continuando con ello y así hacer que las exportaciones de pisco a los Estados Unidos en los próximos años puedan seguir mejorando?

Podríamos decir es una medida positiva ya que estas estrategias influyen en el constante crecimiento del pisco peruano ya que la marca Perú es reconocida a nivel mundial ya que busca construir una reputación en los posibles inversionistas, abanderar los productos exportables.

10. ¿Cuál es su enfoque personal y profesional al respecto?

Bueno, la marca Perú, la denominación del origen y la realidad industrial son factores estratégicos que ayudan al crecimiento del mercado de pisco ya que todos esos factores tienen como objetivo promocionar sus productos y el crecimiento económico de nuestro país. 
Anexo 7. Cuestionario de la Encuesta

Operacionalización de la Variable Independiente

Dimensiones N Número de Preguntas

\begin{tabular}{ll}
\hline Denominación de Origen & 01 al 05 \\
\hline Eventos de Feria & 06 al 10 \\
\hline Marca Perú & 11 al 15 \\
\hline
\end{tabular}

Fuente: Elaboración propia

Operacionalización de la Variable Dependiente

Dimensiones

Términos de Intercambio

Fuente: Elaboración propia
Número de Preguntas

16 al 20 


\section{Cuestionario de la Encuesta.}

\begin{tabular}{|c|c|c|c|c|c|}
\hline & 1 & 2 & 3 & 4 & 5 \\
\hline & 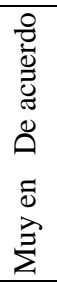 & 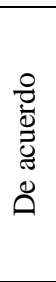 & 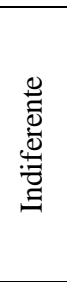 & 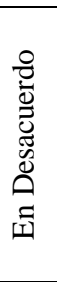 & 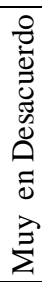 \\
\hline \multicolumn{6}{|l|}{\begin{tabular}{|l|l|} 
1. ¿Considera que la denominación de origen del pisco peruano & \\
incide en recomendaciones internacionales dentro del mercado \\
de los Estados Unidos?
\end{tabular}} \\
\hline \multicolumn{5}{|l|}{$\begin{array}{l}\text { 2. ¿Asume que la denominación de origen del pisco peruano ayuda } \\
\text { al comercio exterior, en particular a los volúmenes de } \\
\text { exportación de este producto a los Estados Unidos? }\end{array}$} & \\
\hline \multicolumn{5}{|l|}{$\begin{array}{l}\text { 3. ¿A su juicio, la denominación de origen del pisco peruano } \\
\text { incide en mayores mercados dentro de los Estados Unidos? }\end{array}$} & \\
\hline \multicolumn{6}{|l|}{$\begin{array}{l}\text { 4. ¿Considera que la denominación de origen del pisco peruano } \\
\text { ayuda al reconocimiento internacional de este producto en los } \\
\text { Estados Unidos? }\end{array}$} \\
\hline \multicolumn{6}{|l|}{$\begin{array}{l}\text { 5. ¿Asume, que la denominación de origen del pisco peruano } \\
\text { incide en las exportaciones de este producto hacia los Estados } \\
\text { Unidos? }\end{array}$} \\
\hline \multicolumn{6}{|l|}{$\begin{array}{l}\text { 6. ¿A su juicio, los eventos de feria del pisco peruano inciden en } \\
\text { nuevos eventos al interior de los Estados Unidos? }\end{array}$} \\
\hline \multicolumn{6}{|l|}{$\begin{array}{l}\text { 7. ¿Considera, que los eventos de feria del pisco peruano ayuda al } \\
\text { comercio exterior, en particular al mercado de los Estados } \\
\text { Unidos? }\end{array}$} \\
\hline \multicolumn{6}{|l|}{$\begin{array}{l}\text { 8. ¿Asumen, que los eventos de feria del pisco peruano inciden } \\
\text { en mayores mercados dentro de los Estados Unidos? }\end{array}$} \\
\hline \multicolumn{6}{|l|}{$\begin{array}{l}\text { 9. ¿A su juicio, los eventos de feria del pisco peruano ayuda al } \\
\text { reconocimiento internacional de este producto en los Estados } \\
\text { Unidos? }\end{array}$} \\
\hline $\begin{array}{l}\text { 10. ¿Considera, que los eventos de feria del pisco peruano inciden } \\
\text { en las exportaciones de este producto hacia los estados unidos? }\end{array}$ & & & & & \\
\hline
\end{tabular}




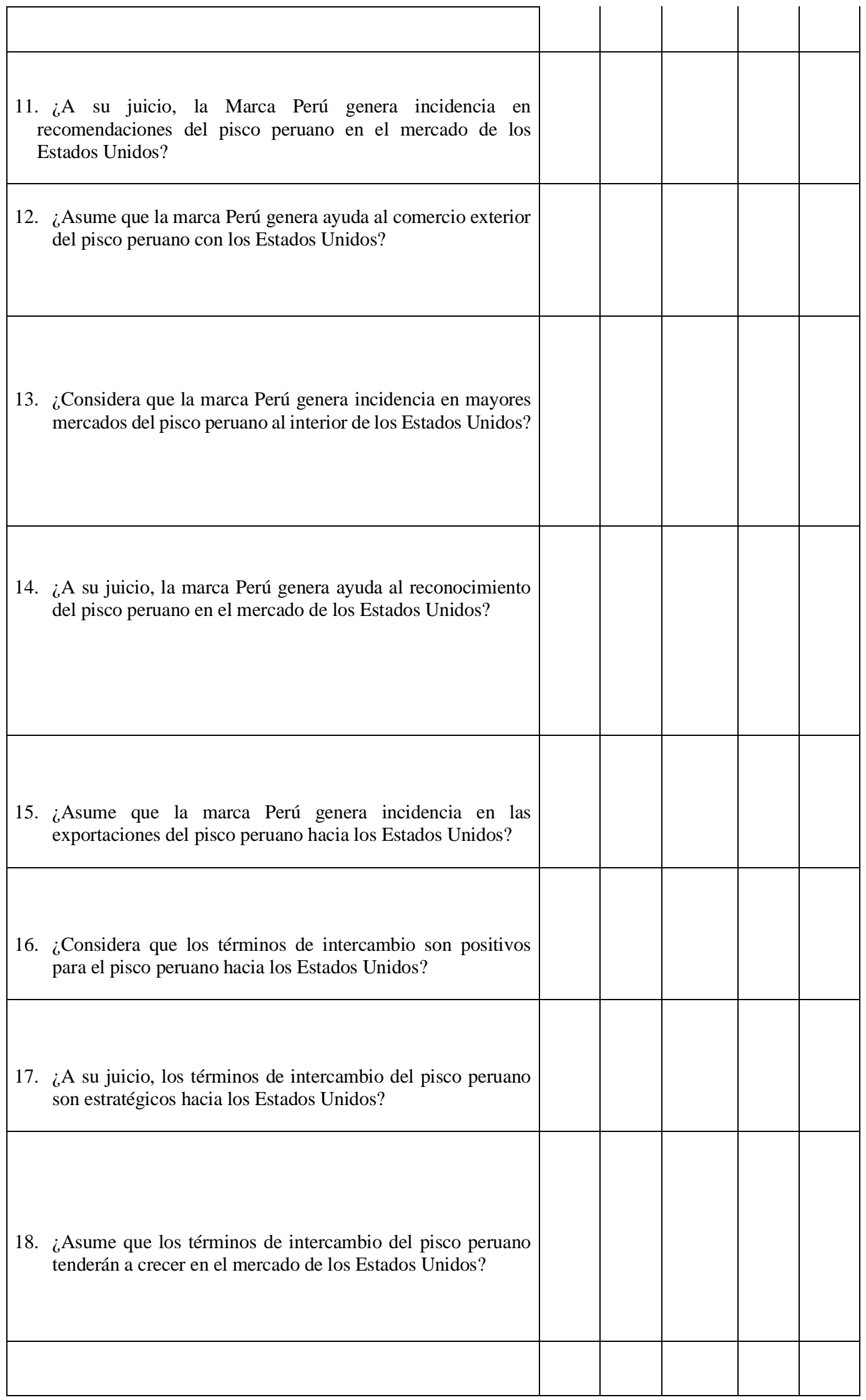




\begin{tabular}{|l|l|l|l|l|}
\hline $\begin{array}{l}\text { 19. ¿Considera que los términos de intercambio del pisco peruano } \\
\text { contribuyen con la balanza comercial de forma positiva con } \\
\text { los Estados Unidos? }\end{array}$ & & & & \\
\hline $\begin{array}{l}\text { 20. ¿A su juicio, los términos de intercambio mantendrán al pisco } \\
\text { peruano como producto bandera? }\end{array}$ & & & $\mid$ & $\mid$ \\
\hline
\end{tabular}

Fuente: Elaboración propia

Anexo 8. Lista de encuestados

\begin{tabular}{cccl}
\hline Id & Nombre y Apellido & Correo electronico & Puesto \\
\hline 1 & Jerson Montesinos & jersonmontesinos32@gmail.com & Ejecutivo del sector pisco \\
2 & Raul Tenorio & tenorioraul144@gmail.com & Ejecutivo del sector pisco \\
3 & Karla Loza & loza.karla76@gmail.com & Ejecutivo del sector pisco \\
4 & Estefania Montenegro & e.monteneg11@gmail.com & Ejecutivo del sector pisco
\end{tabular}




\begin{tabular}{|c|c|}
\hline 5 & Juan Villanueva \\
\hline 6 & Lucas Lopez \\
\hline 7 & Mateo Costa \\
\hline 8 & Esteban Bailetti \\
\hline 9 & Miguel Montenegro \\
\hline 10 & Francesca Cedron \\
\hline 11 & Rose Benito \\
\hline 12 & Harry Pedraza \\
\hline 13 & Brenda Vallejo \\
\hline 14 & Fiorella Hurtado \\
\hline 15 & David Ruiz \\
\hline 16 & Cesar Coronado \\
\hline 17 & Sony Perez \\
\hline 18 & Kelly Melissa \\
\hline 19 & Luis Torpoco \\
\hline 20 & Kateryn Quispe \\
\hline 21 & Jorge Pallete \\
\hline 22 & Rosa Lindo \\
\hline 23 & Leonila Juana \\
\hline 24 & Francisca Chávez \\
\hline 25 & Agustin Condori \\
\hline 26 & Augusto Montoya \\
\hline 27 & Magaly Huaman \\
\hline 28 & Daniel Carrion \\
\hline 29 & Jose Castro \\
\hline 30 & Carlos Lama \\
\hline 31 & Christopher Martínez \\
\hline 32 & Jose Peral \\
\hline 33 & Aldo Fajardo \\
\hline 34 & Arthur Figueroa \\
\hline 35 & José Andrade \\
\hline 36 & Pedro Castilla \\
\hline 37 & Antonella Aqueda \\
\hline 38 & Hansell Placido \\
\hline 39 & Gino Rosales \\
\hline 40 & Lili Rosario \\
\hline 41 & Joe Mendez \\
\hline 42 & Samuele Giomi \\
\hline 43 & Milagros Rivera \\
\hline 44 & Lupe Cardoza \\
\hline 45 & Roxana Vargas \\
\hline 46 & Carmen Gonzales \\
\hline 47 & Rodrigo Rocano \\
\hline 48 & Adolfo Aguilar \\
\hline
\end{tabular}

\begin{tabular}{|c|c|}
\hline l.com & Ejecutivo del sector pisco \\
\hline lucas.lopsan12@gmail.com & Ejecutivo del sector pisco \\
\hline macostamdina@gmail.com & Ejecutivo del sector pisco \\
\hline estebanbailetti.b@gmail.com & Ejecutivo del sector pisco \\
\hline montenegropm123@gmail.com & Ejecutivo del sector pisco \\
\hline f.cedron92@gmail.com & Ejecutivo del sector pisco \\
\hline rosebenitovalladolid@gmail.com & Ejecutivo del sector pisco \\
\hline harrypedraza13@gmail.com & Ejecutivo del sector pisco \\
\hline brendavm16@hotmail.com & Ejecutivo del sector pisco \\
\hline fio.hurtadoflores@gmail.com & Ejecutivo del sector pisco \\
\hline david.ruizvel15@gmail.com & Ejecutivo del sector pisco \\
\hline cesarcoronado.mm@gmail.com & Ejecutivo del sector pisco \\
\hline sony.perezpaucar@gmail.com & Ejecutivo del sector pisco \\
\hline kelly.mendm12@gmail.com & Ejecutivo del sector pisco \\
\hline luis.torpocomunoz@gmail.com & Ejecutivo del sec \\
\hline katequispe.t@gmail.com & Ejecutivo del sector pisco \\
\hline Pallete.jorge1211@gmail.com & Ejecutivo del sector pisco \\
\hline Rosaliendoperu@gmail.com & Ejec \\
\hline leonilaexpopisco@gmail.com & Ejecutivo del sector pisco \\
\hline chavesfrancisca31@gmail.com & Ejecutivo del sector pisco \\
\hline agustin.chpisco@gmail.com & Ejec \\
\hline montoya.augus@gmail.com & Ejecutivo del sector pisco \\
\hline mhuaman022@gmail.com & Ejecutivo del sector pisco \\
\hline dcarrion356@gmail.com & Ejecutivo del sector pisco \\
\hline jose.cpperu@gmail.com & Ejecutivo del sector pisco \\
\hline carloslama662@gmail.com & Ejecutivo del sector pisco \\
\hline matinescristopher@gmail.com & Ejecutivo del sector pisco \\
\hline joseperal474@gmail.com & Ejecutivo del sector pisco \\
\hline aldofajardo60@gmail.com & Ejecutivo del sector pisco \\
\hline Arthurfigueroa15@ hotmail.com & Ejecutivo del sector pisco \\
\hline Jose.expopisco@gmail.com & Ejecutivo del sector pisco \\
\hline Pedrocastilla717@gmail.com & Ejecutivo del sector pisco \\
\hline Aqueda.antocalle@gmail.com & Ejecutivo del sector pisco \\
\hline hanselpla45@gmail.com & Ejecutivo del secto \\
\hline Gino.rosalesb@hotmail.com & Ejecutivo del sector pisco \\
\hline geraldine.lr20@hotmail.com & Ejecutivo del sector pisco \\
\hline joe.menhidalgo@gmail.com & Ejecutivo del sector pisco \\
\hline samuele.giomi02@gmail.com & Ejecutivo del sector pisco \\
\hline mili.riverago09@gmail.com & Ejecutivo del sector pisco \\
\hline cardozalupe.villa@gmail.com & Ejecutivo del sector pisco \\
\hline roxivargas96@gmail.com & Ejecutivo del sector pisco \\
\hline carm.gonzales.96@gmail.com & Ejecutivo del sector pisco \\
\hline rocano.r318@gmail.com & Ejecutivo del sector pisco \\
\hline adolfo.aguilarmar@hotmail.com & Ejecutivo del sector pisco \\
\hline
\end{tabular}




\begin{tabular}{cccl}
49 & Christian Alarcon & christian.alarcon23@hotmail.com & Ejecutivo del sector pisco \\
50 & Irving Rojas & irving.rtorres@ @otmail.com & Ejecutivo del sector pisco \\
\hline
\end{tabular}

Anexo 9. Validación del cuestionario

VALIDACIÓN DEL CUESTIONARIO DE LA ENCUESTA 
Estimado(a):

Presente:

Me dirijo a usted con la finalidad de solicitar su valiosa colaboración en calidad de JUEZ(A) para validar el contenido del instrumento Cuestionario. Instrumento que lleva por título: Cuestionario de "Análisis de Factores de Promoción que incidieron en la Evolución de las Exportaciones de Pisco Hacia los Estados Unidos 2014 - 2018"

Para dar cumplimiento a lo anteriormente expuesto se hace entrega formal de la Operacionalización de variables involucradas en el estudio, los cuestionarios, la tabla de especificaciones respectivas y los dos formatos de validación, el cual deberá llenar de acuerdo a sus observaciones, a fin de orientar y verificar la claridad, congruencia, control de la tendenciosidad y dominio de los contenidos de los diversos ítems de los cuestionarios.

Agradeceré de antemano su receptividad y colaboración. Su apoyo me permitirá adquirir habilidades y competencias profesionales y científicas que forman parte del proceso de investigación.

Quedamos en espera de la retroalimentación respectiva para la mejora del presente estudio.

Muy Atentamente,

Cuya Celis, Kelly Gissel

Rodriguez Paz, Ariana Alexandra

\section{INSTRUMENTO PARA LA VALIDEZ DE CONTENIDO (JUICIO DE EXPERTOS - Encuesta)}

El presente instrumento tiene como finalidad validar el formulario de los "Análisis de Factores de Promoción que incidieron en la Evolución de las Exportaciones de Pisco Hacia los Estados 
Unidos 2014 - 2018" el mismo que será aplicado a la población y muestra indicada en el presente estudio de investigación que lleva el mismo nombre del presente formulario que corresponde a un diseño de investigación de carácter descriptivo correlacional y explicativo no experimental.

\section{Instrucciones}

La evaluación requiere una lectura detallada y completa de cada ítem propuesto a fin de comparar de manera cualitativa con los criterios propuestos relativos a: Claridad de la redacción, Contexto correcto de ítem, Congruencia con el contenido y Dominio del Constructo. Para tal fin, deberá asignar una valoración si el ítem presenta o no los criterios propuestos, y caso contrario se ofrece un espacio para las observaciones si las hubiera.
Juez $\mathbf{N}^{\circ}$ :
1 (Metodólogo)

\begin{tabular}{ll}
\hline Fecha actual: & Mayo 2020 \\
\hline Nombres y Apellidos de Juez: & Braggi A. Bamberger Vargas \\
\hline Grado Académico: & Doctor \\
\hline Puesto de trabajo: & Gerente General \\
\hline Institución donde labora: & Finance Consult \\
\hline Años de experiencia profesión o científica: & 22 años
\end{tabular}

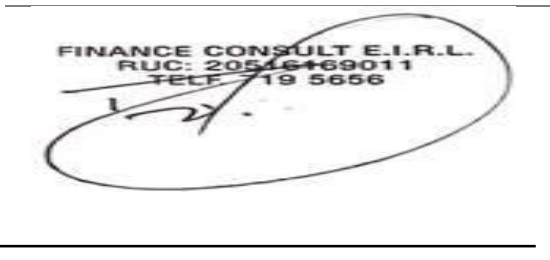

Firma y/o Sello

\section{INSTRUMENTO PARA LA VALIDEZ DE CONTENIDO (JUICIO DE EXPERTOS - Encuesta)}

El presente instrumento tiene como finalidad validar el formulario de los "Análisis de Factores de Promoción que incidieron en la Evolución de las Exportaciones de Pisco Hacia los Estados 
Unidos 2014 - 2018" el mismo que será aplicado a la población y muestra indicada en el presente estudio de investigación que lleva el mismo nombre del presente formulario que corresponde a un diseño de investigación de carácter descriptivo correlacional y explicativo no experimental.

\section{Instrucciones}

La evaluación requiere una lectura detallada y completa de cada ítem propuesto a fin de comparar de manera cualitativa con los criterios propuestos relativos a: Claridad de la redacción, Contexto correcto de ítem, Congruencia con el contenido y Dominio del Constructo. Para tal fin, deberá asignar una valoración si el ítem presenta o no los criterios propuestos, y caso contrario se ofrece un espacio para las observaciones si las hubiera.
Juez $\mathbf{N}^{\circ}$ :
1 (Experto)

\begin{tabular}{ll}
\hline Fecha actual: & Mayo 2020 \\
\hline Nombres y Apellidos de Juez: & Juan Hinojosa Tapia \\
\hline Grado Académico: & Magíster en MBA \\
\hline Puesto de trabajo: & Consultor Empresarial \\
\hline Institución donde labora: & Profesional Independiente \\
\hline Años de experiencia profesión o científica: & 25 años \\
\hline
\end{tabular}

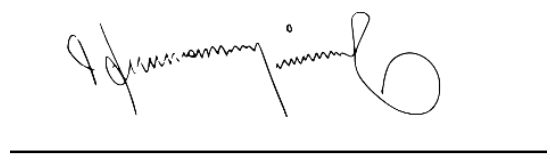

Firma y/o Sello

\section{INSTRUMENTO PARA LA VALIDEZ DE CONTENIDO (JUICIO DE EXPERTOS - Encuesta)}

El presente instrumento tiene como finalidad validar el formulario de los "Análisis de Factores de Promoción que incidieron en la Evolución de las Exportaciones de Pisco Hacia 
los Estados Unidos 2014 - 2018" el mismo que será aplicado a la población y muestra indicada en el presente estudio de investigación que lleva el mismo nombre del presente formulario que corresponde a un diseño de investigación de carácter descriptivo correlacional y explicativo no experimental.

\section{Instrucciones}

La evaluación requiere una lectura detallada y completa de cada ítem propuesto a fin de comparar de manera cualitativa con los criterios propuestos relativos a: Claridad de la redacción, Contexto correcto de ítem, Congruencia con el contenido y Dominio del Constructo. Para tal fin, deberá asignar una valoración si el ítem presenta o no los criterios propuestos, y caso contrario se ofrece un espacio para las observaciones si las hubiera.
Juez $\mathbf{N}^{\circ}$ :
1 (Estadístico)

\begin{tabular}{ll}
\hline Fecha actual: & Mayo 2020 \\
\hline Nombres y Apellidos de Juez: & Davide Stagni \\
\hline Grado Académico: & Ingeniero Economista \\
\hline Puesto de trabajo: & Consultor en Estadística Económica \\
\hline Institución donde labora: & Profesional Independiente \\
\hline Años de experiencia profesión o científica: & 20 años \\
\hline
\end{tabular}

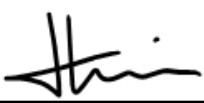

Firma y/o Sello 
INVENTARIO DEL CUESTIONARIO DE: “ANÁLISIS DE FACTORES DE PROMOCIÓN QUE INCIDIERON EN LA EVOLUCIÓN DE LAS EXPORTACIONES DE PISCO HACIA ESTADOS UNIDOS 2015 - 2019 (JUICIO DE EXPERTO)

Inventario del cuestionario del crédito hipotecario y su impacto en las decisiones de compra inmobiliaria en el Perú 2013 - 2017

Calificación: Muy aceptable (5) Aceptable (4) Regular (3) Poco aceptable (2) Inaceptable (1)

\begin{tabular}{|c|c|c|c|c|c|c|c|c|c|c|c|c|c|c|c|c|c|c|c|c|c|c|}
\hline \multirow{2}{*}{$\mathbf{N}^{\circ}$} & \multirow{2}{*}{ Ítems (afirmaciones) } & \multicolumn{5}{|c|}{ Claridad $^{1}$} & \multicolumn{5}{|c|}{ Congruencia $^{2}$} & \multicolumn{5}{|c|}{ Contexto $^{3}$} & \multicolumn{5}{|c|}{$\begin{array}{l}\text { Dominio del } \\
\text { constructo }^{4}\end{array}$} & \multirow{2}{*}{ Sugerencias } \\
\hline & & 5 & 4 & 3 & 2 & 1 & 5 & 4 & 3 & 2 & 1 & 5 & 4 & 3 & 2 & 1 & 5 & 4 & 3 & 2 & 1 & \\
\hline & $\begin{array}{l}\text { La denominación de origen del pisco } \\
\text { peruano incide en recomendaciones }\end{array}$ & $X$ & & & & & & $\mathrm{X}$ & & & & $X$ & & & & & $X$ & & & & & \\
\hline & $\begin{array}{l}\text { La denominación de origen del pisco } \\
\text { peruano ayuda al comercio exterior }\end{array}$ & & $\mathrm{X}$ & & & & $\mathrm{X}$ & & & & & $\mathrm{X}$ & & & & & $\mathrm{X}$ & & & & & \\
\hline & $\begin{array}{l}\text { La denominación de origen del pisco } \\
\text { peruano incide en mayores mercados }\end{array}$ & & $X$ & & & & $\mathrm{X}$ & & & & & & $X$ & & & & $X$ & & & & & \\
\hline
\end{tabular}

${ }^{1}$ Se entiende sin dificultad alguna el enunciado del ítem.

${ }^{2}$ En ítem tiene relación con el constructo (Comprensión Oral de Estructuras Gramaticales)

${ }^{3}$ En el ítem todas las palabras son usuales para nuestro contexto

${ }^{4}$ El ítem evalúa el componente o dimensión específica del constructo (bloques). 


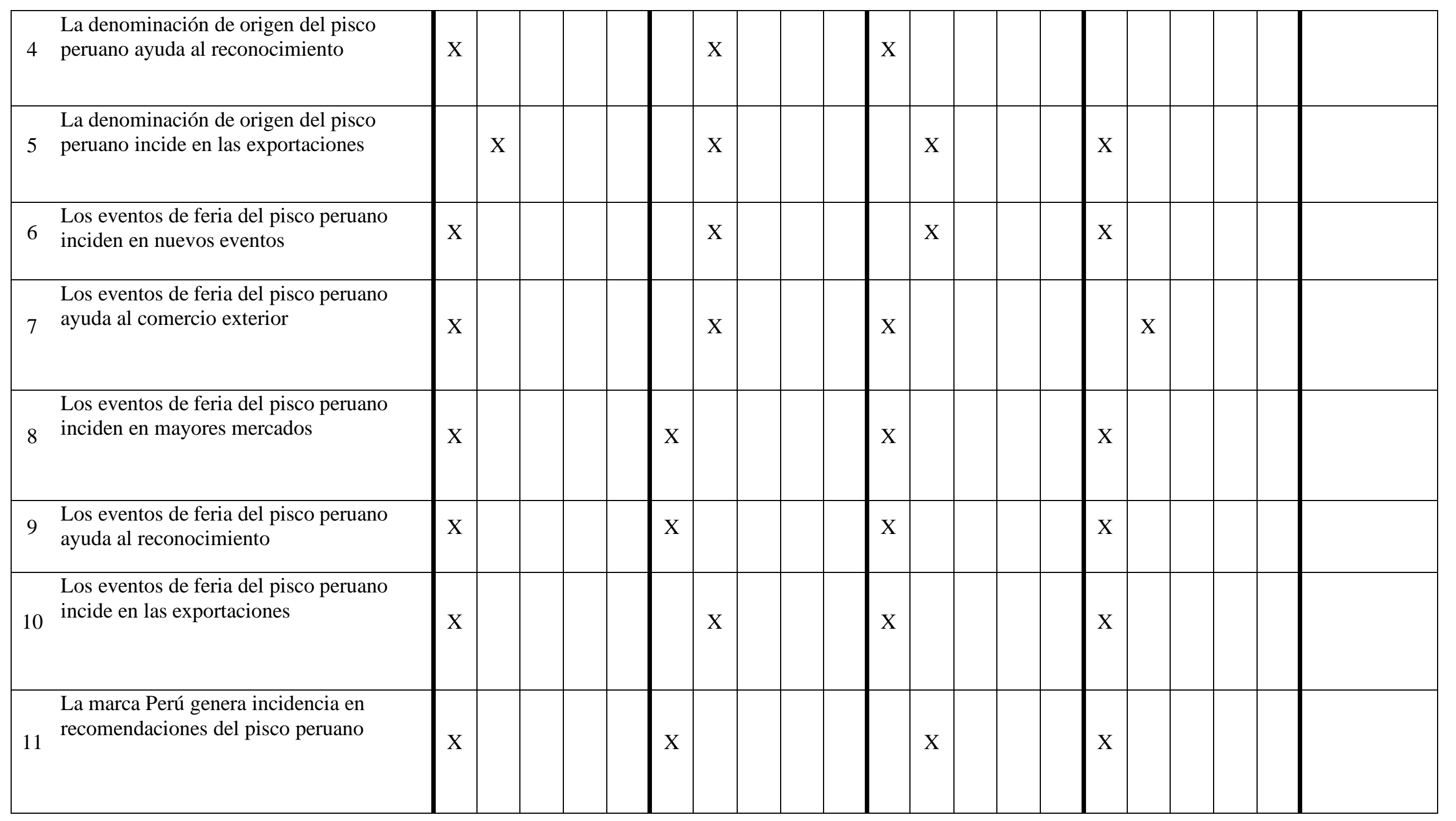




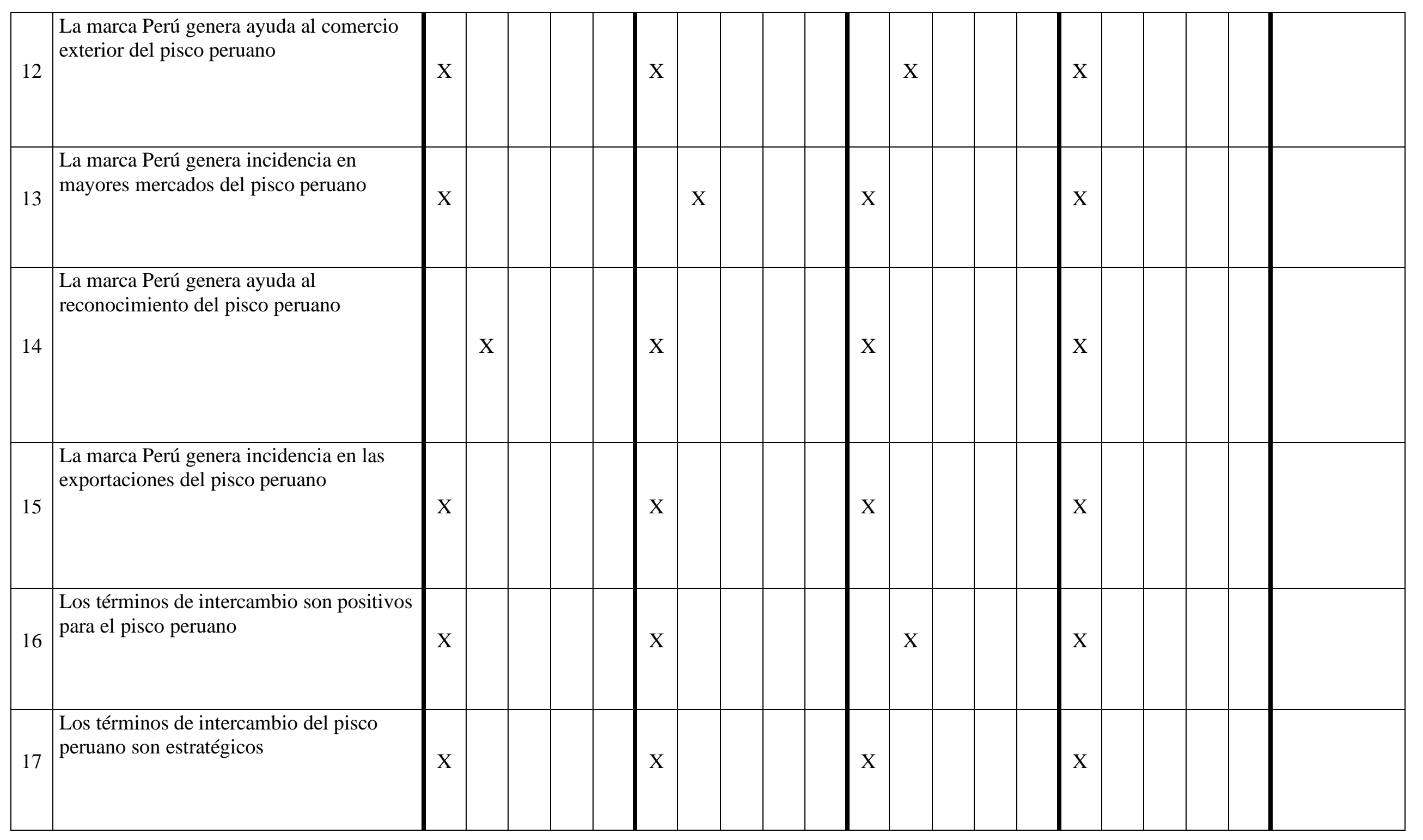




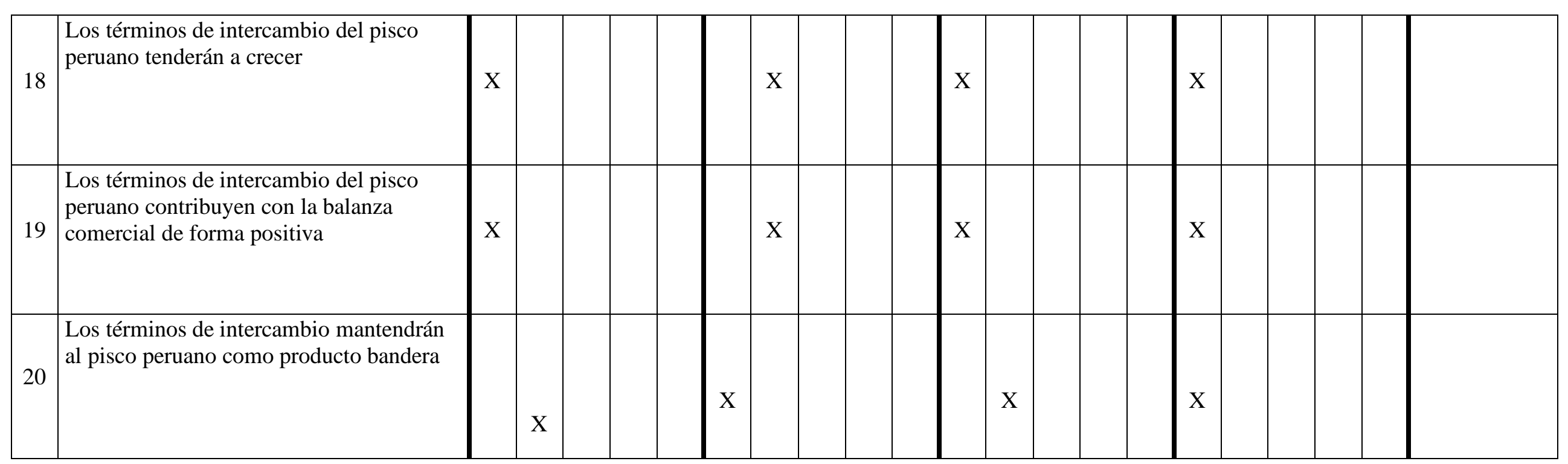

Fuente: Elaboración propia 


\section{CUESTIONARIO DE: “ANÁLISIS DE FACTORES DE PROMOCIÓN QUE INCIDIERON EN LA EVOLUCIÓN DE LAS EXPORTACIONES DE PISCO HACIA ESTADOS UNIDOS 2015 - 2019"}

Este cuestionario tiene como propósito analizar los factores de promoción que incidieron en la evolución de las exportaciones de pisco hacia Estados Unidos 2014 - 2018. Lea con mucha atención y contestar cada pregunta con la mayor honestidad posible. Tener en cuenta la asignación correspondiente: 1 es muy en desacuerdo, 2 en desacuerdo, 3 ni de acuerdo ni en desacuerdo, 4 de acuerdo y 5 muy de acuerdo.

Tabla

Ficha de datos del encuestado

\section{Cuestionario}

Datos Generales

Nombres o Razón Social

Domicilio

Teléfono

Correo Electrónico

Otros

Fuente: Elaboración propia 


\section{CRITERIOS GENERALES PARA VALIDEZ DE CONTENIDO DEL INSTRUMENTO DE: "ANÁLISIS DE FACTORES DE PROMOCIÓN QUE INCIDIERON EN LA EVOLUCIÓN DE LAS EXPORTACIONES DE PISCO HACIA ESTADOS UNIDOS 2015 - 2019”}

\section{DICTAMINADO POR EL JUEZ}

1. ¿Está de acuerdo con las características, forma de aplicación y estructura del INSTRUMENTO?

Muy aceptable (x) Aceptable ( ) Regular ( ) Poco aceptable ( ) Inaceptable ( )

Observaciones: Ninguna

Sugerencias: Ninguna

2. A su parecer, ¿el orden de las preguntas es el adecuado?

$$
\text { SI (x) NO ( ) }
$$

Observaciones: Ninguna

Sugerencias: Ninguna

3. ¿Existe dificultad para entender las preguntas del INSTRUMENTO?

$$
\text { SI ( ) NO } \quad \text { No }
$$

Observaciones: Ninguna

Sugerencias: Ninguna

4. ¿Existen palabras difíciles de entender en los ítems o reactivos del INSTRUMENTO?

$$
\text { SI ( ) NO } \quad \text { No }
$$

Observaciones: Ninguna

Sugerencias: Ninguna

5. Las opciones de respuesta ¿están suficientemente graduados y pertinentes para cada ítem cada pregunta o reactivo del INSTRUMENTO?

$$
\text { SI (x) NO ( ) }
$$

Observaciones: Ninguna

Sugerencias: Ninguna 
6. ¿Los ítems o reactivos del instrumento tienen correspondencia con la dimensión al que pertenece en el constructo?
SI $(x)$
NO ( )

Observaciones: Ninguna

Sugerencias: Ninguna

Anexo 10. Mercado objetivo en Estados Unidos

\begin{tabular}{llll}
\hline \multicolumn{1}{c}{ Nombre de la empresa } & Tipo de empresa & Ubicación \\
\hline 1 House of Wine \& Liquor & Licorería & New Jersey \\
2 ShopRite Wines \& Spirits & Licorería & New Jersey \\
3 Pueblo Meat Market - Newark NJ & Supermercado & New Jersey \\
4 City Fresh Market & Supermercado & New Jersey \\
5 Los Immortales & Supermercado & Patterson \\
6 Pisko's & Licorería & Patterson \\
7 BuyRite Liquor Kearny & Licorería & New Jersey \\
8 Wayne Bottle King - Discount Wine, Beer \& Liquor & Licorería & New Jersey \\
9 Peruvian Import Co & Supermercado & New Jersey \\
10 GalaFresh Supermarket & Supermercado & Patterson \\
11 Best Western Premier NYC Gateway Hotel & Hotel & New Jersey \\
12 Hilton Garden Inn Wayne & Hotel & New Jersey \\
13 Courtyard by Marriott Wayne Fairfield & Hotel & New Jersey \\
14 Residence Inn by Marriott Jersey City & Hotel & New Jersey \\
15 Ramada by Wyndham Wayne Fairfield Area & Hotel & New Jersey \\
\hline
\end{tabular}

Fuente: Consulado del Perú en Patterson - Asuntos Comerciales Elaboración Propia 